\title{
Unraveling the Secret Life of Cryptic Algal Species: Evolution, Phylogeography AND ECO-PHYSIOLOGY OF THE RED AlgA
} BOSTRYCHIA INTRICATA

BY

NARONGRIT MUANGMAI

\begin{abstract}
A thesis
submitted to the Victoria University of Wellington in fulfilment of the requirements for the degree of Doctor of Philosophy in Marine Biology
\end{abstract}

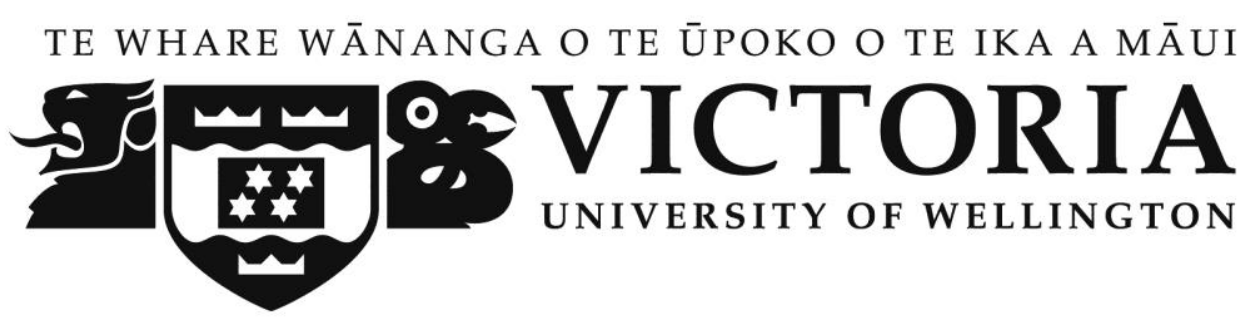

Victoria University of Wellington

Te Whare Wānanga o te Ūpoko o te Ika a Māui (2015) 


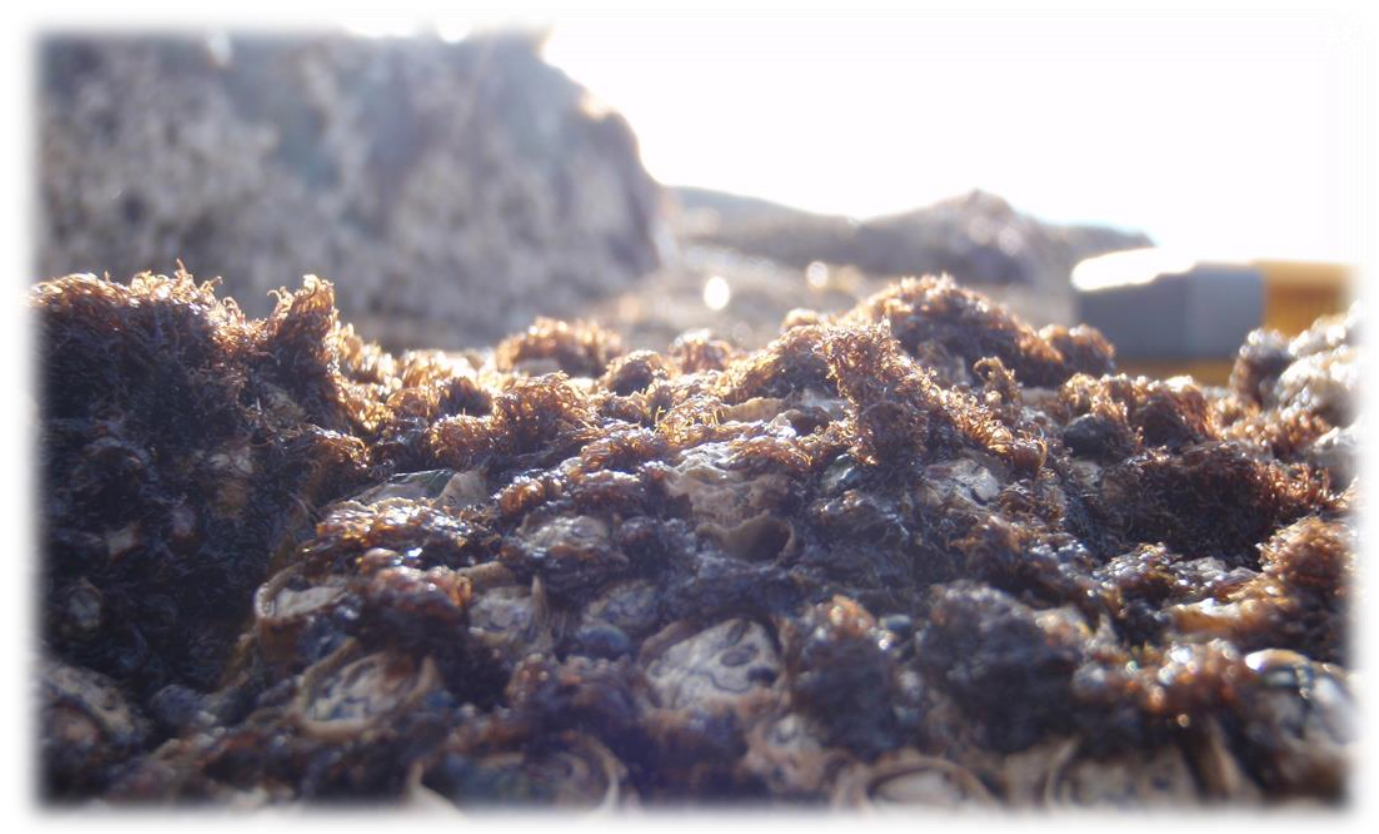

Bostrychia intricata in the intertidal shore of Moa Point, Wellington

"Endless forms most beautiful and most wonderful have been, and are being, evolved."

- Charles Darwin, The Origin of Species. 


\begin{abstract}
Molecular techniques have enhanced our ability to unravel the evolutionary history and hidden diversity of species, and to explain how historical events have helped to shape the demography and dispersal of populations. Cryptic species are typically defined as two or more genetically distinct species that are morphologically indistinguishable. The discovery of cryptic diversity has become a challenge for biologists in understanding the species concepts and biodiversity patterns. Many current studies have revealed the existence of cryptic species, but few studies have focused on their ecological and biological aspects.
\end{abstract}

Bostrychia, a filamentous red alga, has long been used as a model system for studies of evolutionary process and biogeographic history. In the Southern Hemisphere, there are four endemic species: B. arbuscula, B. gracilis, B. intricata and B. vaga. Bostrychia intricata is widely distributed in the Southern Hemisphere, whereas the other three species have more restricted distributions. The aim of this study was to reveal the evolutionary history, phylogeographic pattern and eco-physiological trait within B. intricata.

Phylogenetic analysis based on combined data (mitochondrial COI, chloroplast $r b c \mathrm{~L}$ and nuclear 28S) strongly supported the monophyly of the four Southern Hemisphere Bostrychia species, with B. vaga as a sister species to the other three. Multigene phylogeny and COI-based species delimitation revealed cryptic species diversity within $B$. intricata and B. vaga. Additionally, a COI-based phylogeographic study indicated the existence of three cryptic $B$. intricata species (N2, N4 and N5) in New Zealand. Population analyses demonstrated that cryptic species $\mathrm{N} 2$ populations recently expanded, possibly after the Last Glacial Maximum (LGM), while N4 was more diverse, showing a stable population, which possibly persisted during the LGM. The results suggested that the contrasting pattern in population structure and demographic histories between cryptic species was probably due to the difference in the evolutionary history and survival ability.

Growth experiments clearly showed that cryptic species N4 had a significantly higher specific growth rate than other two species, N2 and N5, in different salinities and temperature, suggesting physiologically differentiation between these cryptic species. Additionally, the small-scale distribution of B. intricata at Moa Point, Wellington of three 
cryptic species showed that N4 was found at the higher tidal position than species N2 and N5. Cryptic species N2 occurred in more wave-exposed areas than other two species.

These results suggest spatial niche differences between cryptic species, possibly allowing them to sympatrically co-exist. This study highlights the fact that cryptic species are distinctly different in many biological characteristics, while maintaining identical morphologies. 


\section{Acknowledgments}

Pursuing a PhD degree is one of the most important journeys in my life. It has been a long way up and down, but here I have reached to the end! Three years of my $\mathrm{PhD}$ study have been supported, encouraged and accompanied by many fabulous people, who have helped me complete this journey.

Beginning with my heartfelt thanks to the most important person, who have walked alongside and endlessly supported me throughout this journey, my wonderful supervisor: Joe Zuccarello. I would like to thank you for providing me a great opportunity to start this $\mathrm{PhD}$ research. I have enjoyed the chances to watch and learn from your knowledge and experience. I truly appreciated the way you always taught and helped me to solve a problem. With a big smile and positive energy, you gave me a heap of inspiration and encouragement, influencing both my personal and academic developments. Thank you very much for offering such quick, thorough and constructive feedback and for helping me to travel to amazing algal conferences in Australia, Indonesia and China. I would like to extend my gratitude to my secondary supervisor, Ken Ryan, for his constant supports and advices, especially with eco-physiological aspects. I also want to thank Nicole Phillip and Jeff Shima for being my $\mathrm{PhD}$ committee members and providing invaluable suggestions and comments for my research project.

A huge thanks goes to all members in Phycology Lab at VUW: Maren Preuss, Christian Boedeker, Joe Buchanan and Madeline Cooper, who helped me immeasurably in my field and lab works, and gave useful advice and support on data analysis and technical aspects. Thanks to Ulla von Ammon, who spent her six months stay at VUW in helping me in running the field works and molecular experiments smoothly. I am thankful to Crid Fraser and John West for their great support and comments on my manuscript. I would like to thank active New Zealand phycologists: Wendy Nelson, Judith Sutherland and Roberta D'Archino for their great friendships and cheerful encouragement. Also special thanks to the administrative and technical staffs at the School of Biological Sciences of VUW for their warm smiles and practical supports. 
I wish to express a deep appreciation to Victoria University of Wellington for offering me a three-years Victoria Doctoral Scholarship and VUW Hardship Fund. Also thanks to International Phycological Society for awarding me a Silva Student Grant, which partially supported my participation of the $21^{\text {th }}$ International Seaweed Symposium in Bali, Indonesia, and to Australasian Society for Phycology and Aquatic Botany for supporting me with Student international travel grant in taking a trip to Wuhan, China for the $7^{\text {th }}$ Asian Pacific Phycological Forum.

I am extremely grateful to friends and colleagues at VUW: Edi Puteri, Cong Zeng, Amy Hoo, Balam Jimenez, Kimberley Maxwell, Sven Sondhauss, Olivia Parra, Shalen Kumar, Catherine Davis, Zaramasina Clark and Megan Shaffer, who have always helped and supported me during the course of this research, making my everyday to be full of joy and happiness and keeping me going through tough times. I would especially like to thank Daisaku Ikeda for his incredible guidance that inspired me daily and to wonderful SOKA family in New Zealand for their unconditional encouragements and supports.

I am very thankful to fantastic friends and colleagues from Thailand, particularly from Faculty of Fisheries, Kasetsart University, for all their helps and supports, even though they are not near.

Lastly, wholehearted thanks go out to my lovely family in Phuket, Thailand. To Dad, Mom, Sister and all relatives, you all are so supreme! Without your continuous love and outstanding help, my $\mathrm{PhD}$ journey would not have happened. Thank you for nurturing my passion, understating my life and always supporting my dreams. I hope I have made you proud. Well, I think I write too much - Again, Thank you very much everybody for being a part of my success! 


\section{Table of Contents}

Title: Unrevealing of the secret life of cryptic algal species: evolution,

Phylogeography and eco-physiology of the red algal Bostrychia intricata i

Abstracts $\quad$ iii

Acknowledgements $\quad \mathrm{V}$

Table of Contents vii

Chapter One: General Introduction......................................1

Research interests $\quad 2$

Species concept 2

Phylogeography 4

The red alga Bostrychia 6

$\begin{array}{ll}\text { Thesis aims } & 13\end{array}$

$\begin{array}{ll}\text { Thesis structure } & 14\end{array}$

Chapter Two: Phylogeny and species delimitation of four

endemic Bostrychia species in the Southern

Hemisphere............................................16

$\begin{array}{ll}\text { Abstract } & 17\end{array}$

$\begin{array}{ll}\text { Introduction } & 18\end{array}$

Material and methods $\quad 21$

Results 25

Discussion 28

Acknowledgement $\quad 34$ 
Chapter Three: Phylogeographic patterns and historical demography of cryptic species of $B$. intricata in New Zealand..........................................35

Abstract $\quad 36$

Introduction $\quad 37$

Material and methods $\quad 40$

Results $\quad 48$

Discussion $\quad 54$

Acknowledgement $\quad 58$

Chapter Four: Physiological response on the growth of different cryptic species of $B$. intricata in various conditions

of salinity and temperature..............................59

$\begin{array}{ll}\text { Abstract } & 60\end{array}$

Introduction $\quad 61$

Material and methods $\quad 63$

Results $\quad 65$

Discussion $\quad 70$

Acknowledgement $\quad 73$

Chapter Five: Small-scale distribution of cryptic B. intricata species at Moa Point, Wellington.........................74

$\begin{array}{ll}\text { Abstract } & 75\end{array}$

Introduction $\quad 76$

Material and methods $\quad 78$

Results $\quad 80$

Discussion $\quad 86$

Acknowledgement $\quad 89$ 
Phylogeographic contrasts of cryptic algal species

References.............................................................100

Appendices.

Appendix Chapter Two

Appendix Chapter Three 134

Appendix Chapter Four 144

Appendix Chapter Five 145

Appendix Chapter Six 


\section{Chapter One}

GENERAL INTRODUCTION 


\section{Research interests}

$\mathrm{My} \mathrm{PhD}$ research interests center on the biodiversity and evolution of cryptic red algal species in New Zealand. Recognitions of cryptic species have recently increased in marine macroalgal taxa, but their roles and biological consequences are still ambiguous. This study aims to advance our understanding in the nature of cryptic red algal species, with respect to evolutionary history, species delimitation, population connectivity and ecophysiology.

This general introduction chapter consists of three main parts: species concepts, phylogeographic studies and the red alga Bostrychia. The first part provides an overview of species concepts followed by a review of cryptic algal species. The second section then focuses on the context of phylogeography and some studies of this field in marine macroalgae in New Zealand. Finally, the third part provides a brief detail of the red alga Bostrychia, covering some general biological aspects and scientific findings of this alga, and then introduces the model organism in this study, B. intricata, with its latest discoveries.

\section{Species concepts}

\section{A key to understanding evolution and biodiversity}

Species are fundamental natural units for biological classification (Mayr 1963, Mishler and Brandon 1987). Biologists have extensively debated for over a half-century how to define species and criteria used to delimit them (Brookfield 2002, De Queiroz 2007, Leliaert et al. 2014). Species concepts originate in taxonomy, and basically, taxonomists defined species in terms of easily distinguishable morphological features (Howard and Berlocher 1998). The morphological species concept (MSC) is the oldest, but still practical, species concept, which defines the species based on their phenotypic differences (Cracraft 1983). However, morphological characters often vary between individuals and within and among populations, and sometimes the discriminating features between two species coincided 
(Coyne and Orr 2004). Therefore morphological criteria may not accurately reflect species.

The biological species concept (BSC) is one of the most influential species concepts. The BSC stipulates that species are actually or potentially interbreeding populations isolated from other such groups (Mayr 1942, Bush 1975). According to the BSC, biological species are established when they are reproductively isolated (Coyne and Orr 2004). Due to the different reproductive modes (e.g. asexual reproduction, self-fertilization, or interbreeding) among taxa, the BSC offer no universal benchmark to delimit species. Another concept, which has been widely used in recent years, is the phylogenetic species concept (PSC). The PSC attempts to identify a species based on a group of individuals sharing at least one uniquely derived characteristic, recognizing as a monophyletic group within its parental pattern of ancestry and descendant (Cracraft 1983, Freeland 2005). This concept is useful to avoid the problem of asexual reproduction and to imply the evolutionary history of species through molecular data, but can cause a problem with overestimation of the number of species (Freeland 2005, White et al. 2007). As no single definition of species concept could fit to all organisms, many biologists therefore have decided to use multiple species concepts in delineating species (Hey 2006, Bickford et al. 2007, Wilkins 2009).

Molecular biology has revolutionized our understanding of evolution, speciation events and diversity of organisms (Barraclough and Nee 2001, Zuccarello et al. 2005, Bickford et al. 2007). Many biological systematics studies have demonstrated that morphological features combined with molecular data are beneficial for solving taxonomic problems and shedding light on the life history of species (Zuccarello and West 2006, Bordie and Zuccarello 2007, Fraser et al. 2010, Martin and Zuccarello 2011, Zuccarello et al. 2015).

In marine algae, species classifications are dominated by morphological species concept (Phillips et al. 2008, Verbruggen 2014). However, algal species delineation and taxonomy are frequently problematic because of the high morphological variability within species (Hurd et al. 2014, Leliaert et al. 2014). Therefore, other species concept based on genetic data, reproductive isolation and physiological variation have been applied in algal groups. Zuccarello and West (2003) showed that genetic data and reproductive isolation could be used as important and reliable criteria for defining species boundaries in the Bostrychia 
radicans (Montagne) Montagne/B. moritziana (Sonder ex Kützing) J. Agardh species complex.

\section{Cryptic species}

The use of molecular data results in the recognition of many cryptic species, and this discovery presents new challenges for species delimitation and an opportunity to study important mechanisms of speciation (Zuccarello and West 2003, Bickford et al. 2007, Payo et al. 2013). In theory, cryptic species are classified as two or more morphologically indistinguishable species, which are genetically divergent (Beheregaray and Caccone 2007, Bickford et al. 2007). Despite morphological similarities, cryptic species could potentially be different in other biological aspects, such as physiology (Chen and Hare, 2008, Dennis and Hellberg 2010), reproduction (Racey et al. 2007, Xu et al. 2010) and biogeographic pattern (Shaw 2001).

In marine macroalgae, since molecular techniques were applied in the field of algal evolution and systematics in the late 1980s (e.g. Goff and Coleman 1988, Bhattacharya et al. 1990, Freshwater et al. 1994), cryptic species diversity has been continuously detected (Zuccarello et al. 1999a, Zuccarello and West 2003, Payo et al. 2013, Fraser et al. 2013, Silberfeld et al. 2013, Vieira et al. 2014). The discovery of cryptic species is increasingly being observed, especially in red algae, but in all areas of evolutionary history, phylogeographic pattern and eco-physiological properties our knowledge is still superficial.

\section{Phylogeography}

\section{Connectivity and dispersal of species and their genes}

Phylogeography is the field of study that aims to explain the process of geographical distribution of gene lineages within the population (Avise 2000). Mitochondrial DNA (mtDNA) sequences are most frequently employed for studying intraspecific phylogeography in most animal taxa (Avise 2000), especially cytochrome oxidase I (COI) 
because of its relatively rapid substitution rate and non-recombining maternal mode of inheritance (Freeland 2005). Other genetic markers are also used, most commonly chloroplast in plant and algae (Zuccarello and West 2003, Inomato et al. 2009, Zuccarello et al. 2011, Fraser et al. 2013) and non-coding nuclear regions in some animals, as well as plants and algae (Cho et al. 2007, Mikheyev et al. 2008, Inomato et al. 2009). Numerous molecular studies have showed that phylogeographic patterns of marine taxa can be driven by a variety of factors, such as vicariance, transoceanic dispersal, climate fluctuation and hydrographic features (Fraser et al. 2009a, Macaya and Zuccarello 2010a, Cumming et al. 2014)

In marine macroalgae, phylogeography and genetic diversity at the population level has been explored and increasingly relied on the analysis of a number of molecular markers such as the internal transcribed spacer (Cho et al. 2007), the plastid-encoded RuBisCo spacer (Zuccarello et al. 2011) and the COX gene family (Zuccarello et al. 1999a, Macaya \& Zuccarello 2010a). The last two genes have been reported as reliable molecular markers for uncovering species relationship, population structure, and the hidden diversity of algae (Zuccarello \& West 2003, Fraser et al. 2009b).

New Zealand has a great geographical diversity that results from different patterns of ocean circulation and climate and these factors can influence the distribution, adaptation and genetic variation of the marine species (Ross et al. 2009, Wallis and Trewick 2009). In New Zealand, intraspecific phylogeographic studies of marine algal species are very preliminary. Most phylogeographic studies have been done in brown seaweed (Macaya and Zuccarello 2010a, Buchanan and Zuccarello 2012, Fraser et al. 2013). These studies showed spatial heterogeneity in genetic diversity among algal species (e.g., Durvillaea antarctica (Chamisso) Hariot, Macrocystis pyrifera (Linnaeus) Agardh, Carpophyllum maschalocarpum (Turner) Greville) from the North Island, with a transition from the bottom of North Island to top of the South Island and subantarctic islands. Evidence also strongly shows that seaweed distribution patterns and population connectivity are influenced by ocean circulation patterns and climate change (Freser et al. 2009c, Macaya and Zuccarello 2010a, Buchanan and Zucarello 2012). However, very little is known about the phylogeographic structure and genetic variation of non-buoyant red seaweed. 


\section{The red alga Bostrychia}

Bostrychia is a filamentous red alga, growing either on other algae or on rocks. This alga is commonly found in mangrove habitats, but is also reported from cold temperate and subantarctic regions (King and Puttock 1989, Zuccarello and West 2011). Bostrychia contains eighteen species, which are widely distributed in tropical to temperate environments (King and Puttock 1989, Zuccarello and West 2006, West et al. 2013) and has been used as a model system for studies of evolution and speciation (Zuccarello and West 2011). Previous studies of molecular phylogeny and phylogeography of Bostrychia have revealed the presence of cryptic species. For example, Bostrychia radicans and $B$. moritziana are morphologically indistinguishable and consisted of several noninterbreeding genealogical lineages (Zuccarello et al. 1999a, Zuccarello and West 2003).

In the Southern Hemisphere, there are four marine endemic Bostrychia species: $B$. arbuscula Harvey, B. gracilis (King \& Puttock) Zuccarello \& West, B. intricata (Bory de Saint-Vincent) Montagne and B. vaga Hooker \& Harvey, and these four species are commonly found in New Zealand (Fig. 1.1) (King and Puttock 1989, Zuccarello and West 2008). Among these four species, B. arbuscula is the largest species, and normally found in the South Island, but has been reported from Cook Strait on the North Island (Adams 1994, Zuccarello and West 2008). Bostrychia gracilis is only observed from northern New Zealand. Bostrychia intricata and B. vaga have wider distribution than the two previous species. Bostrychia vaga has been reported from the North and South Islands of New Zealand, South Africa, the Falkland Islands and the subantarctic islands (Silva et al. 1996, Zuccarello and West 2008). Bostrychia intricata has been found in New Zealand, Australia, South Africa, South America and the subantarctic islands, and has been reported from northern areas, Indonesia and India (King and Puttock 1989, Adams 1994, Silva et al. 1996, Zuccarello and West 2008, Fraser et al. 2013),

Morphologically, these four species are distinguished from other Bostrychia species distributed in the Southern Hemisphere by having more than two tier cells per axial cell (Zuccarello and West 2006). These four species were preliminarily separated into two groups based on cortication pattern: (1) distinct cortication: B. arbuscula and B. gracilis and (2) ecorticate: B. intricata and B. vaga. Bostrychia arbuscula and B. gracilis are 
distinguished only by the presence of acute tips in B. gracilis. While B. intricata is separated from B. vaga by the abundance of lateral branches in B. intricata (King and Puttock 1989, Zuccarello and West 2008). As these four species are recognizable based on few taxonomic characters (e.g. tip shape and abundance of lateral branch), misidentification is likely.

Preliminary molecular phylogenies of Bostrychia species in New Zealand have previously used chloroplast, mitochondrial and nuclear DNA sequences (Zuccarello and West 2008, Fraser et al 2013). Molecular data indicated that B. arbuscula, B. gracilis and B. vaga are closely related species and recognized as the sister group to B. intricata. However, due to the low genetic variation, phylogenetic affinities of these four species were not well resolved. 

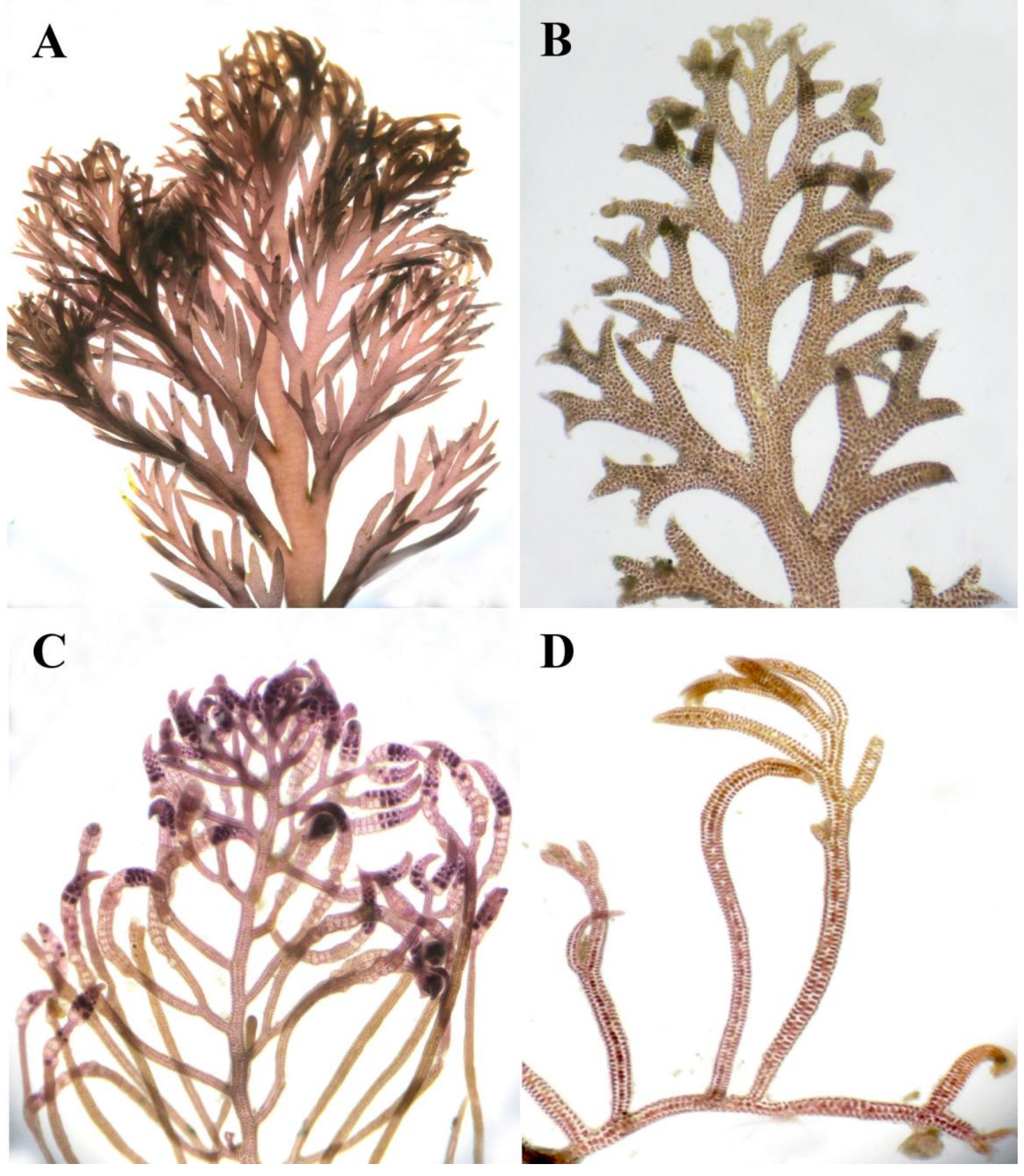

Figure 1.1: Four endemic Bostrychia species distributed in the Southern Hemisphere. (A) B. arbuscula, (B) B. gracilis, (C) B. intricata, (D) B. vaga. 
Bostrychia intricata, as a good candidate of study

Among these four Bostrychia species, the most widespread species throughout the Southern Hemisphere is B. intricata (King and Puttock 1989). It normally grows in the upper intertidal on shaded rocks, rock crevasses, or even on logs (Fig. 1.2) (West et al. 1996, Fraser et al. 2013). This species can be found throughout New Zealand both in the North and South Islands; hence, it has the potential for being a good model in studying phylogeography of red seaweed in New Zealand. Zuccarello and West (2008) studied the phylogenetic diversity and phylogeography of $B$. intricata from the Southern Hemisphere. Genetic data, using the RuBisCo spacer, showed a high degree of genetic variation, indicating several lineages within this species that were found locally (Australia, New Zealand, South Africa and Falkland Islands), suggesting the possibility of cryptic species diversity of B. intricata (Zuccarello and West 2008).

Phylogeographic analyses of $B$. intricata using COI sequences showed a high level of genetic diversity, and four different lineages were observed around the high latitudes of the Southern Hemisphere (Fraser et al. 2013). No obvious morphological differences among these four lineages of $B$. intricata were observed. Fraser et al.'s (2013) study also indicated that one lineage of $B$. intricata was observed in several locations, such as New Zealand, Chile, Snares Island and Tristan da Cunha, suggesting the ability of $B$. intricata to disperse over long distances. Interestingly, two lineages were found in sympatry from the North Island, indicating that even at small spatial scales these lineages co-exist (Fraser et al. 2013).

Previous physiological studies of B. intricata (as Stictosiphonia hookeri) isolated from three locations in cold-temperate Chile and Argentina indicated difference in specific growth rate to different salinities and temperatures (Karsten et al. 1996). Additionally, $B$. intricata collected from different locations have demonstrated differences in temperature of induction of reproductive development (West et al. 1996). These studies suggest the possibility of physiological differences between cryptic algal species of $B$. intricata. 
Species coexistence is a major challenge in community ecology, which underlines various aspects of community organization from the small-scale, to within-patch dynamics, to large-scale, geographic patterns (Tokeshi 1999). Theoretically, it is assumed that the coexistence of cryptic species in sympatry could occur when they occupy different ecological niches (resource and habitats) (Wines and Graham 2005). Evaluating differences in ecological niches may consequently be the key to explain the mechanism facilitating the coexistence of sympatric cryptic species.

In intertidal ecosystem, there are several studies that indicate the ecological niche difference between algal species allowing them to coexist at small-scales (Benzie et al 2000, Zardi et al. 2011). For example, in the Canary Island, the brown alga Dictyota cymatophila Tronholm, M. Sansón et Afonso-Carrillo frequently occurred in waveexposed habitats, whereas $D$. dichotoma (Huds.) J. V. Lamour was found in less exposed areas (Tronholm et al. 2010).

Furthermore, the sympatric occurrences of cryptic algal species have been observed in red algae, including B. intricata (Fraser et al. 2013). These findings raise the questions: How do cryptic algal species manage to coexist? Do cryptic algal species occupy distinct niches in sympatry? However, no studies have previously assessed the sympatric coexistence of cryptic algal species in the field; therefore, these questions still remain unaddressed. 


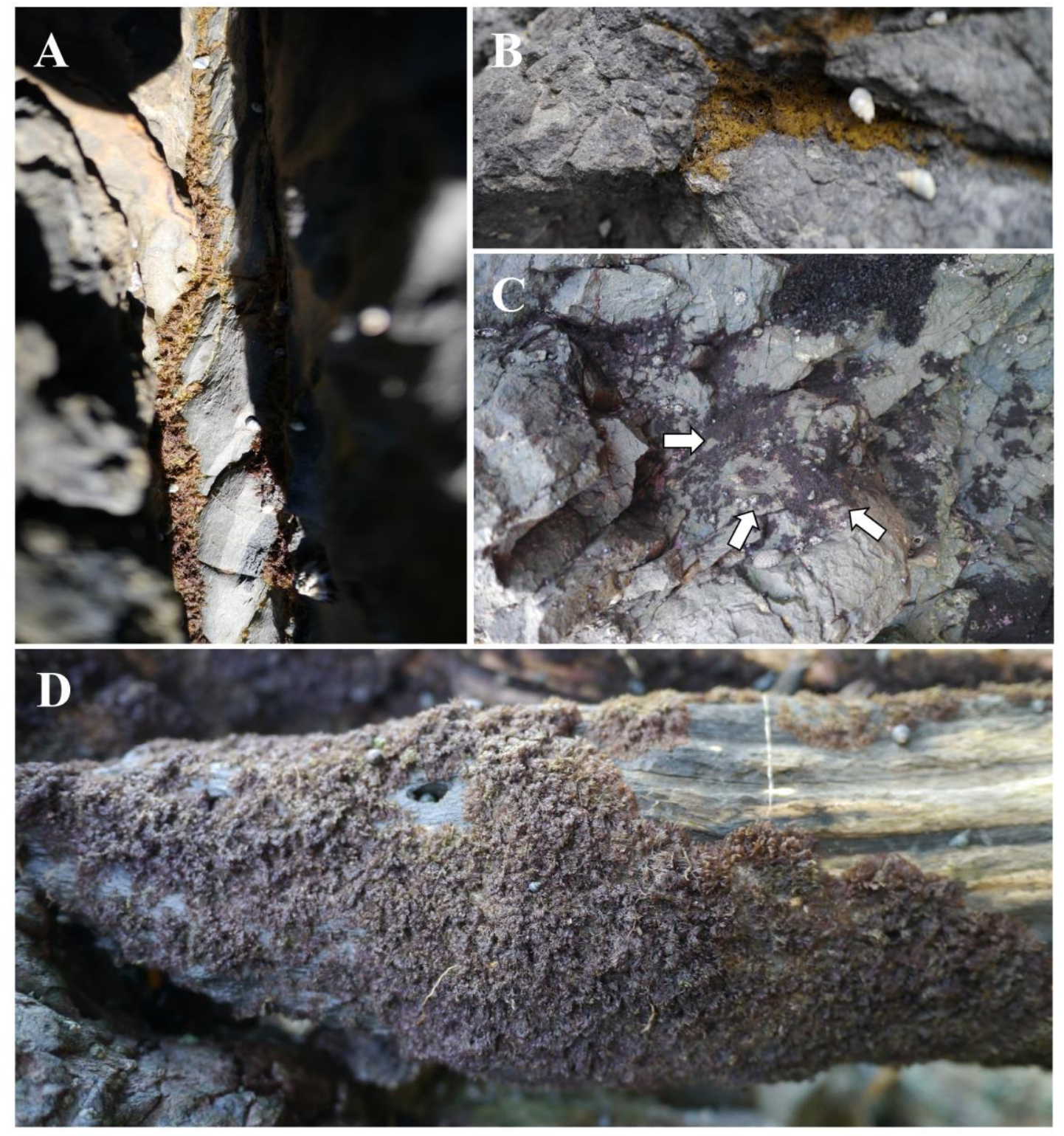

Figure 1.2: Bostrychia intricata grows in different habitats in New Zealand. (A-B) Plants grow in a rock crack on the Kapiti coast, Paraparaumu and Waihau Bay, Bay of Plenty, North Island. (C) Plants occur on the exposed areas at Moa Point, Wellington, North Island (arrows). (D) Plants attach on driftwood on the shore of Hakahaka Bay, Picton, South Island 
Species diversity and distribution patterns of $B$. intricata have previously been revealed using molecular evidence. However, many aspects of their basic biology remain open, such as: what kinds of biological evidence are necessary to demonstrate cryptic species? How does speciation of these cryptic species occur? The phylogeographic patterns of these cryptic species are likely to be non-random with respect to geographic range and, hence, what is the driving force behind such distributional patterns at various spatio-temporal scales? Additionally, the physiological difference observed between $B$. intricata isolates may correlate with their distribution, and therefore does distribution, at large and small scales, of these cryptic species reflects their physiological performance and ecological preference? 


\section{Thesis aims}

The aims of my $\mathrm{PhD}$ research were to clarify the evolution, phylogenetic diversity, largeand small-scale phylogeographic patterns and eco-physiological performances of cryptic B. intricata species. Specific research questions were separately addressed in each chapter.

i) Phylogeny and species delimitation of four endemic Bostrychia species in the Southern Hemisphere (Chapter 2)

- What are the phylogenetic relationships of Southern Hemisphere species of Bostrychia (B. arbuscula, B. gracilis, B. intricata and B. vaga)?

- How many cryptic species of B. intricata are there in the Southern Hemisphere based on multigene phylogenies and species delimitation methods?

- Do the different genetic markers and species delimitation methods yield a similar number of cryptic species?

ii) Phylogeographic patterns and historical demography of cryptic species of $B$. intricata in New Zealand (Chapter 3)

- How many cryptic species of $B$. intricata are distributed along the coastline of New Zealand?

- What are the phylogeographic patterns and demographic histories of the different cryptic B. intricata species?

- Is the phylogeographic pattern of cryptic $B$. intricata species in New Zealand influenced by historical processes (e.g. the Last Glacial Maximum)?

iii) Physiological response on the growth of different cryptic species of $B$. intricata in various conditions of salinity and temperature (Chapter 4)

- Do the different cryptic species of $B$. intricata respond significantly differently in different salinities and temperatures?

- Which cryptic species exhibit a highest specific growth rate in all condition tested? 
- If cryptic $B$. intricata are physiologically divergent, can the physiological differences among cryptic species explain their evolutionary history and distribution pattern in New Zealand?

iv) Small-scale distribution of cryptic $B$. intricata species at Moa Point, Wellington (Chapter 5)

- What are the distribution patterns of cryptic B. intricata in sympatry?

- Do these cryptic species occupy the same spatial ecological niche?

- Which physical parameters shape the population structure and distribution pattern of these cryptic species?

\section{Thesis structure}

This thesis was written as four inter-related chapters, which we propose to submit to peerreview journals.

Chapter 2 has been published (Muangmai, N., West, J. A. and Zuccarello G. C. 2014. Evolution of four Southern Hemisphere Bostrychia (Rhodomelaceae, Rhodophyta) species: phylogeny, species delimitation and divergence times. Phycologia. 53:593-601). I carried out all DNA work and data analyses as well as prepared a first draft of the manuscript. John West helped with sample collections and commented on the manuscript, while my supervisor, Joe Zuccarello, naturally provided constructive guidance and comments, and improved the manuscript.

Chapter 3 has been published (Muangmai, N., Fraser, C. I. and Zuccarello, G. C. 2015 Contrasting patterns of population structure and demographic history in cryptic species of Bostrychia intricata (Rhodomelaceae, Rhodophyta) from New Zealand. Journal of Phycology. 51:574-585). Joe and I conducted most of the field collection. I completed all DNA work and data analyses. I prepared the first draft of the manuscript. Crid Fraser helped with samples collections and commented on the manuscript. Joe gave significant assistance of polishing up my research idea and developing the manuscript. 
Chapter 4 has been accepted for publication (Muangmai, N., Preuss, M. and Zuccarello, G. C. Comparative physiological studies on the growth of cryptic species of Bostrychia intricata (Rhodomelaceae, Rhodophyta) in various salinity and temperature conditions. Phycological Research). I established all algal cultures and did the data analyses. I completed the first draft of the manuscript. Maren Preuss helped set up the experiments, and collect the data. Joe provided considerable suggestions for experimental design and constructive feedback on the manuscript.

Chapter 5 has been prepared as a manuscript, but has not been submitted (Muangmai, N., von Ammon, U. and Zuccarello, G. C. Cryptic species in sympatry: niche partitioning in the cryptic red alga Bostrychia intricata). Ulla Ammon and I conducted most of the field collection and DNA work. I did the data analyses and prepared the first draft of the manuscript. Joe helped to improve research ideas and experimental design. Also he provided suggestions and comments on the manuscript.

All detail and figures of each chapter are mostly similar to the accepted manuscript, although there is some additional information or figures, which did not appear in the publication. Accordingly, there are some repetitions among the chapters, especially in the introduction sections.

Additionally, I have included a single reference list at the end of the thesis, and all supplementary material presented in manuscripts are placed as appendices. 


\section{Chapter Two}

Phylogeny AND SPECIES Delimitation of Four ENDEMIC

BOSTRYCHIA SPECIES IN THE

SOUTHERN HEMISPHERE 


\begin{abstract}
Defining species boundaries is important in order to address evolutionary questions and understand true biodiversity in a region. Determining the actual number of species is not trivial, and numerous species-delimitation algorithms have been developed and extensively applied to a wide range of organisms. The cosmopolitan red-algal genus Bostrychia has been used as a model system to study evolutionary processes, yet phylogeny within the genus and its true species composition are still unresolved. The four species B. arbuscula, $B$. gracilis, $B$. intricata and $B$. vaga represented a distinctive morphotype that was once the basis for segregation into the separate genus Stictosiphonia, and all appearred to be restricted to the Southern Hemisphere. We sequenced genes from all three genomes (plastid: $r b c \mathrm{~L}$; mitochondrial: $\mathrm{COI}$; and nuclear: large-subunit rRNA) to examine the phylogenetic relationships of the four species and to establish their diacritical features. Our phylogenetic analyses from combined datasets strongly supported the monophyly of these species, with B. vaga as a sister species to the other three. Results from phylogenetic analyses of a combined dataset and species-delimitation methods based on COI data demonstrated a congruent pattern of species boundaries, indicating cryptic species diversity within presently constituted $B$. intricata and $B$. vaga. We also estimated the divergence time of these species using substitution rates of combined $r b c \mathrm{~L}$ and $\mathrm{COI}$ datasets calibrated from $B$. calliptera collected around the Isthmus of Panama. Results indicated that these four species formed in the middle Oligocene epoch (ca. $30 \mathrm{Mya}$ ), suggesting a post-Gondwana origin and relatively ancient divergence. We speculate that evolution of these species may have been due to transoceanic dispersal that was facilitated by the circulation of the Antarctic Circumpolar Current (ACC) and subsequent isolation.
\end{abstract}




\section{Introduction}

Speciation is an important biological process by which new species arise (Howard and Berlocher 1998, Hey et al. 2003, Coyer and Orr 2004). Species delimitation is important for giving insights into speciation processes and for determining the actual biodiversity of a given region (Fujita et al. 2012, Carstens et al. 2013). However, speciation is a continuous process that often leads to difficulties and disagreements about how particular species should be defined (Howard and Berlocher 1998, Coyer and Orr 2004). As a result, employing several methods and datasets to delimit species is recommended, and subsequently the achievement of congruent results across the methods is likely to prove most useful for framing reliably supported species boundaries (Carstens et al. 2013, Leliaert et al. 2014).

In algae, delimitating species is frequently quite difficult, especially when based only on morphological and anatomical characters. The main reason is the lack of adequate or obvious diagnostic characters and the high degree of morphological plasticity exhibited within many populations over time and in different habitats (Fraser et al. 2009b, Leliaert et al. 2014, Verbruggen 2014). Since the advent of methods for generating genomic data, many taxonomic problems and evolutionary questions have been more clearly resolved (Freshwater et al. 1994, Lane et al. 2006, Zuccarello et al. 2011). Algal cryptic diversity has also been often uncovered based on genetic data (e.g. Zuccarello et al. 2002, Zuccarello and West 2003, Fraser et al. 2013), and DNA-based species-delimitation analysis methods are often employed for evaluating true species diversity among genera of marine macroalgae (Tronholm et al. 2012, Payo et al. 2013, Siberfeld et al. 2013). The General-mixed-Yule-coalescent (GMYC) method, introduced by Pons et al. (2006), is one of the most common coalescent-based species-delimitation methods, based on the analysis of single-locus data. The GMYC approach emphasizes a transition in the branching pattern to indicate different genetic clusters, which are then generally recognized as 'putative species' within a geographically delimited population (Fujita et al. 2012). The GMYC model can also accommodate singletons (a single haplotype for a species only known from a single specimen), but a high percentage of singletons may lead to an overestimation of species richness (Lim et al. 2011). 
The mangrove-associated red-algal genus Bostrychia Montagne is widely distributed in tropical and warm-temperature habitats of all hemispheres, but it is also found in coldtemperate and subantarctic regions from which mangroves are absent (King and Puttock 1989, Zuccarello and West 2011). Bostrychia is a polysiphonous member of the family Rhodomelaceae (Zuccarello and West 2006, West et al. 2013) that has been used as a model for studies of distribution, evolutionary relationships and speciation processes (reviewed in Zuccarello and West 2011). Previous studies of molecular phylogeny and phylogeographic patterns of Bostrychia have revealed the frequent presence of cryptic species nested within well-known species that have long been regarded as uniformly composed (Zuccarello and West 2002, Zuccarello and West 2003). Bostrychia radicans (Montagne) Montagne and B. moritziana (Sonder ex Kützing) J. Agardh, for example, both consist of several non-interbreeding genealogical lineages (Zuccarello et al. 1999a, Zuccarello and West 2003) that do not display distinguishing characters in habit or at the light-microscope level in morphology or anatomy. Most studies have involved warmtemperate or tropical Bostrychia species, and the diversity and phylogenetic relationships of both warm- and cool-temperate waters of the Southern Hemisphere are very incompletely explored.

Four marine species of Bostrychia, B. arbuscula Hooker \& Harvey, B. gracilis (King \& Puttock) Zuccarello \& West, B. intricata (Bory de Saint-Vincent) Montagne and B. vaga Hooker \& Harvey, are commonly found in the Southern Hemisphere (King and Puttock 1989, Zuccarello and West 2008). These algal species were once assigned to the genus Stictosiphonia (Zuccarello and West 2006). Bostrychia arbuscula and B. gracilis are restricted to New Zealand, whereas B. vaga is found in New Zealand, the subantarctic Islands, South America and South Africa (King and Puttock 1989, Zuccarello and West 2008). Bostrychia intricata is a temperate species having the most widespread distribution in the Southern Hemisphere, as well as being also recorded in Japan (Yoshida et al. 1990), India (Silva et al. 1996) and Indonesia (Post 1936). However, claims that B. intricata occurs in the Northern Hemisphere and tropical regions are suspect and records from those latitudes should be reassessed (Zuccarello and West 2008). Morphologically, the four species under consideration are distinguished from other Bostrychia species distributed in the Southern Hemisphere by having pericentral cells that divide into more than two tier cells (Zuccarello and West 2006, 2008). Traditionally the taxonomy of these species was based on the presence/absence of cortication, which separate them into two informal 
groups: the corticated B. arbuscula and B. gracilis, and the ecorticate species B. intricata and B. vaga. Other taxonomic characters, such as branching pattern or apex shape have been applied in identification within these informal groups (Zuccarello and West 2008). In addition to morphological distinctions, some studies showed differences in polyol contents and low-molecular-weight carbohydrates among these Bostrychia species (reviewed in Zuccarello and West 2011).

Preliminary studies on the molecular phylogeny of Bostrychia species in New Zealand were undertaken by Zuccarello and West (2008). However, the phylogenetic affinities of B. arbuscula, B. gracilis, B. intricata and B. vaga remained poorly resolved. The cytochrome c oxidase subunit I (COI) gene was used to explore the dispersal pattern of $B$. intricata, the results indicating high genetic diversity and strong phylogeographic structure in this species (Fraser et al. 2013). Moreover, high levels of genetic variation within the morphospecies B. intricata revealed multiple cryptic species (Zuccarello and West 2008, Fraser et al. 2013). From these results, the genetic diversity within B. intricata was shown to be clearly underestimated, indicating that knowledge of speciation and evolutionary history in this species was limited.

Our aim in the present study has been to apply molecular data from these Southern Hemisphere species of Bostrychia to examine their phylogenetic relationships, explore cryptic diversity using species-delimitation analytical methods, estimate the divergence rates leading to speciation, and to determine the approximate times of origin of this diversification. 


\section{Materials and Methods}

Algal samples were collected from different locations in the Southern Hemisphere (Fig. 2.1, Appendix 2.1). All samples were preserved in silica gel and then morphologically identified to species based on previous publications (e.g. King and Puttock 1989, Zuccarello and West 2006, 2008). For molecular analyses, algal samples were cleaned with distilled water to remove any sand and dirt, and subsequently the distal parts were used for DNA isolation.

Genomic DNA was extracted using a modified Chelex method following Zuccarello et al. (1999b). Three different molecular markers were used: ribulose-1,5-bisphosphate carboxylase/oxygenase large subunit gene ( $r b c \mathrm{~L}$, plastid DNA), cytochrome c oxidase subunit I gene (COI, mitochondrial DNA) and the Y-fragment of the large-subunit (28S) ribosomal RNA gene (LSU, nuclear DNA; see Harper \& Saunders 2001). PCR and sequencing were performed using different primer combinations: two were rbcLFC and R753, and F577 and rbcLRD (Freshwater \& Rueness 1994; Nam et al. 2000) for rbcL; two were GazF1 and GazR1 (Saunders 2005) or BstCF2 and BstCR2 (Fraser et al. 2013) for COI; and one was Y-for and Y-rev (Harper \& Saunders 2001) for LSU. PCR procedures followed Zuccarello et al. (2002) for $r b c L$, Saunders (2005) and Fraser et al. (2013) for COI, and Zuccarello and West (2006) for LSU. PCR products were confirmed by gel electrophoresis in 1\% agarose, and then purified using ExoSAP-IT (USB, Cleveland, Ohio, USA). Purified PCR products were commercially sequenced (Macrogen Inc., Seoul, Korea).

All sequences were edited and assembled using eBioX software (eBioinformatics, http://www.ebioinformatics.org/index.html). Alignments for individual and combined datasets were prepared using the MUSCLE algorithm in the Geneious 6.0 software package (Biomatters, http://www.geneious.com) and then manually checked by eye. For phylogenetic analyses, datasets included some additional sequences of Bostrychia retrieved from GenBank (Appendix 2.1). Bostrychia moritziana was selected as the outgroup because it is closely related to our Bostrychia species but was located in a different clade ("cladohaptera-clade"; Zuccarello and West 2006). All new sequences 
generated in this study have been submitted to GenBank (accession numbers KM502788 KM502864).

Phylogenetic analyses were performed using both individual and the combined datasets of $r b c \mathrm{~L}, \mathrm{COI}$ and LSU sequences by two different methods: maximum likelihood (ML) and Bayesian inference (BI). Prior to ML and BI analysis, the best-fit model of DNA substitution of each gene was determined with the program Kakusan4 (Tanabe 2011). For the protein-coding datasets $r b c \mathrm{~L}$ and COI, partitioning by codon position and separate DNA-substitution models was chosen for each position. ML analyses for all datasets were performed using Treefinder software (version March 2011, Jobb et al. 2004) within the tool package Phylogear v2.0 (Tanabe 2008), followed by bootstrap analysis conducted with 1000 replications. BI analyses were performed with the program MrBayes v3.1.2 (Ronquist and Huelsenbeck 2003). Two independent analyses, each consisting of four Markov chains, were run simultaneously for 2,000,000 generations, sampling every 100 generations. Log likelihood and parameter values were assessed with Tracers ver. 1.5 (Rambaut and Drummond 2009). A burn-in of $25 \%$ of saved trees was removed, and the remaining trees were used to calculate the Bayesian posterior probability (PP) values. ML and BI trees were edited with the program FigTree v1.3.1 (Rambaut 2009).

Due to low variation of LSU sequences within species, we used $r b c \mathrm{~L}$ and COI for molecular species-delimitation and divergence-time estimation. DNA-based species delimitations were tested using separate datasets of $r b c \mathrm{~L}$ and COI by three different methods: the General-Mixed-Yule-Coalescent model (GMYC); Automatic Barcoding Gap Detection (ABGD) (Puillandre et al. 2012); and Statistical Parsimony Network Analysis (SP) (Hart and Sunday 2007). Additional GMYC model-based species-delimitation analysis was carried out in B. intricata based on combined datasets of COI sequences generated in this study and from Fraser et al. (2013). For the GMYC delimitation method, an ultrametric tree was constructed in BEAST v2.0.2 (Drummond et al. 2012), relying on the uncorrelated lognormal relaxed clock, the GTR $+\mathrm{I}+\mathrm{G}$, and a coalescent tree prior. Bayesian Markov chain Monte Carlo (MCMC) was run for 20 million generations, and trees and parameters sampled every 1000 generations. Log files were visualized in Tracers v1.5 (Rambaut and Drummond 2009) for assessing the stationary state of parameters based on the value of estimate-effective sample size (ESS). After removing $25 \%$ of trees as burnin, the remaining trees were used to generate a single summarized tree in TreeAnnotator 
v2.0.2 (part of the BEAST v2.0.2 package) as an input file for GMYC analyses. The GMYC analyses with a single threshold model were performed in R (R Development Core Team, http://www.R-project.org) under the "splits" package using 'gmyc' function (RForge, http://r-forge.r-project.org/projects/splits/). The ABGD method was tested via a web interface (ABGD web,http://wwwabi.snv.jussieu.fr/public/ abgd/abgdweb.html). Prior to analysis, the model criteria were set as following: intraspecific variability $(P)$ between $0.001\left(P_{\min }\right)$ and $0.1\left(P_{\max }\right)$, minimum gap width $(\mathrm{X})$ of 0.1 , Kimura-2-parameters and 50 screening steps. In addition, statistical parsimony networks of $r b c \mathrm{~L}$ and COI datasets were generated in TCS 1.21 (Clement et al. 2000) with a maximum connection probability set at $95 \%$ statistical confidence.

As there are no fossil records for members of the Rhodomelaceae, we attempted to estimate the divergence time of our species by using substitution rates from the separation of Bostrychia taxa with respect to the time of the emergence of the Isthmus of Panama. Substitution rates of $r b c \mathrm{~L}$ and COI were estimated based on two samples of Bostrychia calliptera (Montagne) Montagne collected from both sides of the Isthmus of PanamaAtlantic Mexico (C3400.MX) and Pacific Colombia (C3191.CO), as were used in a previous study by Zuccarello and West (2002). We accepted the final closure of the Isthmus of Panama 2.5-3.0 million years ago (Mya) (Bartoli et al. 2005) as a calibration point, and calculation of substitution rates followed Kamiya et al. (2004) (Appendix 2.2). Estimation of divergences times was based on the combined dataset of $r b c \mathrm{~L}$ and $\mathrm{COI}$ using BEAST v2.0.2 (Drummond et al. 2012). We set the criteria for BEAST analysis as following: the same partition and substitution model as used in phylogenetic analyses; unlinked site model and clock model with linked trees; and a Yule model as the tree priors. The rates used in the clock model were an uncorrelated lognormal relaxed clock for all datasets, with means rate of 0.041 substitutions/site/million years and $\mathrm{SD}=0.004$ for $r b c \mathrm{~L}$, and 0.14 substitutions/site/million years and $\mathrm{SD}=0.01$ for $\mathrm{COI}$. We ran the MCMC analyses for 40 million generations, sampling every 5000 generations, and then determined the distribution and effective sample size (ESS) of parameters using Tracers v1.5 (Rambaut and Drummond 2009). The initial 25\% of saved trees was removed as the burnin, and a maximum credibility tree based on the remainder was produced using TreeAnnotator v2.0.2 (part of the BEAST v2.0.2 package). The time-calibrated tree with 95\% highest posterior density was visualized and edited in FigTree v1.3.1 (Rambaut 2009). 


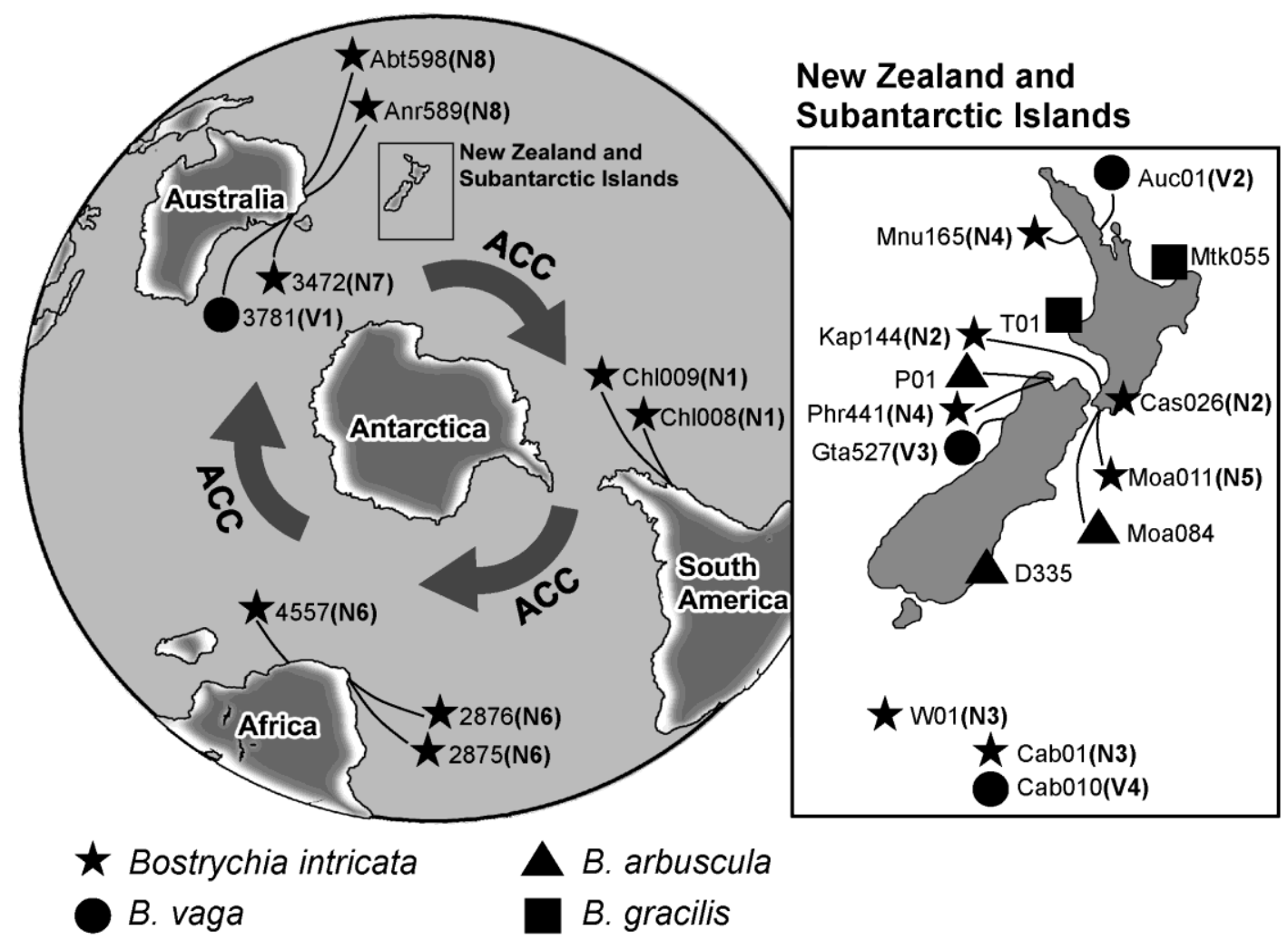

Figure 2.1: Sampling locations of Bostrychia species in New Zealand, Subantarctic Islands (Campbell and Auckland Islands), Australia, Chile and South Africa (see Table S1 for exact detail of each sample). Letters and numbers in bracket indicate the cryptic species based on the congruent results of phylogenetic analyses and COI based-species delimitations. ACC: The Antarctic Circumpolar Current. 


\section{Results}

We successfully obtained the partial sequences of three genes, and our final alignments comprised 1163 bp of $r b c \mathrm{~L}, 375$ bp of COI and 969 bps (including gaps) of LSU for 27 samples of Bostrychia species, including some published sequences downloaded from GenBank (Appendix 2.1). The $1163 \mathrm{bp}$ of $r b c \mathrm{~L}$ were comprised of $29.5 \%$ variable sites, the $375 \mathrm{bp}$ of the COI gene of $42.1 \%$ variable sites and the $969 \mathrm{bp}$ of partial LSU genes of $24.7 \%$ variable sites. The genetic distances of $B$. arbuscula, B. gracilis, $B$. intricata and $B$. vaga are given in Appendix 2.3. Among these three genetic markers, the partial COI gene appears to be more variable than $r b c \mathrm{~L}$ or LSU.

The appropriate DNA substitution models for each gene were calculated (Appendix 2.4). Phylogenetic trees obtained from ML and BI analyses were almost completely topologically congruent for the three individual markers ( $r b c \mathrm{~L}, \mathrm{COI}$ and LSU) (Appendices 2.5, 2.6 and 2.7) and the combined dataset. However, only BI tree based on the combined dataset is presented (Fig. 2.2). ML and BI trees from the combined dataset indicated monophyly of $B$. arbuscula, B. gracilis, B. intricata and B. vaga, the four major clades corresponding to their morphology-based species assignments. Bostrychia vaga was recovered as sister to the remaining species, and the clades of B. arbuscula and B. gracilis were grouped together $(\mathrm{ML}=100 \%, \mathrm{BI}=1.00)$ (Fig. 2.2).

In the clade containing $B$. intricata, multiple well-supported clades were recognized (Fig. 2.2, ML > 90\%, BI > 0.95), suggesting multiple cryptic species (N1 - N8, Fig. 2.2) within that morphospecies as presently circumscribed (King \& Puttock 1989). Among these cryptic species, three tentative groups were established as follows: group A, which consisted of cryptic species N1 from Chile, N3 from the subantarctic islands and N4 from New Zealand; group B, which consisted only of cryptic species N6 from South Africa; and group C, composed of cryptic species N2 and N5 from New Zealand and cryptic species N7 and N8 from southern Australia (Fig. 2.2). Likewise, the clade of B. vaga was split into four cryptic species: V1, from Australia; V2, from northern New Zealand; V3, from southern New Zealand; and V4, from the Campbell Islands (Fig. 2.2). 
We employed three different methods for species delimitation (GMYC, ABGD and SP) for our samples based on the separate $r b c \mathrm{~L}$ and COI datasets. All species-delimitation methods supported a single species of B. arbuscula and B. gracilis for both markers, and indicated multiple species in B. intricata and B. vaga (Fig. 2.2).

Within the $B$. intricata clade, three different methods using the $r b c \mathrm{~L}$ dataset yielded different numbers of species: six species with GMYC $\left(\mathrm{L}_{\mathrm{GMYC}}=135.644>\mathrm{L}_{0}=130.363, P\right.$ $=0.01)$; seven species with ABGD $(P=0.001)$; and five species with SP, although all analyses using the COI dataset consistently resulted in eight species regardless of method (Fig. 2.2). Additional GMYC model analyses using all haplotypes of COI available (unpublished data) and from Fraser et al. (2013) yielded the same number of eight cryptic species in B. intricata (Appendix 2.8). In contrast, all methods applied for B. vaga constantly revealed three cryptic species based on the $r b c \mathrm{~L}$ data, with an additional fourth species from the COI data. The results obtained from all species-delimitation methods in $B$. intricata and B. vaga based on COI were completely congruent with cryptic species N1 N8 and V1 - V4, which were recognized from the phylogenetic analyses (Fig. 2.2).

Our data also showed several singletons in our analysis of putative species in B. intricata and $B$. vaga, these singletons were sometimes due to a single specimen collected in our sampling but also to a lack of variation in multiple samples (unpublished data). This was evident in B. intricata (N5 and N7) and B. vaga (V1 - V4) (Fig. 2.2). 


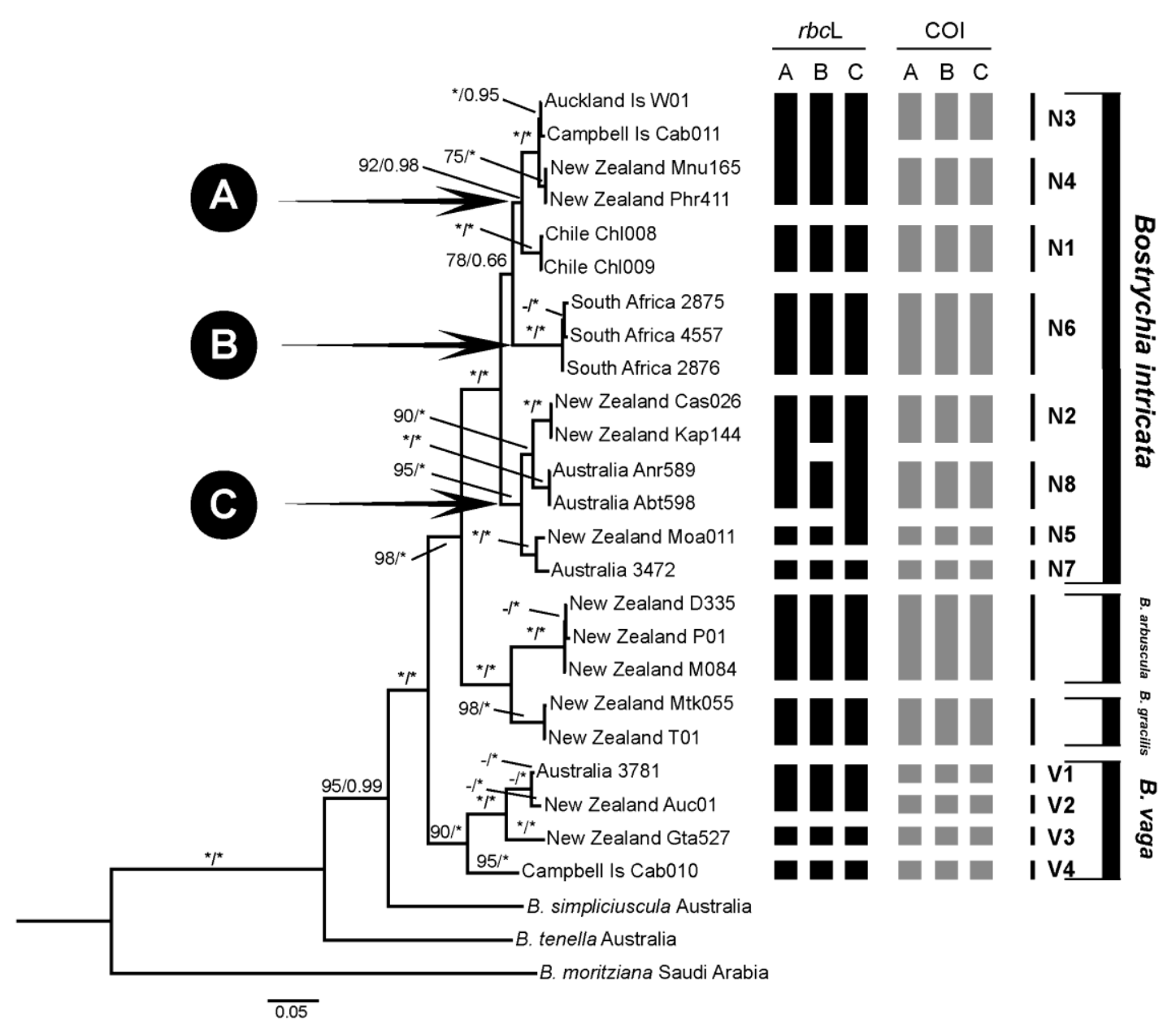

Figure. 2.2: Phylogenetic tree inferred from Bayesian-Inference analyses of the combined dataset of $r b c \mathrm{~L}, \mathrm{COI}$ and LSU for Bostrychia species. Support values at each node are bootstrap values from ML (left) and Bayesian posterior probability (right). Asterisk (*) indicates full support $(100 \%, 1.0)$ in both analyses and hyphen (-) indicates no support. The results of three species delimitation methods: GMYC model (column A), the ABGD (column B) and statistical parsimony (column C), based on $r b c \mathrm{~L}$ (black color) and COI (grey color) are indicated at the right edge of the tree. The black bars and letters indicate the cryptic species obtained from congruent results of phylogenetic analyses and COI based-species delimitations. 
We inferred the divergence time of our species based on substitution rates of the $r b c \mathrm{~L}$ and $\mathrm{COI}$ genes. The rates of $r b c \mathrm{~L}$ and COI obtained by this study from Bostrychia calliptera collected on both sides of the Panama Strait were $3.8-4.5 \times 10^{-10}$ per site per year and 13 $-15 \times 10^{-10}$ per site per year, respectively. Divergence time in the phylogeny was estimated from combined $r b c \mathrm{~L}$ and COI datasets (Fig. 2.3). The origins of B. arbuscula, $B$. gracilis, B. intricata and B. vaga occurred between the late Eocene and early Oligocene, approximately 31 (26-36) Mya. Diversification of the B. vaga clade was around 19 Mya, corresponding to the Early Miocene, whereas the timings of divergences of the $B$. arbuscula and B. gracilis clade and the B. intricata clade were in the Middle Miocene, circa 11 and 13 Mya, respectively (Fig. 2.3). Within B. intricata, the diversification of group B (N6 from South Africa) occurred around 10 Mya, whereas the cryptic species in group A (N1, N3 and N4) and C (N2 and N8, N5 and N7) diverged later, circa 8 Mya. Cryptic species N3 and N4 were the most recent radiations within this morphospecies, circa 2 Mya (Fig. 2.3). In addition, divergence occurred twice between Australia and New Zealand: cryptic species N2 and N8 circa 5 Mya, and cryptic species N5 and N7 circa 3.5 Mya.

\section{Discussion}

Our phylogenetic analyses obtained from combined data of markers for three genomes confirmed the monophyly of the four Bostrychia species B. arbuscula, B. gracilis, B. intricata and B. vaga (Fig. 2.2). Moreover, our results clearly showed well-resolved phylogenetic relationships of these four species, with $B$. vaga recovered as sister to the rest. The close relationship of the corticated species B. arbuscula and B. gracilis was also confirmed, and the ecorticate $B$. intricata also proved to be closely related to these two species (Fig. 2.2). The phylogenetic affinities of all four were not fully in accord with the relationships inferred from the shared morphological character of either distinct cortication and ecortication, as was hypothesized by King and Puttock (1989), which assumed a close relationship of the ecorticate species, $B$. intricata and $B$. vaga, and the corticated species, $B$. arbuscula and B. gracilis. Global phylogenetic analysis of the genus Bostrychia by Zuccarello and West (2006) showed that cortication was randomly distributed in the 
evolutionary history of Bostrychia species, and we therefore maintain that the presence/absence of cortication does not carry any phylogenetic weight, although it does consistently characterize species.

Our molecular data indicate that the morphospecies B. arbuscula and B. gracilis fall into single clades, whereas the morphospecies $B$. intricata and $B$. vaga appeared to be composed of numerous distinct and well-supported clades indicative of cryptic species. Fraser et al. (2013) have reported four cryptic species of B. intricata, corresponding to N1 - N4 from our analyses, from Chile (N1, N4), New Zealand (N2, N4), Tristan da Cunha (N4), the Falkland Islands (N1), Gough Island (N1), Marion Island (N1) and the Subantarctic Islands (N3) based on COI markers, and our expanded sampling covering a greater range has discovered four additional lineages from New Zealand (N5), South Africa (N6) and Australia (N7, N8). Distribution of each lineage is likely to be geographically restricted, except for lineages N1 and N4 that are commonly found in several locations (Fraser et al. 2013). Our analyses revealed the close relationship of lineages between Australia (N7 and N8) and New Zealand (N2 and N5), which strongly supports the proposition that there was historical dispersal and isolation between the lineages from Australia and New Zealand.

We have provided the first report of Bostrychia vaga in Australia. Bostrychia vaga has four cryptic species based on the combined analysis of $r b c \mathrm{~L}, \mathrm{COI}$ and LSU, and speciesdelimitation methods indicate up to four genetic putative species (V1 - V4). Cryptic species V1 and V4 were solely found in Australia and the Campbell Islands, respectively, whereas lineages V2 and V3 were both found only in New Zealand. Although the phylogenic relationships of our B. vaga samples are well supported, we still lack the intensive sampling throughout the entire range of the species that will be necessary in order to understand fully its speciation processes. 


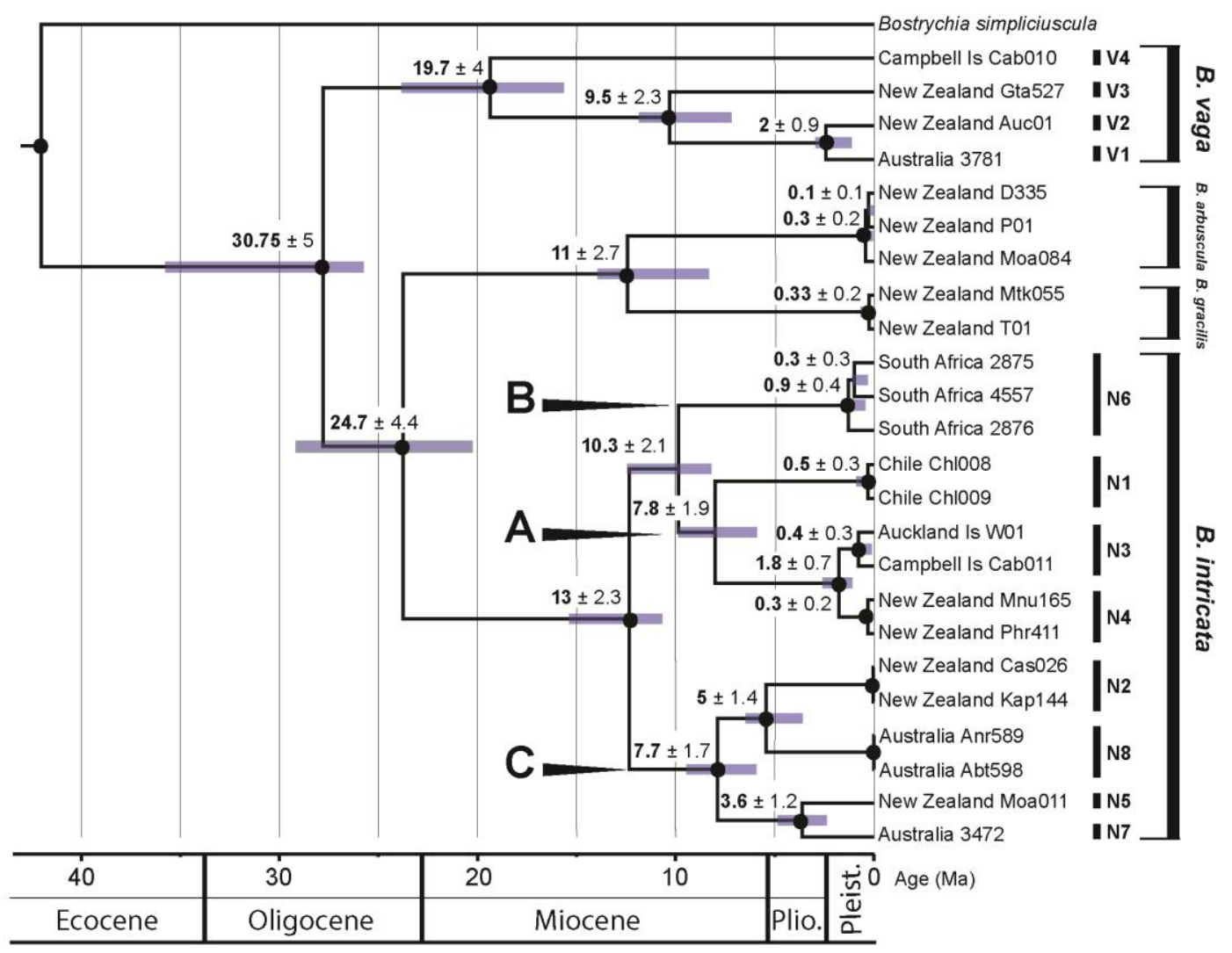

Figure 2.3: Bayesian tree for Southern Hemisphere species of Bostrychia reconstructed using BEAST under a relaxed clock model of the combined data set of $r b c \mathrm{~L}$ and COI. Bars show $95 \%$ highest posterior densities of divergences dates. Mean dates followed by \pm standard deviation (above bars) and scale bar are in million years. Black dots at node indicate the support of $>95 \%$ Bayesian posterior probabilities. 


\section{Delimiting cryptic Bostrychia species}

Our attempt to use two different markers, $r b c \mathrm{~L}$ and COI, in delimitating Bostrychia species by the use of three algorithmic techniques has demonstrated multiple distinct lineages within two of them, B. intricata and B. vaga. Delimited species based on COI provided a greater number of species than those based on $r b c \mathrm{~L}$ and yielded similar species to those determined based on well-supported clades in the phylogenetic analyses. These results support those of Payo et al. (2013) and Silberfeld et al. (2013) in showing mitochondrial-gene-based species-delineation and multilocus-based phylogenetic analysis of algae to be congruent. In addition, our GMYC method also indicated several singleton species in B. intricata (N5 and N7) and B. vaga (V1 - V4) (Fig. 2.2) based on single samples collected in the area. The GMYC model-based species delimitation may overestimate the species number due to sampling error (i.e. singletons), but it still provides an initial hypothesis of the number and extent of species-level groups (Papadopoulou et al. 2009). Delimiting algal species based on the GMYC model commonly produces species based on singletons, as in examples for the red alga Portieria (Payo et al. 2013) and the brown alga Padina (Silberfeld et al. 2013). As with all species circumscriptions, these conclusions are hypotheses that need to be tested with further research. This will be especially important in determining the power of species-delimitation methods to correctly detect species based on rare or low diversity 'species' (i.e. singletons)(Lim et al. 2011).

Our results also have shown that different species-delimitation methods can provide incongruent species boundaries, as found in B. intricata based on $r b c \mathrm{~L}$ analyses (Fig. 2.2). The different results obtained from species-delimitation methods between $r b c \mathrm{~L}$ and COI are likely be influenced by the different mutation rates of these two genetic markers. Our substitution rates of $r b c \mathrm{~L}$ and $\mathrm{COI}$ showed that the mitochondrial genes evolved 3-3.5 times faster than the plastid gene. It is clear that a marker of greater variability (COI) is more suitable for detecting the relatively young divergence events in $B$. intricata and $B$. vaga.

The use of COI for DNA barcoding in resolving problems of species identification and addressing red-algal taxonomic questions was proposed by Saunders (2005) and employed frequently in studies of marine algae (e.g. Saunders 2009, Sherwood et al. 2010, Yang et al. 
2013). The genetic divergence of COI among lineages obtained in this study ranged from $3.7 \%$ to $12.7 \%$ for $B$. intricata and $4.2 \%$ to $16.2 \%$ for $B$. vaga, which are values that are above the threshold generally used to discriminate between species in barcoding studies of red seaweeds (Saunders, 2009, Le Gall and Saunders, 2010). Additionally, species delimitation based on genetic divergence within and between species (the ABGD method) indicated that partition output calculated from COI datasets produced a higher number of lineages than $r b c \mathrm{~L}$, and this could be explained by the difference of intra- versus interspecific genetic variability of these two markers (Appendix 2.3).

Putative species, as discovered by genetic species-delimitation methods, are the first stage in reaching a calculation of true species diversity. If the species delimitation is upheld with increased sampling, then the cryptic natures of these lineages need to be investigated more carefully as it is possible that subtle differences in morphology, at present not detected, can be found. Reproductive incompatibility can also be used to support the species' status (Zuccarello and West 2003). Other criteria, including physiological differences (for example, polyol contents) may help differentiate these cryptic species (Karsten et al. 1992), which, at present can only be identified genetically, and occasionally geographically. New collections of B. intricata and B. vaga should be referred to the N1-N8 and V1-V4 clades presented here to more carefully assess the species diversity found in new areas.

\section{Divergence of Bostrychia species in the Southern Hemisphere}

The divergence time of Bostrychia arbuscula, B. gracilis, B. intricata and B. vaga, as calculated from a substitution-rate based on the combined dataset $(r b c \mathrm{~L}$ and $\mathrm{COI})$, revealed that these four species have a most recent common ancestor in the Middle to Late Oligocene (circa $30.75 \pm 5 \mathrm{Mya}$ ), indicating that diversification of the Bostrychia species in the Southern Hemisphere came after the split up of Gondwana (65-80 Mya, McLoughlin, 2001). Among these four species, cryptic B. intricata species appeared to be the most recent radiations, the most recent divergence between the cryptic species of $B$. intricata having taken place about 2 Mya (cryptic species N3 and N4). These results also indicate that the morphological features of these species have been conserved over long periods of time, some 25 Mya for the corticated species B. arbuscula and B. gracilis and circa 30 Mya for the ecorticate species B. intricata and B. vaga. This morphological stability has also been noted in other Bostrychia species complexes by Zuccarello and West (2002, 
2003). Our data revealed that the divergence of southern-hemisphere Bostrychia species was earlier than that of the southern-hemisphere brown algal species of Durvillaea $(15.3 \pm$ 7 Mya; Fraser et al. 2010) and Lessonia (5 Mya; Martin and Zuccarello 2012), indicating that the processes leading to speciation or longevity of species may be different between these brown and red algal species.

As the formation of the Southern-Hemisphere Bostrychia species examined in our study took place subsequent to the break-up of Gondwana, their present geographical distribution may best be explained by transoceanic dispersal followed by allopatric speciation, a scenario that has also been purposed for Durvillaea (Fraser et al. 2010). Transoceanic distribution, especially for B. intricata and B. vaga, is likely to have been achieved through the circulation of Antarctic Circumpolar Current (ACC) that began following the opening of the Drake Passage (32-28 Mya; McLoughlin, 2001) and Tasmania Seaway (33.5 Mya; Hassold et al. 2009), which conforms closely to the divergence time of our monophyletic progenitor of the Bostrychia species that we have studied (ca. 30 Mya). Furthermore, two separate divergence events affecting $B$. intricata occurred between Australia and New Zealand, suggesting at least two dispersals across the Tasman Sea between 3-7 Mya. This is interesting in light of work showing that floating and non-floating algae and associated fauna have dispersed fairly regularly across the southern ocean at latitudes corresponding to the distributions of the Bostrychia species (Macaya and Zuccarello 2010b, Nikula et al. 2010, Fraser et al. 2013). However, algae at lower latitudes (e.g. Northern New Zealand and Southern Australia) do not disperse easily as compared to those distributed at higher latitudes that are more directly in contact with the ACC (Fraser et al. 2009c). It would seem that in lower-latitudes dispersal is rare (few establishments over millions of years) although still important in driving diversity and producing species.

In conclusion, our molecular data indicated the monophyletic origin of Bostrychia arbuscula, B. gracilis, B. intricata and B. vaga in the Southern Hemisphere, and uncovered cryptic diversity in B. intricata and B. vaga. Eight cryptic species of B. intricata and four of B. vaga were strongly supported by the phylogenetic analyses, as well as in all species-delimitation approaches based on COI data. We suggest that species boundaries, especially for cryptic algal species, should be estimated by multiple methods of species delimitation, with the different suitable markers combined with phylogenetic analyses. The 
mitochondrial marker (COI) is very useful for exploring algal diversity, especially for recently diverging species. We have also performed a first estimation of timing of divergence based on a combined dataset of $r b c \mathrm{~L}$ and COI, and we have used estimated substitution rates determined in a congeneric (B. calliptera) isolated by a well known vicariant event. We found that the divergence and distribution of Bostrychia lineages in the Southern Hemisphere may be correlated with the circulation of the ACC when the Drakes Passage and Tasmanian Seaway opened.

\section{Acknowledgements}

We express our appreciation to Christian Boedeker for comments on earlier version of this manuscript, and anonymous reviewers that improved the manuscript. We thank those who helped us obtaining algal samples: Fiona Scott, Maria Eliana Ramirez, Ceridwen Fraser, Mike Wilcox and Wendy Nelson. We also thank the Victoria University of Wellington for providing a scholarship to NM. Long-term financing for this work has been provided through personal funds of JAW and from the Australian Research Council, Australian Biological Resources Study and Hermon Slade Foundation grants to JAW/GCZ. 


\section{Chapter Three}

Phylogeographic Patterns AND Historical

DEMOGRAPHY OF CRYPTIC SPECIES OF

BOSTRYCHIA INTRICATA IN NEW ZEALAND 


\begin{abstract}
Spatial patterns of genetic diversity provide insight into the demography and history of species. Morphologically similar but genetically distinct 'cryptic' species are increasingly being recognized in marine organisms through molecular analyses. Such species are, on closer inspection, often discovered to display contrasting life histories or occasionally minor morphological differences; molecular tools can thus be useful indicators of diversity. Bostrychia intricata, a marine red alga, is widely distributed throughout the Southern Hemisphere, and comprises many cryptic species. We used mitochondrial COI sequences to assess the genetic variation, population genetic structure and demographic history of $B$. intricata in New Zealand. Our results supported the existence of three cryptic species of $B$. intricata (N2, N4 and N5) in New Zealand. Cryptic species N4, which was found throughout New Zealand, showed a higher genetic diversity and wider distribution than the other two species, which were only found in the North Island and northern South Island. Our analyses showed low to moderate genetic differentiation among eastern North Island populations for cryptic species N2, but high differentiation among North and South Island populations for N4, suggesting different population structure between these cryptic species. Data also indicated that N2 has recently undergone population expansion, probably since the Last Glacial Maximum (LGM), while the higher genetic diversity in N4 populations suggests persistence in situ through the LGM. The contrasting population structures and inferred demographic histories of these species highlight that life history can vary greatly even among morphologically indistinguishable taxa.
\end{abstract}




\section{Introduction}

Present-day patterns of genetic diversity can allow inference of dispersal and connectivity among marine populations, and can contribute to our understanding of how historical climatic events, oceanographic conditions and tectonic processes have influenced the evolution and demographic history of marine organisms (Hewitt 2004, Lomolino et al. 2006, Hemmer-Hansen et al. 2007, Fraser et al. 2012). In the high latitudes of the Southern Hemisphere, numerous recent studies have shed light on the diversity, distribution and biogeographic patterns of marine populations (reviewed by Allcock and Strugnell 2012, Fraser et al. 2012). Phylogeographic studies have provided strong evidence for significant population structure in numerous marine organisms (Brante et al. 2012, Le Port and Lavery 2012, Fraser et al. 2013). Such structure can be used to infer how species, and populations within species, have responded to past processes such as climate change. For example, higher genetic diversity in low versus high latitude populations has been interpreted to reflect postglacial recolonization of higher latitude areas following recession of ice at the LGM (e.g. crustaceans: Nikula et al. 2010; kelp: Fraser et al. 2009c, 2010, Macaya and Zuccarello 2010a, b).

New Zealand (NZ) consists of two main islands, the North and South Islands, which have striking geological and environmental differences, such as northern volcanoes and southern glaciated regions. The complex geographical and oceanographic (Appendix 3.1) systems have resulted in phylogeographic structure in both terrestrial and marine taxa (Ross et al. 2009, Wallis and Trewick 2009). Several phylogeographic studies of marine species have detected deep genetic splits between northern/southern and eastern/western geographical regions (Apte and Gardner 2002, Sharyn et al. 2006, Ross et al. 2009, 2012) (Appendix 3.1). In contrast, other studies have detected little or no phylogeographic structure around New Zealand, indicating broad population connectivity in some groups (Smith et al. 2002, Waters and Roy 2003). Inconsistency of phylogeographic patterns observed among marine taxa in New Zealand suggests that different species respond in different ways, possibly due to species-specific dispersal ability, reproductive strategies or species' and demographic history. 
The phylogeographic structure of several brown seaweeds, e.g., Carpophyllum maschalocarpum (Turner) Greville, Durvillaea antarctica (Chamisso) Hariot, Macrocystis pyrifera (Linnaeus) C. Agardh, has previously been investigated in NZ (Fraser et al. 2009c, Macaya and Zuccarello 2010a, Buchanan and Zuccarello 2012). These studies, which relied largely on data from mitochondrial markers, demonstrated spatial heterogeneity in genetic diversity among seaweed populations from the North Island, with a transition region between the bottom of the North Island and the top of the South Island (Fraser et al. 2009c, Buchanan and Zuccarello 2012). In addition, genetic evidence indicated that the distribution and population connectivity of these buoyant brown seaweeds has been strongly influenced by surface ocean circulation patterns (e.g. Antarctic Circumpolar Currents - ACC) and historical events (e.g., the LGM) (Fraser et al. 2009c, Macaya and Zuccarello 2010a, Buchanan and Zuccarello 2012, Collins et al. 2010). Whereas population structure and dispersal patterns of brown seaweeds in New Zealand have been quite well studied, research on other groups of seaweed - especially nonbuoyant taxa with limited dispersal potential - has been relatively uncommon. Although non-buoyant taxa should theoretically be less capable of long-distance dispersal than robust, buoyant taxa, and might therefore be expected to show stronger phylogeographic structure (Fraser et al. 2013), dispersal capacity alone is not always a good predictor of population connectivity (Waters et al. 2013).

The genus Bostrychia Montagne is a filamentous red alga of the family Rhodomelaceae, order Ceramiales, and currently contains $\sim 19$ species, which are widely distributed in tropical and temperate regions (King and Puttock 1989, Zuccarello and West 2006). Bostrychia has been used as a model system to study evolution, speciation processes, and population connectivity (reviewed in Zuccarello and West 2011). For example, studies on genetic diversity of Bostrychia radicans (Montagne) Montagne and B. moritziana (Sonder ex Kützing) J. Agardh show that these two morphospecies consist of seven noninterbreeding genealogical lineages, some of which occur in sympatry (Zuccarello and West 2003, Zuccarello et al. 2006, Zuccarello et al. 2011), suggesting the presence of cryptic species (Zuccarello et al. 1999a; Zuccarello and West 2003). However, while the phylogenetic diversity and phylogeography of the warm-temperate Bostrychia species have been well studied, diversity and distribution patterns of Bostrychia species endemic to the Southern Hemisphere are still poorly documented. 
The most widespread Bostrychia species throughout the Southern Hemisphere is $B$. intricata (Bory de Saint-Vincent) Montagne (King and Puttock 1989, Zuccarello and West 2008). This species is normally found in clumps in the upper intertidal either on shaded rocks (King \& Puttock 1989) or logs (Fraser et al. 2013). Phylogenetic research using plastid-encoded Rubisco spacer sequences of $B$. intricata has indicated high levels of genetic diversity within this species, suggesting the presence of multiple cryptic species (Zuccarello and West 2008). More recent research on the evolution of Bostrychia species endemic to the Southern Hemisphere based on phylogenetic analyses and species delimitation methods using three different molecular markers indicated that eight cryptic species (N1-N8) should be recognized within B. intricata, three of which (N2, N4 and N5) occur in NZ (Chapter 2). Additionally, multigene phylogenetic analyses have previously demonstrated that cryptic species N2 and N5 shared a more recent common ancestor than cryptic species N4, and these findings are consistent with dating analyses, which indicated the diversification of cryptic species N2 and N5 have occurred after N4 (Chapter 2). Preliminary studies on the phylogeography of $B$. intricata from the high latitudes of the Southern Hemisphere (New Zealand, southern South America and some sub-Antarctic islands) indicated strong phylogeographic structure within this species, although some lineages showed evidence of recent long-distance, trans-oceanic dispersal (Fraser et al. 2013).

Despite the broad-scale studies of phylogenetic diversity and phylogeography of $B$. intricata in the Southern Hemisphere, our knowledge of how much these cryptic species differ in aspects of their genetic diversity, connectivity and history are still limited. By investigating the phylogeography and population structure of cryptic $B$. intricata species in NZ based on partial COI sequences, we test the hypotheses that (i) different cryptic species exhibit significant differences in genetic diversity and demographical history, and (ii) phylogeographic patterns in these cryptic species are driven by, and can be linked to, historical events and changing environments. 


\section{Materials and Methods}

Algal sampling

Specimens of the morphospecies B. intricata were collected along the coasts of the North and South Islands of NZ in 2011-2012. Details of locations and sample sizes for 43 populations (NZ1-NZ43) are listed in Table 3.1. This morphospecies normally formed patches on shaded rocks in the upper intertidal. To avoid collecting the same individual, algal samples were randomly collected from patches, which were at least $0.5 \mathrm{~m}$ apart. Algal specimens were preserved in silica gel in the field. All specimens were identified based on previous species descriptions (e.g. King and Puttock 1989, Zuccarello and West 2008). For DNA analyses, algal samples were rinsed with autoclaved seawater to remove any sand and dirt, and then the apical portions were used for DNA isolation.

\section{DNA Extraction, PCR and Sequencing}

DNA was extracted using a modified Chelex method (Zuccarello et al. 1999b). We chose the short fragment of cytochrome c oxidase subunit I (COI, mitochondrial DNA) as an appropriate molecular marker for this population study as it showed the greatest level of genetic variation in discriminating cryptic species within B. intricata when compared to other markers (Chapter 2). PCR amplification and sequencing of COI was performed using either primers GazF1 and GazR2 (Saunders 2005) or BstCF2 and BstCR2 (Fraser et al. 2013). The PCR reaction profile followed Saunders (2005) or Fraser et al. (2013). PCR amplification was checked by electrophoresis on a $1 \%$ agarose gel, and PCR products were subsequently purified using ExoSAP-IT (USB, Cleveland, OH, USA). Purified PCR products were sequenced commercially (Macrogen Inc., Seoul, Korea).

\section{Alignment of DNA sequence and data analyses}

All DNA sequences were edited and aligned using Geneious 6.0 software (Biomatters, http://www.geneious.com) and then manually checked. For phylogenetic analyses, the data set included all haplotypes obtained from this study and additional sequences retrieved from GenBank (Appendix 3.2). Phylogenetic relationships were determined using 
Maximum Likelihood (ML) and Bayesian Inference (BI), and two sequences of $B$. arbuscula and B. gracilis were used as outgroups following Muangmai et al. (2014). DNA substitution models were determined using Kakusan 4 (Tanabe 2011). ML analyses were performed in raxmlGUI v1.3 (Silvestro and Michalak 2012) with the GTR + I + R under the option 'ML + thorough bootstrap', and bootstrapping values were calculated from 1,000 pseudoreplicates. BI analyses were conducted with MrBayes v3.2 (Ronquist et al. 2012) under the best model indicated by BIC (K80 + G to the codon position 1 and HKY85 + G to the codon position 2 and 3). Two runs of Markov Chain Monte Carlo (MCMC) were performed for 2,000,000 generations, sampling every 100 generations, and the first $25 \%$ of saved trees were discarded as burn-in. ML and BI trees were edited with the program FigTree v1.3.1 (Rambaut 2009).

Haplotype analysis was performed using the data set that included all sequences generated in this study and haplotypes from Fraser et al. (2013). The genetic diversity indices, including number of haplotypes $(H)$, number of segregating sites $(S)$, haplotype diversity $(H d)$ and nucleotide diversity $(\pi)$, for each population were assessed using DnaSP v5.10.01 (Librado and Rozas 2009). Statistical parsimony networks were constructed using TCS 1.21 (Clement et al. 2000) to observe the relationships among haplotypes.

Cryptic species were defined based on phylogenetic and species delimitation methods (Chapter 2), and population structure and demographic history were separately analysed for each major lineage. For population genetic analysis, populations with a sample size of eight individuals or more were selected (Felsenstein 2006), and two populations from a previous study (Fraser et al. 2013) were included (here coded as populations NZ44 from Brighton, South Island, and NZ46 from Stewart Island: see Table 3.1). Pairwise fixation index $\left(F_{\mathrm{ST}}\right)$ values between populations were calculated using Arlequin v 3.5.1.3 (Excoffier and Lischer 2010). The significance of $F_{\text {ST }}$ values was estimated by 1023 random permutations (Schneider et al. 2000). Population structure was further analysed using the SAMOVA algorithm (Dupanloup et al. 2002) to define groups of populations based on the combined information between geographic distances and genetic variation, implemented in SPADS 1.0 (Dellicour and Mardulyn 2014). The criteria for SAMOVA analysis were set as the number of groups $(\mathrm{K})$ ranging from two to 10, and 10,000 runs of iterations with 10 repetitions. The optimal number of $\mathrm{K}$ was considered based on a maximum or plateau of $F_{\mathrm{CT}}$ value. Furthermore, populations were partitioned into the 
biogeographic regions described by Apte and Gardner (2002) and Shears et al. (2008), as eastern north, western north, eastern south and western south regions (Appendix 3.1), and population differentiation among these four regions was subsequently tested using the hierarchical analysis of molecular variance (AMOVA) in Arlequin, with significance determined by 10,000 permutations.

Historic population demography was determined using three different methods: statistical tests of neutrality, mismatch distribution and the estimation of time to the most recent common ancestor. Tajima's $D$ (Tajima 1989) and Fu's $F_{\mathrm{S}}$ tests were used to test for deviation from selective neutrality, and these analyses were carried out using DnaSP. Analyses of mismatch distribution were performed in Arlequin with 1000 bootstrap replicates. This method can indicate past population expansion by mode shape: unimodal for a recent population expansion and multimodal for a stationary population at demographic equilibrium (Harpending 1994). The time to most recent common ancestor (TMRCA) was assessed using BEAST v2.0.2 (Drummond et al 2012). Mutation rates for COI were estimated following Chapter 2 with $0.13-0.15$ substitutions per site per million years. Data were partitioned by codon, and substitution models were set as for the phylogenetic analyses. The MCMC analyses were achieved with four independent runs for 20 million generations under the assumptions of an uncorrelated log-normal relaxed clock and a Yule model prior. The initial $25 \%$ of saved trees were removed as the burn-in, and a maximum credibility tree based on the remainder was produced using TreeAnnotator v2.0.2 (part of the BEAST v2.0.2 package). The time-calibrated tree with 95\% highest posterior density was visualized in FigTree. 
Table 3.1. Sampling sites of cryptic species N2, N4 and N5 of B. intricata in New Zealand and genetic diversity indices. Code= Population code, $N=$ number of samples, $H=$ number of haplotypes, $S=$ number of segregating sites, $H d=$ haplotype diversity, $\pi=$ nucleotide diversity.

\begin{tabular}{|c|c|c|c|c|c|c|c|c|}
\hline Code & Sampling site & Coordinates & $N$ & Haplotypes Present & $\boldsymbol{H}$ & $S$ & Hd & $\pi$ \\
\hline \multicolumn{9}{|c|}{ North Island } \\
\hline NZ1 & Casnell Island, Leigh & $\begin{array}{l}36^{\circ} 29^{\prime} 14.21^{\prime \prime S} \\
174^{\circ} 43^{\prime} 37.24^{\prime \prime} \mathrm{E}\end{array}$ & 4 & $\mathrm{~N} 2=2 \mathrm{~A}(4)$ & 1 & 0 & - & - \\
\hline NZ2 & $\begin{array}{l}\text { Sandspit, Snells beach, } \\
\text { Leigh }\end{array}$ & $\begin{array}{l}36^{\circ} 24^{\prime} 13.82^{\prime \prime S} \\
174^{\circ} 44^{\prime} 09.76 " \mathrm{E}\end{array}$ & 4 & $\mathrm{~N} 2=2 \mathrm{~A}(4)$ & 1 & 0 & - & - \\
\hline NZ3 & $\begin{array}{l}\text { Waitemata Harbour, } \\
\text { Auckland }\end{array}$ & $\begin{array}{l}36^{\circ} 50^{\prime} 28.93 " \mathrm{~S} \\
174^{\circ} 43^{\prime} 49.74^{\prime \prime} \mathrm{E}\end{array}$ & 10 & $\begin{array}{l}\mathrm{N} 4=4 \mathrm{E} 8(4), 4 \mathrm{E} 9(3), 4 \mathrm{E} 10(2), \\
\text { 4E11(1) }\end{array}$ & 4 & 7 & 0.77 & 0.0069 \\
\hline NZ4 & $\begin{array}{l}\text { Kaikoura Island, Huaraki } \\
\text { Gulf }\end{array}$ & $\begin{array}{l}36^{\circ} 10^{\prime} 29.40^{\prime \prime S} \\
175^{\circ} 19^{\prime} 35.56 " \mathrm{E}\end{array}$ & 1 & $\mathrm{~N} 4=4 \mathrm{E} 8(1)$ & 1 & 0 & - & - \\
\hline NZ5 & $\begin{array}{l}\text { Tekaha, Maraetai Bay, } \\
\text { East Cape }\end{array}$ & $\begin{array}{l}37^{\circ} 43 ' 36.19^{\prime \prime S} \\
177^{\circ} 41^{\prime} 27.83 " \mathrm{E}\end{array}$ & 10 & $\mathrm{~N} 2=2 \mathrm{~A}(10)$ & 1 & 0 & - & - \\
\hline NZ6 & Waihau Bay, East Cape & $\begin{array}{l}37^{\circ} 31^{\prime} 11.63^{\prime \prime S} \\
177^{\circ} 55^{\prime} 17.27 " \mathrm{E}\end{array}$ & 10 & $\mathrm{~N} 2=2 \mathrm{~A}(5), 2 \mathrm{D}(2), 2 \mathrm{~K}(3)$ & 3 & 2 & 0.68 & 0.0021 \\
\hline NZ7 & Lottin Point, East Cape & $\begin{array}{l}37^{\circ} 32 ' 57.05^{\prime \prime S} \\
178^{\circ} 08^{\prime} 03.06 " \mathrm{E}\end{array}$ & 10 & $\mathrm{~N} 2=2 \mathrm{~A}(4), 2 \mathrm{G}(1), 2 \mathrm{~K}(5)$ & 3 & 2 & 0.64 & 0.0020 \\
\hline NZ8 & $\begin{array}{l}\text { Waipatiki Beach, Hawkes } \\
\text { Bay }\end{array}$ & $\begin{array}{l}39^{\circ} 18^{\prime} 01.79^{\prime \prime} \mathrm{S} \\
176^{\circ} 58^{\prime} 43.22^{\prime \prime} \mathrm{E}\end{array}$ & 10 & $\mathrm{~N} 4=4 \mathrm{R}(8), 4 \mathrm{~S}(2)$ & 2 & 1 & 0.36 & 0.0009 \\
\hline NZ9 & Porangahua beach, & $40^{\circ} 18^{\prime} 02.65^{\prime \prime S}$ & 10 & $\mathrm{~N} 2=2 \mathrm{~A}(8), 2 \mathrm{E}(2)$ & 2 & 1 & 0.48 & 0.0012 \\
\hline
\end{tabular}




\begin{tabular}{|c|c|c|c|c|c|c|c|c|}
\hline & Hawkes Bay & $176^{\circ} 40^{\prime} 15.49^{\prime \prime} \mathrm{E}$ & & & & & & \\
\hline NZ10 & Castle Point, Wellington & $\begin{array}{l}40^{\circ} 54^{\prime} 05.15^{\prime \prime} \mathrm{S} \\
176^{\circ} 13^{\prime} 48.61 " \mathrm{E}\end{array}$ & 10 & $\mathrm{~N} 2=2 \mathrm{~F}(4), 2 \mathrm{G}(6)$ & 2 & 3 & 0.53 & 0.0042 \\
\hline NZ11 & Cape Palliser, Wellington & $\begin{array}{l}41^{\circ} 36^{\prime} 45.48^{\prime \prime S} \\
175^{\circ} 17^{\prime} 50.83^{\prime \prime} \mathrm{E}\end{array}$ & 12 & $\begin{array}{l}\mathrm{N} 2=2 \mathrm{~A}(10) \\
\mathrm{N} 4=4 \mathrm{E} 1(2)\end{array}$ & $\begin{array}{l}\mathrm{N} 2=1 \\
\mathrm{~N} 4=1\end{array}$ & $\begin{array}{l}\mathrm{N} 2=0 \\
\mathrm{~N} 4=0\end{array}$ & $\begin{array}{l}\mathrm{N} 2=- \\
\mathrm{N} 4=-\end{array}$ & $\begin{array}{l}\mathrm{N} 2=- \\
\mathrm{N} 4=-\end{array}$ \\
\hline NZ12 & Moa Point, Wellington & $\begin{array}{l}41^{\circ} 20^{\prime} 40.78^{\prime \prime} \mathrm{S} \\
174^{\circ} 48^{\prime} 35.34^{\prime \prime} \mathrm{E}\end{array}$ & 19 & $\begin{array}{l}\mathrm{N} 2=2 \mathrm{~A}(14) \\
\mathrm{N} 4=4 \mathrm{E} 1(3) \\
\mathrm{N} 5=5 \mathrm{~A}(2)\end{array}$ & $\begin{array}{l}\mathrm{N} 2=1 \\
\mathrm{~N} 4=1 \\
\mathrm{~N} 5=1\end{array}$ & $\begin{array}{l}\mathrm{N} 2=0 \\
\mathrm{~N} 4=0 \\
\mathrm{~N} 5=0\end{array}$ & $\begin{array}{l}\mathrm{N} 2=- \\
\mathrm{N} 4=- \\
\mathrm{N} 5=-\end{array}$ & $\begin{array}{l}\text { N2 }=- \\
\text { N4 }=- \\
\text { N5 }=-\end{array}$ \\
\hline NZ13 & $\begin{array}{l}\text { Manukau Harbour, } \\
\text { Auckland }\end{array}$ & $\begin{array}{l}36^{\circ} 55^{\prime} 52.43^{\prime \prime} \mathrm{S} \\
174^{\circ} 45^{\prime} 18.74^{\prime \prime} \mathrm{E}\end{array}$ & 11 & $\mathrm{~N} 4=4 \mathrm{E} 1(7), 4 \mathrm{E} 7(3), 4 \mathrm{E} 8(1)$ & 3 & 2 & 0.61 & 0.0016 \\
\hline NZ14 & New Plymouth, Taranaki & $\begin{array}{l}39^{\circ} 03^{\prime} 21.67^{\prime \prime S} \\
174^{\circ} 03^{\prime} 35.31^{\prime \prime} \mathrm{E}\end{array}$ & 6 & $\begin{array}{l}\mathrm{N} 2=2 \mathrm{~A}(3) \\
\mathrm{N} 4=4 \mathrm{E} 1(3)\end{array}$ & $\begin{array}{l}\mathrm{N} 2=1 \\
\mathrm{~N} 4=1\end{array}$ & $\begin{array}{l}\mathrm{N} 2=0 \\
\mathrm{~N} 4=0\end{array}$ & $\begin{array}{l}\mathrm{N} 2=- \\
\mathrm{N} 4=-\end{array}$ & $\begin{array}{l}\mathrm{N} 2=- \\
\mathrm{N} 4=-\end{array}$ \\
\hline NZ15 & Cape Egmont, Taranaki & $\begin{array}{l}39^{\circ} 16^{\prime} 26.79^{\prime \prime} \mathrm{S} \\
173^{\circ} 45^{\prime} 09.52^{\prime \prime} \mathrm{E}\end{array}$ & 8 & $\begin{array}{l}\mathrm{N} 2=2 \mathrm{~A}(1) \\
\mathrm{N} 4=4 \mathrm{E} 1(4), 4 \mathrm{E} 5(2), 4 \mathrm{E} 6(1)\end{array}$ & $\begin{array}{l}\mathrm{N} 2=1 \\
\mathrm{~N} 4=3\end{array}$ & $\begin{array}{l}\mathrm{N} 2=0 \\
\mathrm{~N} 4=2\end{array}$ & $\begin{array}{l}\mathrm{N} 2=- \\
\mathrm{N} 4= \\
0.66\end{array}$ & $\begin{array}{l}\mathrm{N} 2=- \\
\mathrm{N} 4=0.0023\end{array}$ \\
\hline NZ16 & Kapiti Coast, Wellington & $\begin{array}{l}41^{\circ} 01^{\prime} 21.19^{\prime \prime S} \\
174^{\circ} 54^{\prime} 26.21^{\prime \prime} \mathrm{E}\end{array}$ & 6 & $\begin{array}{l}\mathrm{N} 2=2 \mathrm{~A}(4) \\
\mathrm{N} 5=5 \mathrm{~A}(2)\end{array}$ & $\begin{array}{l}\mathrm{N} 2=1 \\
\mathrm{~N} 5=1\end{array}$ & $\begin{array}{l}\mathrm{N} 2=0 \\
\mathrm{~N} 5=0\end{array}$ & $\begin{array}{l}\text { N2 }=- \\
\text { N5 }=-\end{array}$ & $\begin{array}{l}\mathrm{N} 2=- \\
\mathrm{N} 5=-\end{array}$ \\
\hline NZ17 & $\begin{array}{l}\text { Titahi Bay, Porirua } \\
\text { Wellington }\end{array}$ & $\begin{array}{l}41^{\circ} 06^{\prime} 20.79^{\prime \prime} \mathrm{S} \\
174^{\circ} 49^{\prime} 24.49^{\prime \prime} \mathrm{E}\end{array}$ & 10 & $\mathrm{~N} 4=2 \mathrm{E} 1(10)$ & 1 & 0 & - & - \\
\hline NZ18 & Red Rock, Wellington & $\begin{array}{l}41^{\circ} 20^{\prime} 56.38^{\prime \prime} \mathrm{S} \\
174^{\circ} 44^{\prime} 27.25^{\prime \prime} \mathrm{E}\end{array}$ & 17 & $\mathrm{~N} 2=2 \mathrm{~A}(11), 2 \mathrm{~J}(6)$ & 2 & 1 & 0.48 & 0.0012 \\
\hline
\end{tabular}




\begin{tabular}{|c|c|c|c|c|c|c|c|c|}
\hline \multicolumn{9}{|c|}{ South Island } \\
\hline NZ19 & Hakahaka Bay, Picton & $\begin{array}{l}41^{\circ} 17 ' 58.22^{\prime S} \\
174^{\circ} 06^{\prime} 50.76 " \mathrm{E}\end{array}$ & 8 & $\begin{array}{l}\mathrm{N} 2=2 \mathrm{~A}(2) \\
\mathrm{N} 4=4 \mathrm{E} 1(6)\end{array}$ & $\begin{array}{l}\mathrm{N} 2=1 \\
\mathrm{~N} 4=1\end{array}$ & $\begin{array}{l}\mathrm{N} 2=0 \\
\mathrm{~N} 4=0\end{array}$ & $\begin{array}{l}\mathrm{N} 2=- \\
\mathrm{N} 4=-\end{array}$ & $\begin{array}{l}\mathrm{N} 2=- \\
\mathrm{N} 4=-\end{array}$ \\
\hline NZ20 & Paparoa Point, Kaikoura & $\begin{array}{l}42^{\circ} 14^{\prime} 10.51 " \mathrm{~S} \\
173^{\circ} 50^{\prime} 48.81 " \mathrm{E}\end{array}$ & 4 & $\mathrm{~N} 4=4 \mathrm{Q}(4)$ & 1 & 0 & - & - \\
\hline NZ21 & Halfmoon Bay, Kaikoura & $\begin{array}{l}42^{\circ} 15^{\prime} 40.11 " \mathrm{~S} \\
173^{\circ} 48^{\prime} 39.65^{\prime \prime} \mathrm{E}\end{array}$ & 10 & $\mathrm{~N} 4=4 \mathrm{Q}(10)$ & 1 & 0 & - & - \\
\hline NZ22 & $\begin{array}{l}\text { Port Levy, Banks } \\
\text { Peninsula }\end{array}$ & $\begin{array}{l}43^{\circ} 38^{\prime} 52.49^{\prime \prime S} \\
172^{\circ} 49^{\prime} 10.36^{\prime \prime} \mathrm{E}\end{array}$ & 6 & $\mathrm{~N} 4=4 \mathrm{~A}(6)$ & 1 & 0 & - & - \\
\hline NZ23 & $\begin{array}{l}\text { Pigeon Bay, Banks } \\
\text { Peninsula }\end{array}$ & $\begin{array}{l}43^{\circ} 40^{\prime} 34.11 " \mathrm{~S} \\
172^{\circ} 53 ' 27.58 " \mathrm{E}\end{array}$ & 10 & $\mathrm{~N} 4=4 \mathrm{~A}(8), 4 \mathrm{E} 1(2)$ & 2 & 3 & 0.36 & 0.0028 \\
\hline NZ24 & $\begin{array}{l}\text { French Farm Bay, } \\
\text { Akaroa, Bank Peninsula }\end{array}$ & $\begin{array}{l}43^{\circ} 46 ' 21.43^{\prime S} \\
172^{\circ} 54^{\prime} 50.99 " \mathrm{E}\end{array}$ & 10 & $\mathrm{~N} 4=4 \mathrm{~A}(5), 4 \mathrm{E} 1(4), 4 \mathrm{P}(1)$ & 3 & 7 & 0.64 & 0.0064 \\
\hline NZ25 & Dunedin & $\begin{array}{l}45^{\circ} 53^{\prime} 13.70^{\prime \prime S} \\
170^{\circ} 30^{\prime} 44.72 " \mathrm{E}\end{array}$ & 4 & $\mathrm{~N} 4=4 \mathrm{~A}(4)$ & 1 & 0 & - & - \\
\hline NZ26 & Titirangi Bay, Havelock & $\begin{array}{l}41^{\circ} 01^{\prime} 08.73 " \mathrm{~S} \\
174^{\circ} 07 ' 57.36^{\prime \prime} \mathrm{E}\end{array}$ & 12 & $\begin{array}{l}\mathrm{N} 2=2 \mathrm{~A}(8), 2 \mathrm{C}(2) \\
\mathrm{N} 4=4 \mathrm{E} 1(2)\end{array}$ & $\begin{array}{l}\mathrm{N} 2=2 \\
\mathrm{~N} 4=1\end{array}$ & $\begin{array}{l}\mathrm{N} 2=1 \\
\mathrm{~N} 4=0\end{array}$ & $\begin{array}{l}\mathrm{N} 2=0.35 \\
\mathrm{~N} 4=-\end{array}$ & $\begin{array}{l}\mathrm{N} 2=0.0009 \\
\mathrm{~N} 4=-\end{array}$ \\
\hline NZ27 & Kenupuru Bay, Havelock & $\begin{array}{l}41^{\circ} 11^{\prime} 42.31 " \mathrm{~S} \\
174^{\circ} 04^{\prime} 28.01 " \mathrm{E}\end{array}$ & 5 & $\begin{array}{l}\mathrm{N} 4=4 \mathrm{E} 1(4) \\
\mathrm{N} 5=5 \mathrm{~B}(1)\end{array}$ & $\begin{array}{l}\mathrm{N} 4=1 \\
\mathrm{~N} 5=1\end{array}$ & $\begin{array}{l}\mathrm{N} 4=0 \\
\mathrm{~N} 5=0\end{array}$ & $\begin{array}{l}\text { N4 = - } \\
\text { N5 = - }\end{array}$ & $\begin{array}{l}\text { N4 = - } \\
\text { N5 = - }\end{array}$ \\
\hline NZ28 & Te Mahia Bay, Havelock & $\begin{array}{l}41^{\circ} 12^{\prime} 57.31 " \mathrm{~S} \\
173^{\circ} 58^{\prime} 16.61 " \mathrm{E}\end{array}$ & 1 & $\mathrm{~N} 4=4 \mathrm{E} 1(1)$ & 1 & 0 & - & - \\
\hline NZ29 & Double Cove, & $41^{\circ} 14^{\prime} 00.40^{\prime \prime S}$ & 6 & $\mathrm{~N} 2=2 \mathrm{~A}(3)$ & $\mathrm{N} 2=1$ & $\mathrm{~N} 2=0$ & $\mathrm{~N} 2=-$ & $\mathrm{N} 2=-$ \\
\hline
\end{tabular}




\begin{tabular}{|c|c|c|c|c|c|c|c|c|}
\hline & Marlborough & $174^{\circ} 00^{\prime} 55.51^{\prime \prime} \mathrm{E}$ & & $\mathrm{N} 4=4 \mathrm{E} 1(3)$ & $\mathrm{N} 4=1$ & $\mathrm{~N} 4=0$ & $\mathrm{~N} 4=-$ & $\mathrm{N} 4=-$ \\
\hline NZ30 & Okiwi Bay, Marlborough & $\begin{array}{l}41^{\circ} 06^{\prime} 08.72^{\prime \prime} \mathrm{S} \\
173^{\circ} 39^{\prime} 30.96^{\prime \prime} \mathrm{E}\end{array}$ & 11 & $\begin{array}{l}\mathrm{N} 2=2 \mathrm{I}(1) \\
\mathrm{N} 4=4 \mathrm{E} 1(9), 4 \mathrm{E} 3(1)\end{array}$ & $\begin{array}{l}\mathrm{N} 2=1 \\
\mathrm{~N} 4=2\end{array}$ & $\begin{array}{l}\mathrm{N} 2=0 \\
\mathrm{~N} 4=1\end{array}$ & $\begin{array}{l}\mathrm{N} 2=- \\
\mathrm{N} 4=0.20\end{array}$ & $\begin{array}{l}\mathrm{N} 2=- \\
\mathrm{N} 4=0.0005\end{array}$ \\
\hline NZ31 & Cable Bay, Nelson & $\begin{array}{l}41^{\circ} 09^{\prime} 18.93^{\prime \prime S} \\
173^{\circ} 25^{\prime} 03.61 " \mathrm{E}\end{array}$ & 8 & $\begin{array}{l}\mathrm{N} 2=2 \mathrm{H}(1), 2 \mathrm{I}(1) \\
\mathrm{N} 4=4 \mathrm{E} 1(2), 4 \mathrm{E} 4(1), 4 \mathrm{O}(1)\end{array}$ & $\begin{array}{l}\mathrm{N} 2=2 \\
\mathrm{~N} 4=3\end{array}$ & $\begin{array}{l}\mathrm{N} 2=1 \\
\mathrm{~N} 4=10\end{array}$ & $\begin{array}{l}\mathrm{N} 2=0.66 \\
\mathrm{~N} 4=0.83\end{array}$ & $\begin{array}{l}\mathrm{N} 2=0.0017 \\
\mathrm{~N} 4=0.0139\end{array}$ \\
\hline NZ32 & Burton, Nelson & $\begin{array}{l}41^{\circ} 19^{\prime} 10.52^{\prime \prime S} \\
173^{\circ} 10^{\prime} 28.72 " \mathrm{E}\end{array}$ & 13 & $\begin{array}{l}\mathrm{N} 2=2 \mathrm{~A}(1) \\
\mathrm{N} 4=4 \mathrm{E} 1(12)\end{array}$ & $\begin{array}{l}\mathrm{N} 2=1 \\
\mathrm{~N} 4=1\end{array}$ & $\begin{array}{l}\mathrm{N} 2=0 \\
\mathrm{~N} 4=0\end{array}$ & $\begin{array}{l}\mathrm{N} 2=- \\
\mathrm{N} 4=-\end{array}$ & $\begin{array}{l}\mathrm{N} 2=- \\
\mathrm{N} 4=-\end{array}$ \\
\hline NZ33 & $\begin{array}{l}\text { Astrolabe, Sandy Bay, } \\
\text { Abel Tasman National } \\
\text { Park }\end{array}$ & $\begin{array}{l}40^{\circ} 59^{\prime} 46.93^{\prime \prime} \mathrm{S} \\
173^{\circ} 00^{\prime} 40.86^{\prime \prime} \mathrm{E}\end{array}$ & 10 & $\mathrm{~N} 4=4 \mathrm{E} 1(10)$ & 1 & 0 & - & - \\
\hline NZ34 & $\begin{array}{l}\text { Coquille Bay, Abel } \\
\text { Tasman National Park }\end{array}$ & $\begin{array}{l}40^{\circ} 59^{\prime} 21.04^{\prime \prime S} \\
173^{\circ} 01^{\prime} 49.51 " \mathrm{E}\end{array}$ & 10 & $\mathrm{~N} 4=4 \mathrm{E} 1(10)$ & 1 & 0 & - & - \\
\hline NZ35 & $\begin{array}{l}\text { Tinline Bay, Abel Tasman } \\
\text { National Park }\end{array}$ & $\begin{array}{l}40^{\circ} 59^{\prime} 25.25^{\prime \prime} \mathrm{S} \\
173^{\circ} 01^{\prime} 40.51^{\prime \prime} \mathrm{E}\end{array}$ & 4 & $\mathrm{~N} 4=4 \mathrm{E} 1(4)$ & 1 & 0 & - & - \\
\hline NZ36 & Wainui Bay, Tasman & $\begin{array}{l}40^{\circ} 48^{\prime} 13.01 " \mathrm{~S} \\
172^{\circ} 57^{\prime} 11.13^{\prime \prime} \mathrm{E}\end{array}$ & 11 & $\mathrm{~N} 4=4 \mathrm{E} 1(11)$ & 1 & 0 & - & - \\
\hline NZ37 & Pohara, Tasman & $\begin{array}{l}40^{\circ} 49^{\prime} 47.53 " \mathrm{~S} \\
172^{\circ} 53^{\prime} 32.16^{\prime \prime} \mathrm{E}\end{array}$ & 11 & $\mathrm{~N} 4=4 \mathrm{E} 1(10), 4 \mathrm{E} 2(1)$ & 2 & 1 & 0.51 & 0.0013 \\
\hline NZ38 & $\begin{array}{l}\text { Wharariki Beach, } \\
\text { Puponga }\end{array}$ & $\begin{array}{l}40^{\circ} 30^{\prime} 02.63 " \mathrm{~S} \\
172^{\circ} 40^{\prime} 52.24 " \mathrm{E}\end{array}$ & 10 & $\mathrm{~N} 4=4 \mathrm{~T}(7), 4 \mathrm{~V}(2), 4 \mathrm{Y}(1)$ & 3 & 2 & 0.51 & 0.0018 \\
\hline NZ39 & Whanganui Inlet, Tasman & $\begin{array}{l}40^{\circ} 34^{\prime} 52.61^{\prime \prime S} \\
172^{\circ} 37^{\prime} 47.46 " \mathrm{E}\end{array}$ & 12 & $\mathrm{~N} 4=4 \mathrm{E} 1(7), 4 \mathrm{~V}(5)$ & 2 & 9 & 0.62 & 0.0132 \\
\hline
\end{tabular}




\begin{tabular}{|c|c|c|c|c|c|c|c|c|}
\hline NZ40 & $\begin{array}{l}\text { Gentle Annie Seaside, } \\
\text { Westport }\end{array}$ & $\begin{array}{l}41^{\circ} 30^{\prime} 21.81^{\prime \prime S} \\
171^{\circ} 56^{\prime} 46.86 " \mathrm{E}\end{array}$ & 10 & $\mathrm{~N} 4=4 \mathrm{~W}(10)$ & 1 & 0 & - & - \\
\hline NZ41 & $\begin{array}{l}\text { Gibson Beach, Cape } \\
\text { Foulwind, Westport }\end{array}$ & $\begin{array}{l}41^{\circ} 44^{\prime} 53.13 " \mathrm{~S} \\
171^{\circ} 28^{\prime} 16.06 " \mathrm{E}\end{array}$ & 10 & $\mathrm{~N} 4=4 \mathrm{~V}(7), 4 \mathrm{X}(3)$ & 2 & 1 & 0.46 & 0.0012 \\
\hline NZ42 & Tauranga Bay, Westport & $\begin{array}{l}41^{\circ} 46 ' 25.31^{\prime S} \\
171^{\circ} 27^{\prime} 17.71^{\prime \prime} \mathrm{E}\end{array}$ & 10 & $\mathrm{~N} 4=4 \mathrm{~T}(4), 4 \mathrm{~V}(6)$ & 2 & 1 & 0.53 & 0.0014 \\
\hline NZ43 & $\begin{array}{l}\text { Charleston, North of } \\
\text { Woodpecker Bay }\end{array}$ & $\begin{array}{l}42^{\circ} 00^{\prime} 01.32^{\prime \prime} \mathrm{S} \\
171^{\circ} 23^{\prime} 44.46^{\prime \prime} \mathrm{E}\end{array}$ & 10 & $\mathrm{~N} 4=4 \mathrm{~T}(7), 4 \mathrm{U}(1), 4 \mathrm{~V}(2)$ & 3 & 3 & 0.60 & 0.0023 \\
\hline \multicolumn{9}{|c|}{ South Island - additional data from Fraser et al. (2013) } \\
\hline NZ44 & Brighton, Dunedin & $\begin{array}{l}45^{\circ} 566^{\prime} 54.91 " \mathrm{~S} \\
170^{\circ} 20^{\prime} 12.72 " \mathrm{E}\end{array}$ & 9 & $\mathrm{~N} 4=4 \mathrm{~A}(8), 4 \mathrm{~N}(1)$ & 2 & 8 & 0.22 & 0.0048 \\
\hline NZ45 & $\begin{array}{l}\text { Ringaringa, Stewart } \\
\text { Island }\end{array}$ & $\begin{array}{l}45^{\circ} 54^{\prime} 09.07 " \mathrm{~S} \\
168^{\circ} 08^{\prime} 41.10^{\prime \prime} \mathrm{E}\end{array}$ & 7 & $\begin{array}{l}\mathrm{N} 4=4 \mathrm{~A}(4), 4 \mathrm{~B}(1), 4 \mathrm{C}(1), \\
4 \mathrm{~F}(1)\end{array}$ & 4 & 3 & 0.64 & 0.0023 \\
\hline NZ46 & The Neck, Stewart Island & $\begin{array}{l}45^{\circ} 55^{\prime} 25.37^{\prime \prime} \mathrm{S} \\
168^{\circ} 11^{\prime} 26.95^{\prime \prime} \mathrm{E}\end{array}$ & 8 & $\mathrm{~N} 4=4 \mathrm{~A}(6), 4 \mathrm{~B}(1), 4 \mathrm{C}(1)$ & 3 & 2 & 0.52 & 0.0015 \\
\hline
\end{tabular}




\section{Results}

Genetic diversity and distribution

Partial COI sequences of 376 bps were successfully obtained from 384 samples of 43 populations of $B$. intricata around NZ (Fig. 3.1, Table 3.1). Genetic distance among these sequences ranged from $0.2 \%$ to $12.8 \%$. Phylogenetic trees obtained from ML and BI analyses were almost completely topologically congruent, and supported the hypothesis that three different cryptic species of B. intricata: N2, N4 and N5, referred to in Muangmai et al. (2014), occur in NZ (Appendix 3.3). Of the 384 samples, most of the samples (250) were from species N4, while another 128 and six samples belonged to species N2 and N5, respectively. A total of 35 different haplotypes were identified (10 for N2, 23 for N4 and 2 for N5) in this study (Fig. 3.2, Table 3.1). Haplotype and genetic diversity indices of the three cryptic species in each population are presented in Table 3.1. Haplotype diversity $(H d)$ ranged from 0.35 to 0.68 for species $\mathrm{N} 2$ and from 0.20 to 0.83 for species N4 (Table $3.1)$. Nucleotide diversity $(\pi)$ was relatively low for all species, varying from 0.0009 to 0.0042 for species N2, and from 0.0005 to 0.0139 for species N4 (Table 3.1).

The most widely distributed cryptic species of $B$. intricata in NZ was N4, which was recorded in 37 populations (Fig. 3.1). In contrast, species N2 and N5 were restricted to the North Island and top of the South Island (Fig. 3.1). Species N2 was detected in 19 populations, whereas species N5 was rare and only found in three populations (NZ16, NZ19 and NZ27) around Cook Strait, the strait between the North and South Islands. Although two different species were found to coexist at quite a few (12) sites, only one site (Moa Point: NZ12) had all three species occurring in sympatry (Fig. 3.1).

Haplotype networks constructed for the partial COI dataset (including NZ haplotypes from Fraser et al. 2013) are presented in Fig. 3.2. Species N2 revealed 11 haplotypes (1-4 bp differences), and its haplotype network was star-like with a central, common haplotype $2 \mathrm{~A}$ (71\% of samples), occurring across nearly all populations where this species was found (Fig. 3.2). Haplotypes $2 \mathrm{~K}$ and $2 \mathrm{G}$ were only detected from populations on the east coast of the North Island, while haplotype 2I was shared among populations from the top of the South Island (Fig. 3.1, Table 3.1). The seven other haplotypes were found only in single 
populations (Table 1). Cryptic species N4 showed the highest diversity, comprising 28 haplotypes (1-16 bp difference) with complex relationships (Fig. 3.2). Several common haplotypes were detected, for example 4E1, 4A and 4V. 4E1 was the most abundant haplotype, which occurred in 22 of 46 populations around NZ, accounting for $44 \%$ of the samples for this species. Haplotype 4A was commonly found in populations on the east coast of the South Island (14\%), while haplotype 4V was shared across populations around the west coast of the South Island (8\%) (Fig.3.1 and Table 3.1). Another eight haplotypes of N4 were observed in at least two populations, whereas the remaining 17 haplotypes were only found in single populations (Fig. 3.1, Table 3.1). Cryptic species N5 had low diversity, containing only two haplotypes, 5A and 5B, (2 bp differences), and far fewer samples of this species were found than for the other two species. Haplotype 5A was found in populations from the southern North Island (NZ12 and NZ16), while 5B was only found in one population, NZ27, from the top of South Island (Fig. 3.1, Table 3.1).

\section{Population structure}

Population differentiation was separately analysed for cryptic species N2 (9 populations) and N4 (21 populations). Population pairwise $F_{\text {ST }}$ values indicated significant, but low genetic differentiation among some populations of cryptic species N2 (Appendix 3.4). Other distant populations were not significantly differentiated (Appendix 3.4). For example, the Titirangi Bay population (NZ 26) from the top of the South Island was weakly, but significantly genetic differentiated from populations at the bottom of the North Island (Red rock (NZ18) and Moa Point (NZ12)), less than 80 kilometers away, but not significantly different from more distant populations from the upper eastern North Island (Maraetai Bay (NZ5) and Waihau Bay (NZ6), more than 1000 kilometers away) (Appendix 3.4). In contrast, species N4 showed highly significant population differentiation between some areas (Appendix 3.5). Genetic differentiation between proximate populations was also observed on the west coast of the South Island. For example, the Gentle Annie population (NZ40) was significantly differentiated from the nearby population (less than $40 \mathrm{~km}$ away) of Gibson Beach (NZ41) as well as the more distant population (more than $900 \mathrm{~km}$ away) of Waipatiki Beach (NZ8) (Appendix 3.5).

Population structure analyses based on the SAMOVA algorithm showed that 9 populations of cryptic species N2 were clustered into two groups: Castle Point population (group 1; 
NZ10) and eastern North Island and top of South Island (group 2; NZ5, NZ6, NZ7, NZ9, NZ11, NZ12, NZ18 and NZ26) (maximum $F_{\mathrm{CT}}=0.336, P<0.05$ at $\mathrm{K}=2$ ), whereas 21 populations of cryptic species $\mathrm{N} 4$ were assigned to six differentiated groups $\left(F_{\mathrm{CT}}=0.824\right.$, $P<0.05$ at $\mathrm{K}=6$ ) (Fig. 3.3). The six groups of cryptic species N4 proposed by SAMOVA were: west coast of North Island and top of South Island (group 1; NZ3, NZ13, NZ17, NZ30, NZ32, NZ33, NZ34, NZ36 and NZ37), east coast of North Island (group 2: NZ8), east coast of South Island (group 3: NZ21, and group 4: NZ 23, NZ24, NZ44 and NZ46) and west coast of South Island (group 5; NZ41, NZ42 and NZ43 and group 6; NZ38 and NZ 39) (Fig. 3.3). Furthermore, AMOVA analysis of species N4 using the grouping scheme based on four major biogeographic regions proposed by Apte and Gardner (2002) and Shears et al. (2008) (Appendix 3.1) indicated that 67.57\% of the genetic variation occurred among groups of western and eastern North Island and western and eastern South Island $\left(F_{\mathrm{CT}}=0.621, P<0.01\right)$, while lower levels of genetic variation $(14.83 \%)$ existed among populations within groups $\left(F_{\mathrm{SC}}=0.542, P<0.01\right)$ (Appendix 3.6).

\section{Demographic history and dating analyses}

The Tajima's D and Fu neutrality tests were used to observe historical population expansions for all populations of cryptic species N2 and N4 of B. intricata. Significantly negative values of both Tajima's $\mathrm{D}$ and Fu tests $\left(D=-1.38, P<0.05 ; F_{S}=-3.78, P<0.05\right)$ were observed for species $\mathrm{N} 2$, indicating a recent population expansion. By contrast, the positive value of Tajima's $\mathrm{D}$ and Fu tests $\left(D=0.55, P<0.05 ; F_{S}=1.26, P=0.41\right)$ were detected for species $\mathrm{N} 4$, suggesting demographically stable populations for this species. Similarly, the mismatch distribution for species N2 was unimodal, supporting a hypothesis of expanding populations, whereas cryptic species N4 showed a multimodal distribution, suggesting more stable populations (Appendix 3.7). Different patterns of historic population demography in these two cryptic species of B. intricata were further supported by the TMRCA analyses.

Diversification between species was inferred to have occurred in the late Pleistocene $(<0.2$ million years ago) (Appendix 3.8). The diversification of cryptic species N2 appears to have occurred between 81,000 - 19,000 years ago, while the diversification of cryptic species N4 occurred earlier, around 190,000 - 86,000 years ago (Appendix 3.8). Cryptic species N5 seemed to be recently evolved, around 50,000 - 1,300 years ago (Fig. S4). 
Although the dating analyses clearly showed the different divergence times among three cryptic species, caution is necessary for cryptic species N5 since only two haplotypes from a few locations were used in the analysis.

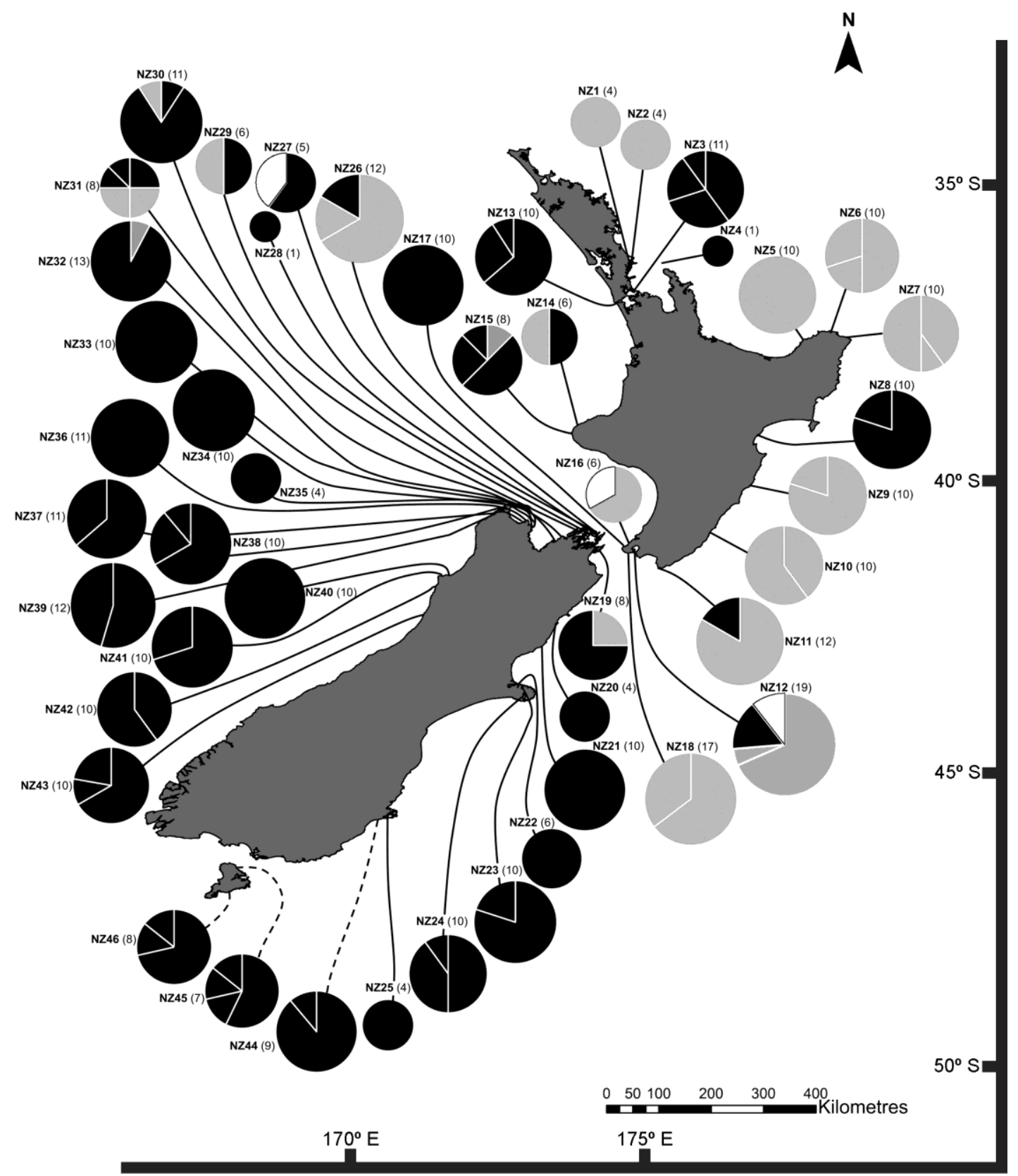

Figure 3.1: Distribution of three cryptic Bostrychia intricata species based on COI data in NZ. Each pie chart shows the proportion of cryptic species and their haplotypes. Shading represent different cryptic species: Grey: species N2; Black: species N4; and White: species N5. Population codes and sample sizes (in parentheses) are indicated next to the pie charts (see also Table 3.1). 


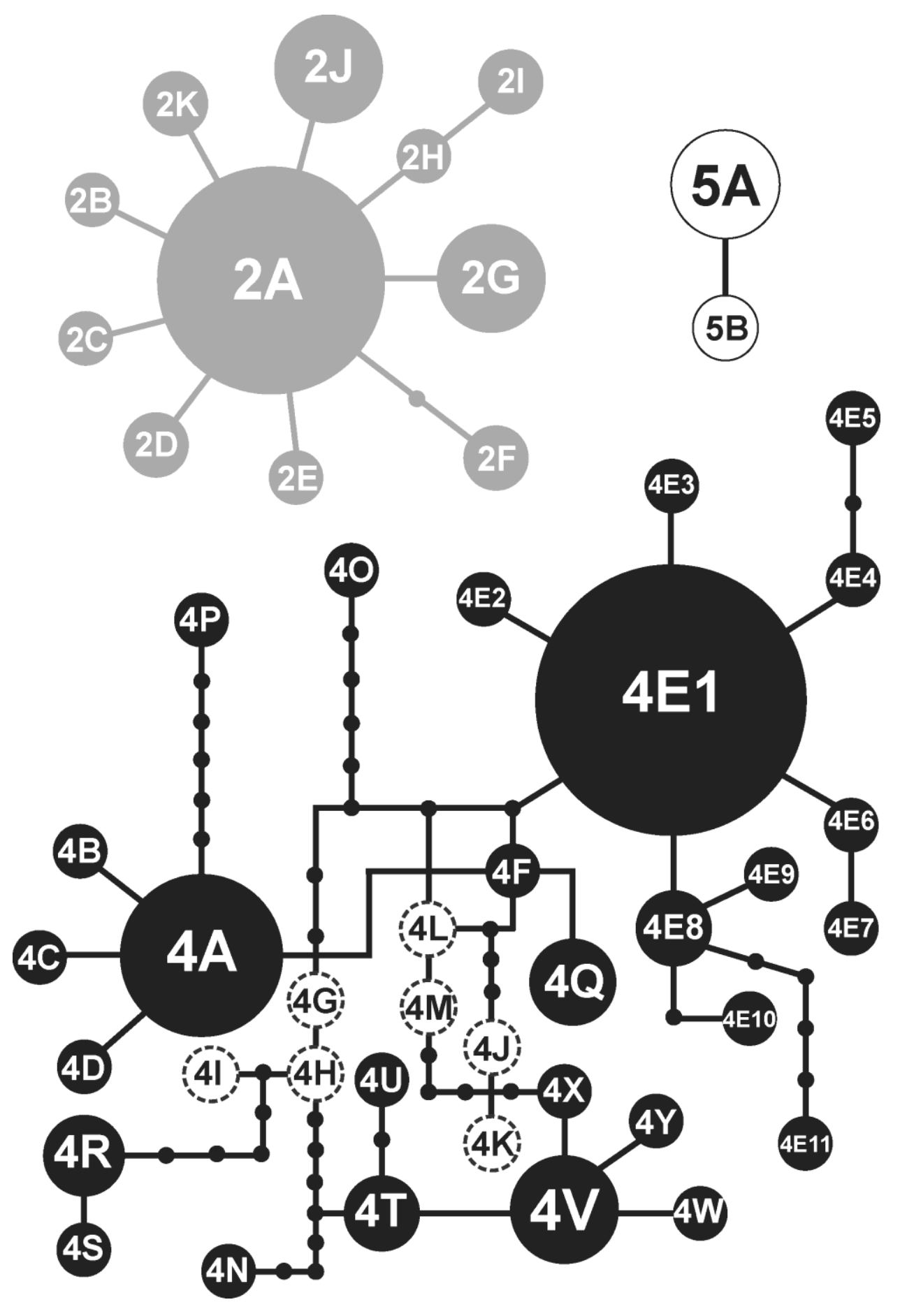

Figure 3.2: COI haplotype networks for cryptic Bostrychia intricata species (N2, N4, N5) obtained from the TCS analyses. Colors represent the different cryptic species as indicated in Fig. 3.1. Solid circles correspond to haplotypes found in this study, and dashed circles correspond to haplotypes from Fraser et al. (2013). Small circles represent inferred missing or extinct haplotypes. 

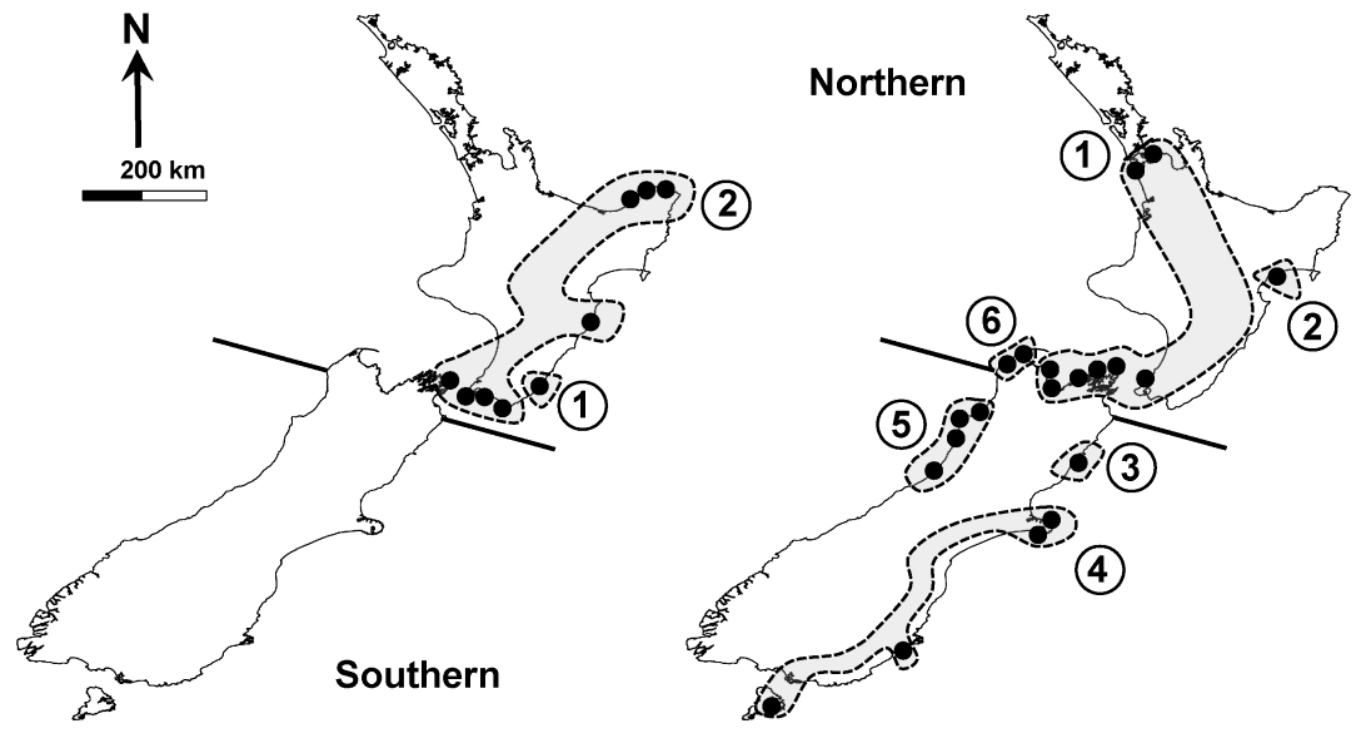

A) Cryptic species N2

B) Cryptic species N4

Figure 3.3: Cluster analyses based on SAMOVA for cryptic Bostrychia intricata species N2 (A) and N4 (B). Small circles represent the populations sampled in this analysis (see Fig 3.1 and Table 3.1). Shaded areas show population grouping designated by $\mathrm{K}=2$ for cryptic species N2 (group 1 and 2) and $\mathrm{K}=6$ for cryptic species N4 (group $1-6$ ). Solid black lines show the separation of the northern and southern biogeographic provinces of New Zealand according to Apte and Gardner (2002). 


\section{Discussion}

Our molecular analyses indicated different levels of genetic variation and distribution patterns among the three cryptic species of $B$. intricata in New Zealand, suggesting that each has experienced a different demographic history. Our broad-scale analyses, with samples from 43 sites around the country, strongly support the occurrence of three cryptic species within $B$. intricata in NZ, as previously indicated in Chapter 2; although this earlier study used far fewer samples from NZ. This finding emphasizes that low sample sizes may not necessarily impede species delimitation, as the present study using hundreds of samples indicated the same number of cryptic species as our previous work with considerably fewer samples (Chapter 2). However, large samples are still necessary to properly assess the genetic diversity and phylogeographic pattern of algal species (Zuccarello et al. 2006, 2011). Cryptic species have been detected in other Bostrychia species (Zuccarello and West 2003, 2006,Chapter 2) and in other red algal genera (e.g., Porteria hornemannii, Payo et al. 2013 and Spyridia filamentosa, Zuccarello et al. 2002).

Many phylogeographic studies of algae in NZ have previously indicated genetic differences between northern and southern regions. High levels of genetic variation were found in North Island populations of the brown macroalga $C$. maschalocarpum and $D$. antarctica, whereas relatively low genetic variation was encountered in the South Island for C. maschalocarpum, D. antarctica and M. pyrifera (Fraser et al. 2009c, Macaya and Zuccarello 2010a, Buchanan and Zuccarello 2012). In rough accordance with these findings, we detected three cryptic species (N2, N4 and N5) in northern and central New Zealand, whereas only one cryptic species (N4) was found in southern New Zealand (Fig. 3.2). Nonetheless, considerable genetic diversity was detected within and among populations of species N4 in southern New Zealand. High levels of genetic heterogeneity have previously been observed in a brown alga, Adenocystis utricularis (Bory) Skottsberg, from the eastern coast of the South Island (Fraser et al. 2013), and it has been proposed that both $A$. utricularis and B. intricata may be less susceptible to population decline during glacial periods than the larger kelps (Fraser et al. 2013). 
The distribution of cryptic species N2 and N5 was confined to the North Island and top of the South Island, restricted to north of Cape Campbell (east coast) and Golden Bay (west coast) of the South Island (Appendix 3.1). Many phylogeographic studies of marine taxa in NZ have previously demonstrated that contemporary upwelling or ocean currents around Cape Campbell and Golden Bay form a significant biogeographic barrier between the northern and southern biogeographic province (Appendix 3.1). This was found, for example, in greenshell mussel (Apte and Gardner 2002), seastars (Spocer and Roy 2002, Ayers and Waters 2005) and limpets (Goldstien et al. 2006). It is possible that the restricted northern distribution observed in B. intricata species N2 and N5 is due to this north-south biogeographic break and the inability of these species to traverse this barrier. However, previous population studies of NZ seaweed showed no evidence for this northsouth split. For example, the brown alga Carpophyllum maschalocarpum exhibited a population disjunction in the middle of the North Island (Buchanan and Zuccarello 2012). The observed incongruent pattern of species distribution may be attributable to the differences in life history, dispersal and adaptive capacity of the various cryptic species.

Present-day patterns of high levels of genetic diversity can indicate population stability (Grant and Bowen 1998). The differences in genetic diversity and distributions between cryptic $B$. intricata species suggests that the three species may have originated and evolved at different times in the past. Our dating of diversification indicated that species N4 is older than either species N2 or N5. If cryptic species N4 arose early, it would have had more time to accumulate mutations than the other cryptic species, and would have had a longer time to adapt to conditions around NZ. It may also have benefited from a relative absence of competition; assuming that all three cryptic species share similar habitat requirements, the later-evolving lineages will have had to compete with existing populations of species $\mathrm{N} 4$ for resources.

Another non-mutually exclusive possibility is that these cryptic species have responded differently to historical events and regional climate change, and this promoted the disparity in genetic composition and distribution patterns between them. The LGM is a well-known historic event that played an important role in shaping population diversity and connectivity of many taxa in the Southern Hemisphere (Fraser et al. 2012), and its main impacts were approximately 27,000 - 18,000 years ago (Suggate and Almond 2005). Some studies indicated that the LGM had a significant impact on the genetic diversity and 
structure of algal species. For example, the observed genetic homogeneity of some brown seaweeds (Carpophyllum maschalocarpum and Durvillaea antarctica) from low latitude populations (South Island of New Zealand and sub-Antarctic Island) suggest that these algae may have be removed by ice scouring during the LGM or changes in water temperature, subsequently recolonizing these regions post-glacially (Fraser et al. 2009, Buchanan and Zuccarello 2012). The LGM could well have driven some of the patterns of genetic diversity and distribution within cryptic $B$. intricata species. Of the three different cryptic $B$. intricata species, we found that the origin of species N4 $(190,000-86,000$ years ago) predated the LGM, and this cryptic species seemed to have survived the glacial period while retaining its genetic diversity, as indicated by the high-level genetic diversity and wide distribution in both North and South Islands. On the other hand, the diversifications of cryptic species N2 (81,000 - 19,000 years ago) and N5 (50,000 - 1,300 years ago) could have occurred during the LGM or have post-dated the LGM. The low genetic diversity and more limited distribution observed in cryptic species N2 and N5 could be explained by two possibilities. Firstly, cryptic species N2 and N5 were eliminated from southern areas, and populations in the north contracted, and later were prevented from moving southward after the LGM; secondly these two species diversified after the LGM and then expanded their populations but were prevented from dispersing past the north-south barrier. Both scenarios suggest the influences of climate change after glaciation (e.g. warmer seawater in northern New Zealand or rising seawater level at the Cook Strait) on their diversifications and distribution. From these observed patterns, we also hypothesize that the three cryptic species may have different genetic-physiological adaptations and abilities to persistent in changing environments, as found in the red alga, Caloglossa ogasawaensis Okamura (Kamiya and West 2014). Further studies on whether these cryptic $B$. intricata species have different eco-physiological responses (e.g. temperature, exposure) would help to shed light on the mechanisms facilitating genetic differentiation and distribution patterns in Bostrychia and other marine red algae.

In the Southern Hemisphere, phylogeographic research on marine macroalgae have shown that the patterns of population differentiation and connectivity have been strongly influenced by dispersal potential (Fraser et al. 2009c, Macaya and Zuccarello 2010a), habitat availability and density (Montecinos et al. 2012) and the effect of historical events and environmental change (Fraser et al. 2009c, Macaya and Zuccarello 2010b, Buchanan and Zuccarello 2012). For example, kelp species (e.g. Durvillaea antarctica and 
Macrocystis pyrifera) with high dispersal potential have demonstrated a higher level of population connectivity than other marine algae with low effective dispersal potential (e.g. Mazzaella laminarioides) (Fraser et al. 2009c, Macaya and Zuccarello 2010b, Montecinos et al. 2012). In B. intricata, we detected low to moderate genetic differentiation among populations of cryptic species N2, and high differentiation among populations of N4, suggesting different patterns of population structure between the species. These findings concur with our haplotype network results, as well as inferred demographic history and divergence times, which indicated that cryptic species N2 has expanded more recently than species N4. We suggest that the differences observed in these two species could probably be explained by the differences in evolutionary history and dispersal ability of species.

Our SAMOVA results support the major biogeographic provinces previously proposed for NZ, with northern/southern biogeographic provinces (B. intricata N4 groupings 1, 2, 6 versus 3, 4, 5) (Apte and Gardner 2002, Sharyn et al. 2006) and a genetic split between western/eastern regions, especially on the South Island (B. intricata N4 groupings 5,6 versus 3, 4) (Jones et al. 2008, Veale \& Lavery 2012) (Fig. 3.3). However, SAMOVA analyses for cryptic species N2 and N4 suggested that these groupings were partially incongruent with the 11 bioregions proposed by Shears et al. (2008), with some groupings spanning several of the proposed regions, especially on the North Island. For example, we found evidence for connectivity between the northeastern and the Portland regions on the North Island for cryptic species N2 (group 1, Fig. 3.3) and the Raglan region and the Abel region on the North Island for cryptic species N4 (group 1, Fig. 3.3). Our mitochondrial data may not, however, have been able to detect all biogeographic detail; more rapidlyevolving markers (such as microsatellites) could be used in future studies to assess whether fine-scale structure or population connectivity occurs in these regions.

In conclusion, our data clearly show the occurrence of three cryptic species within $B$. intricata (N2, N4 and N5) in NZ. We have been unable to find any morphological differences between these species. Bostrychia species have few morphological characters that can be used to differentiate species (Zuccarello and West 2003), and can hinder description of new taxa identified via molecular approaches. The three cryptic species do, however, differ substantially in their levels of genetic diversity, distribution patterns and demographic histories. While a single marker may not provide all the evidence of a species' history, variable organellar markers can nonetheless give important insights into 
the processes driving patterns of diversity, and are commonly used when tools for appropriate nuclear markers have not been identified. These findings highlight that different patterns of species history can be quite substantial in species that are morphologically indistinguishable (cryptic species). Future research including physiological analyses should be carried out to assess whether these species differ in nonmorphological features such as timing of reproduction.

\section{Acknowledgments}

For help with collections, we thank: Wendy Nelson, Mike Wilcox, Christian Boedeker and Maren Preuss. We also thank John West for useful discussion and Joe Buchanan for molecular analyses help. Special thanks the Victoria University of Wellington for providing a scholarship to NM. 


\section{Chapter Four}

Physiological ResPonse ON THE GROWTH OF DifFERENT CRYPTIC SPECIES OF BOSTRYCHIA INTRICATA IN VARIOUS CONDitions OF SALINITY AND TEMPERATURE 


\begin{abstract}
Inter- and intra-specific physiological variations of intertidal macroalgae have been well investigated. However, studies on physiological responses of cryptic algal species have been poorly documented. Bostrychia intricata is a widespread marine red alga in the Southern Hemisphere, and has many cryptic species. We investigated the effect of different salinities and temperatures on the specific growth rate of three cryptic species (N2, N4 and N5) of B. intricata from New Zealand. Our data indicated that all cryptic species grew at the full range of salinities and temperature tested, and exhibited significant differences between their specific growth rates. Cryptic species N4 had a higher growth rate than the other two cryptic species under all experimental conditions, whereas cryptic species N2 occasionally showed a higher growth rate than cryptic species N5 at high salinities and lower temperatures. The distinct physiological properties of these cryptic species could explain their distributional pattern (a wider distribution of cryptic species N4 than N2 and N5) in New Zealand. The physiological divergence among the cryptic species could be related to their levels of genetic divergence, with more similar physiologies among cryptic species with a more recent common ancestor. Our findings underline that morphologically indistinguishable cryptic algal species are different in other aspects and are independent entities.
\end{abstract}




\section{Introduction}

Cryptic species are defined as groups of distinct species, which are difficult or impossible to distinguish morphologically (Beheregaray and Caccone 2007). The discovery of cryptic species has greatly increased with the advent of molecular techniques and species delimitation methods (Bickford et al. 2007, Wiens 2007, Payo et al. 2013, Chapter 2), As a rule, cryptic species are genetically distinct, but they can also be physiologically differentiated, as found in copepods (Chen and Hare, 2008), marine diatoms (Degerlund et al. 2012), rotifers (Leasi et al. 2013) and snails (Dennis and Hellberg 2010). It is feasible that genetic changes since they last shared a common ancestor could contribute to the physiological differentiation between cryptic species.

Macroalgae are a diverse group of photosynthetic organisms, which are functionally important in aquatic ecosystem (Graham et al. 2009). The diversity and taxonomy of macroalgae has been studied extensively, and many algal species, especially in red algae, exhibited a high number of cryptic species (Zuccarello et al. 2002, Zuccarello and West 2003, 2006, Payo et al. 2013, Kamiya and West 2014, Chapter 2). Despite the recognition that cryptic diversity is relatively common in red algal species, our understanding of the eco-physiology and biochemistry within cryptic algal species is still limited.

In the intertidal macroalgae experience a wide range of environmental gradients in wave exposure, light intensity, salinity and temperature (Hurd et al. 2014). Among the physicochemical environmental components, salinity and temperature are major factors influencing macroalgae communities and distribution (Hurd et al. 2014). Many physiological studies have previously demonstrated that salinity and temperature affect the growth and photosynthetic activity of macroalgae, and several algal species were considered well-adapted to a relatively-wide rage of salinity and temperatures, suggesting their potential for eco-physiological adaptation (Breeman 1988, Orfanidis et al. 1999, Zuccarello et al. 2001, Phooprong et al. 2007, Hayakawa et al. 2012, Watanabe et al. 2014). Physiological differentiations among different haplotypes within species have also been observed in mangrove red algal, Bostrychia Montagne and Caloglossa (Harvey) Martens (Karsten et al. 1993, 1994, Zuccarello et al. 2001). However, very few studies 
have examined the physiological distinctions between cryptic algal species, as for example in Caloglossa ogasawaraensis Okamura (Kamiya and West 2014).

Bostrychia intricata (Bory de Saint-Vincent) Montagne is a filamentous red alga that is commonly found in the cold temperate intertidal around the Southern Hemisphere, and its evolution, phylogenetic diversity, phylogeography, physiology and reproduction have been studied (Karsten et al. 1996, West et al. 1996, Zuccarello and West 2008, Fraser et al. 2013, Chapter 2). Recent studies on DNA-based species delimitation showed that $B$. intricata consists of eight cryptic species (N1 - N8), three of which (N2, N4 and N5) are found in New Zealand (Chapter 2). In New Zealand, B. intricata species N4 is widely distributed in both the North and South Islands, while the other two cryptic species are confined to northern regions (north of the top of South island) (Chapter 3). Furthermore, the different cryptic species can co-exist in some habitats around Cook Strait, which separates the North and South Islands of New Zealand (Chapter 3). Previous physiological studies of three B. intricata (as Stictosiphonia hookeri) isolates from Chile indicated difference in specific growth rate to different salinities and temperatures. However, these isolates were not genetically characterized so it was not confirmed if they are genetically distinct (Karsten et al. 1996). Accordingly, whether genetically defined cryptic B. intricata species are physiologically different is still unknown.

In this study we determine the effect of differences in salinity and temperature on the specific growth rate of three cryptic species of $B$. intricata collected in the same and different locations around New Zealand in order to test two hypotheses: (i) these cryptic species have diverged physiologically even though they are morphologically indistinguishable and (ii) cryptic species with greater physiological abilities has a larger distribution. 


\section{Materials and Methods}

\section{Algal collection and maintenances}

We isolated seven Bostrychia intricata from different localities around New Zealand. These isolates were from three cryptic species: N2, N4 and N5, according to Chapter 2. The details of location, collection date, reproductive state and genetic composition for each isolate were shown in Table 4.1. Each of the B. intricata isolates was grown separately in a $250 \mathrm{~mL}$ sterile plastic container (Magenta LLC, Chicago, IL, USA), containing 150 - 180 $\mathrm{mL}$ autoclaved seawater at approximately 33 psu with half-strength modified Provasoli's enrichment (MPE) medium (5 mL PES per 1 L sterile seawater) (West and McBride 1999) (Fig. 4.1). The culture medium was replaced every two to three weeks, and sometimes Penicillin G sodium salt $(0.5-1 \mathrm{mg}$ ) (AMRESCO, Solon, OH, USA) and germanium dioxide $(0.1-0.25 \mathrm{mg} / \mathrm{L})$ were directly added into algal cultures for the control of bacteria and diatom contamination (Zuccarello et al. 2001). Algal specimens were cultured in laboratory cooled incubators (Sanyo Electric Co. Ltd., Tokyo, Japan) at $15 \pm 1{ }^{\circ} \mathrm{C}$ under the light intensity of $40 \pm 5 \mu \mathrm{mol}$ photons $\mathrm{m}^{-2} \mathrm{~s}^{-1}$ provided by cool-white fluorescent tubes. The photoperiod was set at a 10-14h light-dark cycle. These culture conditions are very similar to other growth studies on these algae (Karsten et al. 1996). All stock cultures were maintained for over a year before use in growth experiments.

\section{Growth experiments}

We observed the growth rate of all $B$. intricata isolates under the combination of three different levels of salinity: 25,32 and $40 \mathrm{psu}$; and temperature: 10,15 and $20^{\circ} \mathrm{C}$. Ranges of the two parameters were chosen based on a preliminary physiological study and previous research on this species or other Bostrychia species (Karsten et al. 1994a, 1996; West et al. 1996). Salinity levels were adjusted by diluting sterile seawater with distilled water for the salinity 25 experiment, or by adding artificial sea salt (Sigma, St. Louis, MO, USA) for the salinity 40 experiment, and subsequently enriched with half-strength MPE medium. The three different temperatures were individually operated in separate incubators. The light intensity and photoperiod were set at the same condition as in stock culture for all treatments. 
Apical portions of algal samples were cut into small pieces $(1-1.5 \mathrm{~cm})$, and three individual fragments of each isolate were prepared for each treatment. The fragments from different isolates were randomly placed in six-well plastic plates (Geriner Bio-One Ltd, Frickenhausen, Germany) and each well was filled with $2 \mathrm{~mL}$ MPE media, which was renewed every two weeks (Fig. 4.1). Six-well plates with test samples were simultaneously incubated at different temperature in separate culture chambers. In the chamber, the light sources were located on the left and right sides, and to provide the same irradiation to all fragments, the plates were repositioned every two days. All experiments were carried out for 4 weeks.

Growth rates were measured based on the changes in thallus area, which were calculated using digital images (Ryder et al. 1999, Zuccarello et al. 2001). Digital images were recorded at the beginning and the end of experiments. All fragments were placed on microscope slides, covered by a cover glass, and subsequently photographed under the Leica MZ8 stereomicroscope (Leica Microsystems, Wetzlar, Germany) equipped with Sony A77 DSLR camera (Sony Corporation, Tokyo, Japan). To capture large thalli, the thallus was divided into smaller pieces to avoid overlapping of branches for accurate area measurement. The thalli areas on captured images were measured as square pixels using ImageJ 1.48 software (http://rsb.info.nih.gov/ij/). Actual thallus area was selected using the threshold function, or in the case of unclear images, the area was carefully outlined by hand.

\section{Calculation and statistical analysis}

Calculation of the specific growth rate $\left(\mathrm{SGR}\right.$, in \% day ${ }^{-1}$ ) followed the formula of Ryder et al. (1999): $\mathrm{SGR}=100\left(\ln A_{t}-\ln A_{i}\right) t^{-1}$, where $A_{t}=$ the area at time $\mathrm{t}, A_{i}=$ the area at time $=0$. All statistical analyses were performed using IBM SPSS Statistics version 21 for Mac (IBM Corporation, Chicago, IL, USA). The growth experiment data were analysed using a multiple-factor analysis of variance (ANOVA) in order to verify the significant difference between treatments and different salinity and temperature combinations among isolates (Zuccarello et al. 2001). In addition, a one way-ANOVA followed by a Tukey's multiple range test was used to compare the growth rate among isolates, which cultured in three different salinities and temperatures (Zuccarello et al. 2001, Hayakawa et al. 2012).. 


\section{Results}

Seven isolates of $B$. intricata grew in all treatments, and the specific growth rates of these isolates were different in the various salinity and temperature conditions (Fig. 4.2). All isolates had maximum specific growth rates (SGR $>1 \% \mathrm{~d}^{-1}$ ) at salinity of $32 \mathrm{psu}$ and temperature of $15^{\circ} \mathrm{C}$, whereas minimum rates (SGR $<0.7 \% \mathrm{~d}^{-1}$ ) were mostly observed at increased salinity and temperature (40 psu and $20^{\circ} \mathrm{C}$ ), except for isolate M5 (minimum at $25 \mathrm{psu}$ and $10^{\circ} \mathrm{C}$ ) (Fig. 4.2, Appendix 4.1). ANOVA test indicated significant interactions between isolates, salinity and temperatures (Table 4.2, $P<0.005$ ), suggesting that the combined effect of salinity and temperature on the growth rate differed between the isolates.

The Tukey's test indicated significant differences in specific growth rate between some isolates (Fig. 4.2, $P<0.05$ ). In all treatments, all isolates belong to cryptic species N4 (isolates M4, P4 and C4) grew significantly better than the other isolates of cryptic species N2 (isolates M2, C2 and T2) and N5 (isolate M5), with at least 80\% higher specific growth rates (Fig. 4.2). Isolates M2, C2 and T2 (cryptic species N2) was significantly different from isolates M5 (cryptic species N5), with approximately 15\% greater specific growth rate, in some conditions $\left(10{ }^{\circ} \mathrm{C}\right.$ with salinities of 32 and $40 \mathrm{psu}$ ). These seven isolates all exhibited very low growth rates, of less than $0.7 \%$, under higher temperature $\left(20^{\circ} \mathrm{C}\right)$ in all salinity treatments (Fig. 4.2). Differences among isolates of all three cryptic species were found at lower temperatures $\left(10^{\circ} \mathrm{C}\right)$ with the two higher salinities (32 and $\left.40 \mathrm{psu}\right)$ (Fig. $4.2)$.

Differences in specific growth rate among isolates within the cryptic species were occasionally observed for cryptic species N2 and N4 (Fig. 4.2). In cryptic species N2, isolate C2 and T2 showed a higher growth rate than isolate M2 ( 10\% differences) only at $15^{\circ} \mathrm{C}$ and 32 psu (Fig. 4.2). In cryptic species N4, growth rates of isolates M4 and P4 were significantly lower than isolate $\mathrm{C} 4$ ( 15\% differences) under three experimental conditions with the different combinations of temperature and salinity: $10{ }^{\circ} \mathrm{C}-40 \mathrm{psu}, 15$ ${ }^{\circ} \mathrm{C}-25$ psu and $20{ }^{\circ} \mathrm{C}-32$ psu (Fig. 4.2). 
Table 4.1. Details of isolate codes, collection sites, dates, reproducti

ve state and cryptic species of Bostrychia intricata used in this growth experiments. Cryptic species and haplotype designations based on Chapter 2 and 3.

\begin{tabular}{|c|c|c|c|c|c|}
\hline Isolate code & Locality & Collection dates & Reproductive state & Cryptic species & Haplotype \\
\hline M2 & $\begin{array}{l}\text { Moa Point, Wellington, North Island } \\
\left(41^{\circ} 20^{\prime} 40.78^{\prime \prime S} 174^{\circ} 48^{\prime} 35.34^{\prime E}\right)\end{array}$ & 18 April 2012 & Vegetative & $\mathrm{N} 2$ & $2 \mathrm{~A}$ \\
\hline $\mathrm{T} 2$ & $\begin{array}{l}\text { Titirangi Bay, Havelock, South Island } \\
\left(41^{\circ} 01^{\prime} 08.73 " \mathrm{~S} 174^{\circ} 07^{\prime} 57.36^{\prime E}\right)\end{array}$ & 13 Jan 2013 & Tetrasporangial & $\mathrm{N} 2$ & $2 \mathrm{C}$ \\
\hline M4 & $\begin{array}{l}\text { Moa Point, Wellington, North Island } \\
\left(41^{\circ} 20^{\prime} 40.78^{\prime \prime S} 174^{\circ} 48^{\prime} 35.34^{\prime \prime E}\right)\end{array}$ & 23 July 2012 & Vegetative & N4 & $4 \mathrm{E} 1$ \\
\hline $\mathrm{P} 4$ & $\begin{array}{l}\text { Pohara, Tasman, South Island } \\
\left(40^{\circ} 49^{\prime} 47.53^{\prime \prime S} 172^{\circ} 53^{\prime} 32.16^{\prime E}\right)\end{array}$ & 2 February 2013 & Vegetative & N4 & $4 \mathrm{E} 2$ \\
\hline
\end{tabular}




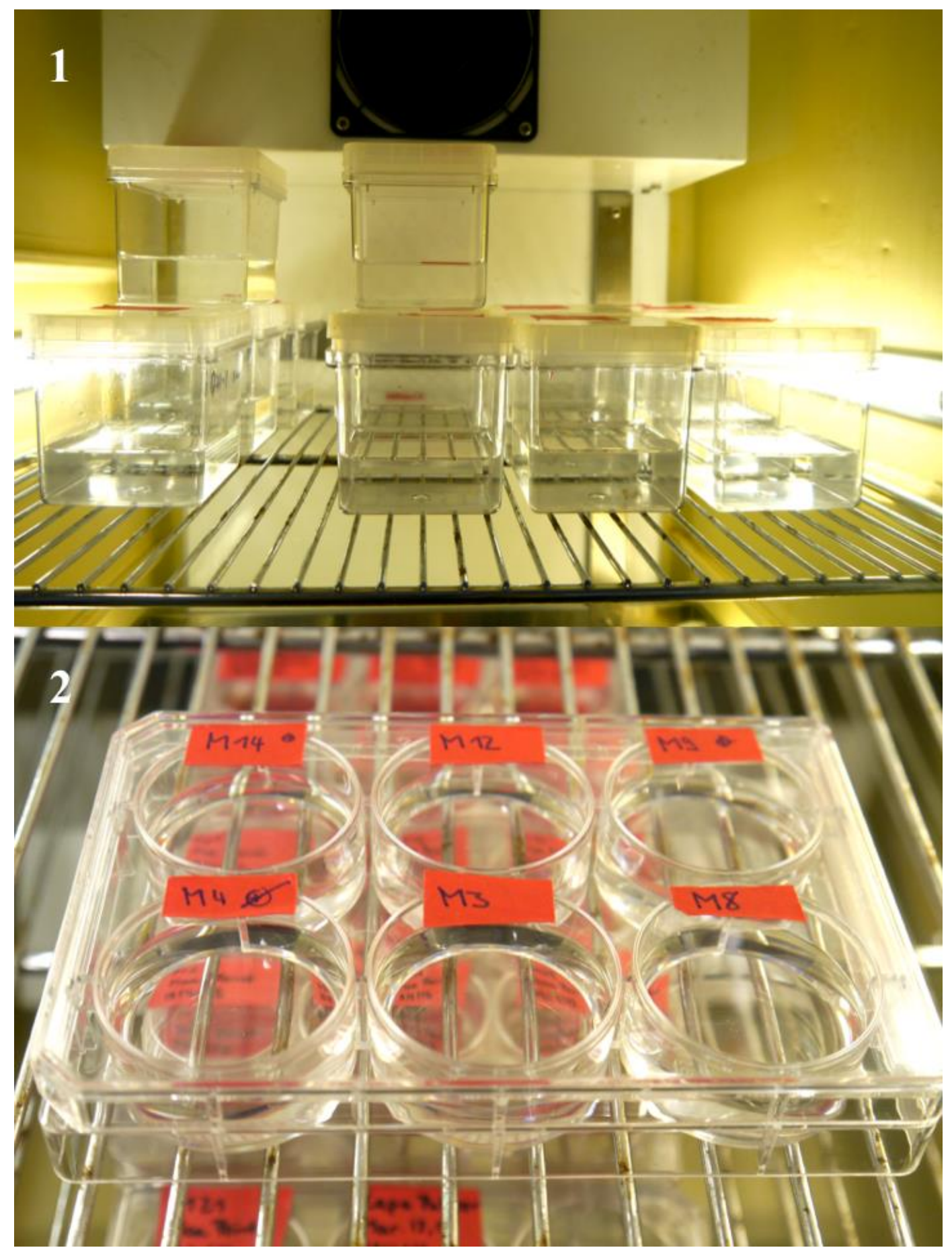

Figure 4.1: (1) Stock culture of B. intricata in $250 \mathrm{~mL}$ sterile plastic container filled with autoclaved seawater and medium under controlled light and temperature. (2) Fragments of B. intricata were randomly placed in six-well plates. 


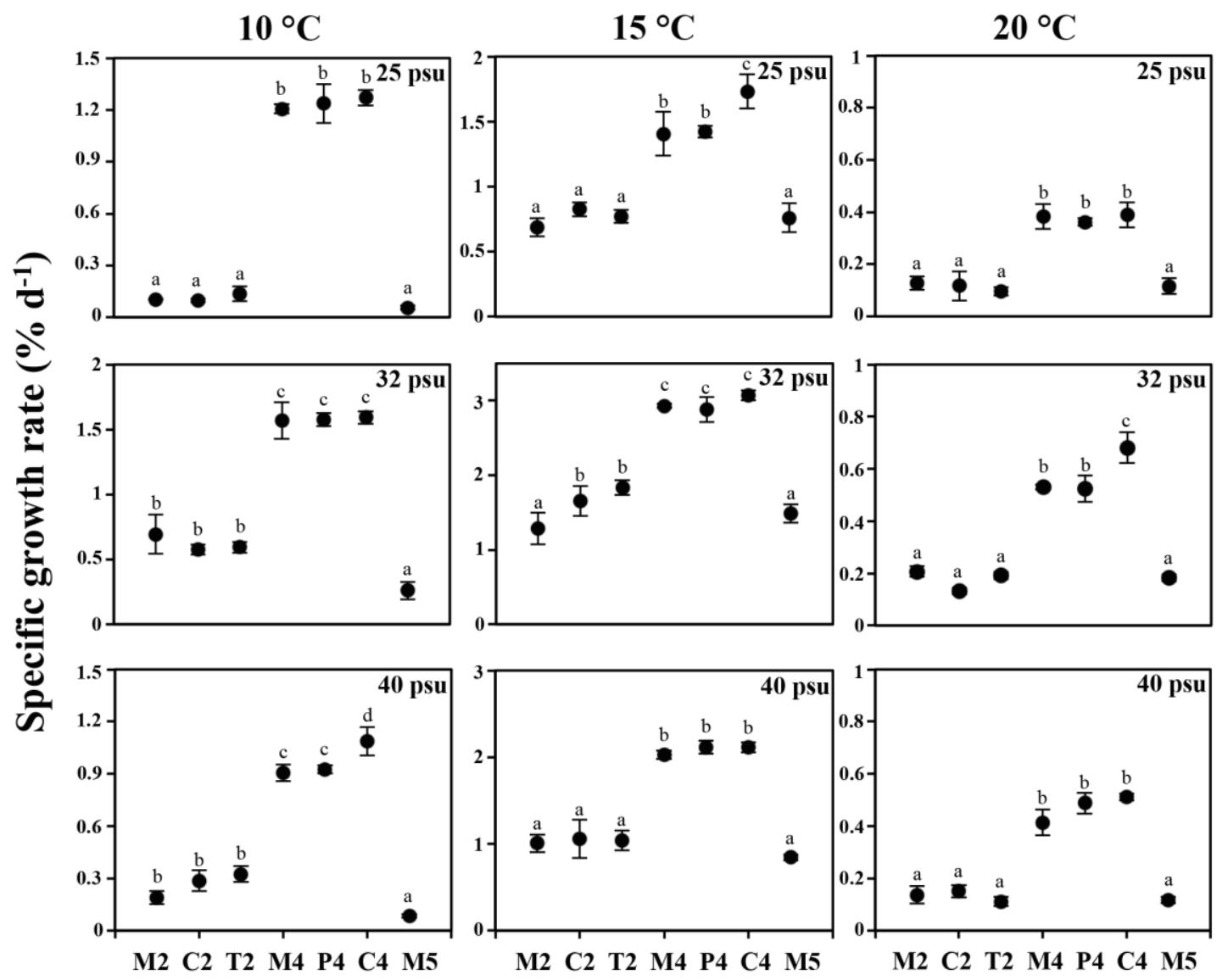

B. intricata isolates

Figure 4.2: Mean specific growth rate $( \pm \mathrm{SE})$ of all Bostrychia intricata isolates belonging to three cryptic species, N2 (isolates M2, C2, T2), N4 (M4, P4, C4) and N5 (M5), at three salinities and temperatures $(n=3)$. The different letters indicate significant difference $(P<$ $0.05)$. 
Table 4.2. Summary of ANOVA results for the growth experiment data

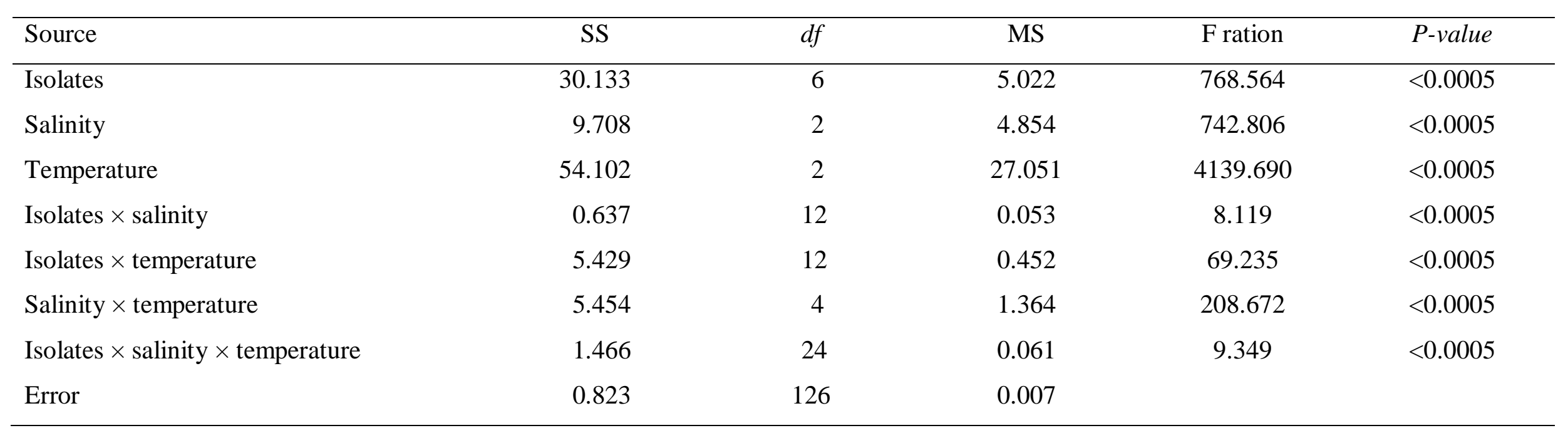

SS, sum of squares; $d f$, degree of freedom; MS, mean square. 


\section{Discussion}

The discovery of physiological differences between cryptic species has recently increased for marine species (Chen and Hare 2008, Degerlund et al. 2012, Leasi et al. 2013), but less so in marine macroalgae (e.g. Cladophora glomerata (Linnaeus) Kützing, Hayakawa et al. 2012, and Ulva prolifera Müller, Ogawa et al. 2013). In marine red algae, physiological distinction between cryptic species has been observed for Caloglossa ogasawaraensis, indicating that different cryptic species grow in particular saline environments (Kamiya and West 2014). Under our experimental conditions, the data clearly showed that all isolates had their optimal growth in these condition at the same salinity and temperatures $\left(15^{\circ} \mathrm{C}\right.$ and salinity of 32$)$ (Fig. 4.2, Appendix 4.1). Cryptic species N4 growth was significantly different from cryptic species N2 and N5 showing higher specific growth rate in our experimental treatments. While these finding could be attributed to preference to the culture conditions for $\mathrm{N} 4$, these findings do suggest that physiological differences exist and differentiation has occurred among these cryptic $B$. intricata species. Cryptic species N2 and N5 mostly showed a similar growth pattern, but were significantly differed from each other at the lower temperature conditions. Global phylogenetic diversity within cryptic $B$. intricata species has previously demonstrated that cryptic species N2 and N5 evolved from a more recent common ancestor than either did to N4 (Chapter 2).

Considering these results, it is possible that levels of physiological differentiation among these cryptic species have diverged since they shared a most recent common ancestor (MRCA) with the similarity maintained, or only marginally diverging, since the MRCA of N2 and N5. While the longer history of divergence of N4 is reflected in its greater physiological distinctness.

In $B$. intricata, found in the upper intertidal zone, our preliminary studies showed that this species can survive in wider range of salinity conditions, from 15 to $50 \mathrm{psu}$, but only grew significantly between 25 to 40 psu (Muangmai, unpublished data), These results are congruent with previous physiological experiments by Karsten et al. (1996), indicating an ability for survival in a board salinity range, 5 to $60 \mathrm{psu}$ in this species. Our studies showed differences in physiological performance to salinity variations between the three cryptic species. Cryptic species N4 had considerably greater growth than species N2 and N5 in all salinity levels. 
All isolates of B. intricata grew in the temperature tested, although showed higher growth rate between $10-15{ }^{\circ} \mathrm{C}$. Our results are consistent with the physiological studies of $B$. intricata (as Stictosiphonia hookeri) from South America (Karsten et al. 1996), which exhibited optimal growth in temperature ranging from 10 to $20{ }^{\circ} \mathrm{C}$. We also detected that cryptic species N4 always had a higher specific growth rate than the other two cryptic species at all temperatures tested.

It is possible that the increased growth of cryptic species N4, in different temperatures and salinities, gives this cryptic species a competitive advantage in some environmental situations (e.g. more southern colder climates; higher intertidal environments). Previous studies on macroalgal distribution indicated that temperature tolerances were partly responsible to pattern of geographic distribution of algal species (Breeman 1998, Orfanidis et al. 1999, Hurd et al. 2014). New Zealand exhibited a remarkable variability of sea surface temperatures, due to its latitudinal range, ranging from 15 to $18{ }^{\circ} \mathrm{C}$ in North Island and from 11 to $15^{\circ} \mathrm{C}$ in South Island (Uddtrom and Oien 1999). The north-south water temperature differences could partially affect the diversity and distribution pattern of some marine algae in New Zealand. For example, the distribution and diversity of Carpophyllum maschalocarpum (Turner) Greville was suggested to be due partially to sea surface temperature changes during and after glacial periods (Buchanan \& Zuccarello 2012). Phylogeographic studies of New Zealand B. intricata species have shown that cryptic species N4 is widely distributed all around New Zealand, whereas cryptic species N2 and N5 were only found in northern regions (Chapter 3). Contrasting distribution patterns in cryptic species of the New Zealand B. intricata; a wide distribution in cryptic species N4 versus northern-limited dispersal in cryptic species N2 and N5, could possibly be explained by differences between these cryptic species in their ability to grow effectively at different temperatures .

Our physiological data are useful in possibly explaining the occurrence of different cryptic algal species at the same location. Theoretically, coexistence of sympatric species can take place when species have at least slight differences in food resources, reproductive strategies, physiological responses or habitats conditions (Gause 1932, Amato et al. 2007, Tronholm et al. 2010). A preliminary study in the population structure of $B$. intricata showed that the cryptic species (N2, N4 and N5) could co-occur together at Moa Point, 
Wellington (Chapter 3). In the present study, we found physiological differentiation among the three cryptic species collected from Moa Point (isolates M2, M4 and M5), and these differences could potentially promote their coexistence at the area. While cryptic algal species could sympatrically coexist due to their differential physiological adaptations, the distribution pattern of different these cryptic species at small-scales in natures are still unknown. Future studies on $B$. intricata must consider how these cryptic species coexist, in relation to the relevant environmental factors (e.g. tidal level, sun exposure and wave exposure).

Physiological differentiations among haplotypes of cryptic algal species have been observed in Bostrychia and Caloglossa (Karsten et al. 1993, 1994b, Zuccarello et al. 2001). For example, three haplotypes of Caloglossa vieillardii (Kützing) Setchell (as $C$. leprieurii) from eastern Australia were physiologically different, with haplotype A showing a lower growth rate and photosynthetic capacity than haplotypes B and C (Zuccarello et al. 2001). We also detected inter-haplotype differences in growth rate for cryptic species N2 and N4. For cryptic species N2, haplotype 2A (isolate M2) significantly differed from haplotype $2 \mathrm{C}$ (isolate $\mathrm{T} 2$ ) and $2 \mathrm{G}$ (isolate $\mathrm{C} 2$ ) under one experimental condition $\left(15^{\circ} \mathrm{C}\right.$ and $32 \mathrm{psu}$ ), whereas in cryptic species $\mathrm{N} 4$, haplotype 4T (isolate $\mathrm{C} 4$ ) have a higher growth rate than the other two haplotypes 4E1 (isolate M4) and 4E2 (isolate P4) at some conditions (Fig. 4.2, Table 4.1). Our previous studies on haplotype diversity of the mitochondrial gene COI of these cryptic species showed differences of 1 or 2 base pair between the haplotypes of $\mathrm{N} 2(2 \mathrm{~A}, 2 \mathrm{C}$ and $2 \mathrm{G})$ and 1 or 11 base pair between the haplotypes of N4 (4E1, 4E2 and 4T) (Chapter 3). This suggests that even within cryptic species, with very little genetic difference, physiology can vary.

In conclusion, our data clearly show variations in SGR among three cryptic species of $B$. intricata at different salinities and temperatures. Cryptic species N4 has a greater tolerance to a wide range of salinities and temperatures than cryptic species N2 and N5, and these physiological properties could contribute in their greater distribution in New Zealand. Our findings provide concrete evidence that morphologically indistinguishable cryptic algal species can be physiologically divergent. Due to a high cryptic diversity of $B$. intricata (Chapter 2), we suggest that further physiological studies, including other cryptic species from different regions, for example, Australia (N7 and N8), subantarctic island (N3) or South Africa (N6), can be beneficial to gain more understanding of the genetic- 
physiological diversity and evolution within morpho-cryptic algal species, and possibly explain the geographic distribution of the different cryptic species of $B$. intricata in the Southern Hemisphere. In addition, future research should focus on other physiological characters (e.g. photosynthetic capacity at different levels of desiccation and light intensity) among cryptic $B$. intricata species. This will increase our knowledge of physiological properties and adaptations in cryptic algal species.

\section{Acknowledgement}

We are very grateful to Ulla von Ammon for preliminary experiments and Cong Zeng for help in statistical analyses. We also thank John West and Christian Boedeker for valuable discussions. Special thanks the Victoria University of Wellington for providing a scholarship to NM. 


\section{Chapter Five}

SMALL-SCALE DiSTRIBUTION OF CRYPTIC

Bostrychia INTRICATa SPECies at MoA Point, Wellington 


\begin{abstract}
Niche partitioning is an important ecological mechanism, which allow competing species to occupy a certain resource or habitat, consequently creating their stable coexistence in the area. Sympatric coexistences of cryptic species, indistinguishable morphological taxa, have increasingly been detected based on molecular data, and this discovery raises the interesting question of how cryptic species, which could be hypothesized to need identical ecological resources, can coexist. The red alga Bostrychia intricata is commonly found along the shore of New Zealand. Previous studies indicated several cryptic species within this morphospecies and that some are sympatric. This study aimed to determine whether cryptic $B$. intricata do coexist at a small-scale by occupying distinct niches. Along the shore of Moa Point, Wellington, we conducted intensive sampling of $B$. intricata in different habitats with respect to tidal position, wave and sun exposure levels. Our genetic data clearly showed the coexistence of three cryptic species of B. intricata: N2, N4 and N5. Multiple samples from individual algal patches indicated that the patch was made of the same ramet. The distribution of these cryptic species was not random and varied significantly. Cryptic species N4 was found at a higher tidal position than species N2 and N5, whereas cryptic species N2 occurred in more wave-exposed areas than the other species. Discriminant analysis indicated that tidal height strongly influenced the distribution pattern among cryptic species. Our observations demonstrate that different cryptic algal species partition intertidal habitats (niches), which may facilitate their coexistence in sympatry.
\end{abstract}




\section{Introduction}

In community ecology, the niche is often defined as a specific resource, behavior or environmental circumstance of one species, which is generally influenced by biotic and abiotic factors, such as inter- and intra-specific interactions, gradients of light and temperature or seawater chemistry (Odum 1959, Silvertown 2004, Levinton 2013). In intertidal ecosystems, many studies have demonstrated temporal and spatial niche differentiations (e.g., reproductive timing, tidal position and exposure level) among competing taxa allowing them to coexist at small-scales (Benzie et al. 2000, De Troch et al. 2003, Sampayo et al. 2007, Tronholm et al. 2010, Lai et al. 2011, Zardi et al. 2011). For example, within mid-intertidal pools along the northern Gulf of California, the brown alga Sargussum johnstonii Setchell \& Gardner grew at a shallower depth than S. sinicola subsp. camouii (Dawson) Norris \& Yensen in pools (McCourt 1984).

Recently, molecular data have been used to solve taxonomic problems in marine species and uncovered hidden diversity (Knowlton 2000, Zuccarello and West, 2003, 2006, Lindstrom 2008, Tronholm et al. 2010). Cryptic species are a group of two or more morphologically indistinguishable species, which are genetically divergent (Bickford et al. 2007). In marine red algae, the incidence of cryptic species is relatively common (Zuccarello et al. 2002, Zuccarello and West 2003, Payo et al. 2013, Chapter 3). While morphologically identical, cryptic red algal species can be distinctly different in other aspects of their biology: e.g. distribution patterns, mating systems and physiological performance (Kamiya et al. 1998, Zuccarello and West 2003, Kamiya and West 2014, Chapter 2 and 3).

Competitive exclusion principle was originally proposed by Gause (1934) to explain competition of different species for the same ecological niches (resources and habitats) and leading one species to exclude the other (Hardin 1960). Several studies in animal and plant communities have demonstrated that in the same area, competing species could stably coexist by occupying different niches (Tokeshi 1999, Silvertown 2004, Zhang et al. 2004). Discovering the coexistence of cryptic algal species challenges this classical concept of competition (Zuccarello et al. 2003, Fraser et al. 2013, Chapter 3). The shared morphology of cryptic algal species would suggest that they need similar, or even identical, ecological 
niches and would compete with each other. Therefore, the species that has a competitive advantage would eliminate its competitors from the area, and coexistence would be unlikely. Recently, several studies have shown that cryptic algal species are ecophysiologically distinct (Škaloud and Rindi 2013, Kamiya and West 2014), suggesting that these cryptic species may have specialized on the particular resource or habitat (niche) and this would allow them to coexist.

Bostrychia intricata (Bory de Saint-Vincent) Montagne is a common intertidal red alga occurring in the Southern Hemisphere (Chapter 2). This species has been studied in various biological aspects, including taxonomy, evolution, phylogeography, reproduction and physiology (Karsten et al. 1996, West et al. 1996, Zuccarello and West 2008, Fraser et al. 2013, Chapter 2 and 3). Global phylogenetic diversity plus species delimitation analyses indicated eight cryptic species within this morphospecies, three of which are found in New Zealand (N2, N4 and N5) (Chapter 2). Phylogeographic studies of New Zealand $B$. intircata indicated the coexistence of different cryptic species in some populations around Cook Strait (Chapter 3).

There are at least two possible explanations for the coexistence of sympatric cryptic species of B. intricata. First, is that different cryptic species occupy different niches. Our growth experiments of three sympatric cryptic species of $B$. intricata (N2, N4 and N5) from Moa Point (Cook Strait, North Island) have previously indicated physiological differences among these cryptic species (Chapter 4). It is possible that the physiological differentiation seen in culture among $B$. intricata species, could lead to the species inhabiting different ecological niches and allow the coexistence of these cryptic species. Another possibility of coexisting is a vacant niche space filling process on a 'first-come, first-served' basis (Sale 1982, Brokaw and Busing 2000, Gillespie and Roderick, 2002). This concept emphasizes that the first species to arrive has a better chance to occupy the space and establish their population than later arrivals. It is a random process as to which species could fill the open ecological niches regardless of species-specific niches preferences, and this likely fits with the situation of large communities when competitive exclusion occurs slowly (Silvertown and Law 1987, Brokaw and Busing 2000). However, clear evidence to clarify how the coexistence of cryptic $B$. intricata species occurs in the microhabitat is still needed. 
This study aims to test the hypothesis that the cryptic algal species can coexist in sympatry when they occupy different intertidal habitat (niches partitioning), with respect to physical environmental factors. We surveyed the distribution of cryptic species of $B$. intricata in a population at Moa Point, Wellington with reference to physical factors: tidal position, wave and sun exposure. We firstly examined whether the coexistence of these cryptic species is likely to be facilitate by niche partitioning or just a random selection mechanism. Secondly, we would like to see which physical factors play a more significant role in promoting the microhabitat distribution pattern of cryptic $B$. intricata species.

\section{Materials and Methods}

Sampling

Samples of B. intricata were collected at Moa Point, Wellington (41 $20^{\circ} 40.78 " \mathrm{~S}$

$174^{\circ} 48^{\prime} 35.34^{\prime \prime E)}$. Due to the patchy distribution of these species, we sampled $1-2$ patches from each rock approximately every 2 meters. To test if patches were composed of single or multiple genets (identical genetic made-up), we sampled $2-3$ ramets per patch. We recorded three physical factors for each patch: (1) tidal height, (2) sun exposure and (3) wave exposure. To estimate the tidal level, we used a theodolite to measure the height of each algal patch above the sea surface calibrated to the predicted low tide for that day (Meteorological Service of New Zealand: http://metservice.com/marine/tides/wellington). The degree of exposure to sun and wave was measured following Lewis (1964) and Schneider and Helmuth (2007) with some modifications. We classified sun exposure based on algal position: "sun-protected" habitat if the algae was found in a rock crevasse or on the underside of a rock; and "sun-exposed" in other areas. We classified wave exposure based on the direction the alga faced: "wave-exposed" if the alga was facing the open coast and "wave-protected" if the alga faced the shore.

All algal samples were placed in silica gel in the field. Algal specimens were identified based on previous species descriptions (e.g. King and Puttock 1989, Zuccarello and West 2008). For DNA analyses, algal samples were rinsed in autoclaved seawater to remove any sand and dirt, and then the apical portions were used for DNA isolation. 


\section{Molecular analyses}

Due to the large number of samples, we applied single-stranded conformation polymorphism (SSCP) analysis to screen the genetic variation within the population. DNA was isolated using a modified Chelex method (Zuccarello et al. 1999a). The short fragment of mitochondrial cytochrome c oxidase subunit I gene (COI) ( $200 \mathrm{bp})$ was selected as an appropriate molecular marker for PCR amplification (Chapter 2 and 3). PCR amplification was performed using primers (BiCOI_168F: 5'-GGAGCYGCRGTAGAYTTAGCRA TTT-3' and BiCOI_372R: 5'-TYGTAATTGCTCCRGCTAAAAC-3') designed from previous COI sequences (Chapter 3). The PCR reactions followed Fraser et al. (2013).

For SSCP analysis, we prepared a gel, $225 \mathrm{~mm}$ long and $0.75 \mathrm{~mm}$ thick (BioRad, Hercules, CA, USA), by combining 20\% (37.5:1) acrylamide/bis-acrylamide solution (Sigma Aldrich, St Louis, MO, USA), 0.5x TBE buffer, 0.5\% ammonium persulphate and $0.05 \%$ tetramethylethylenediamine (Biorad, Herecule, CA, USA). Three $\mu \mathrm{L}$ of PCR product were mixed with $9 \mu \mathrm{L}$ of loading dye (98\% formamide, $0.025 \%$ bromophenol, $0.025 \%$ xylene cyanol and $10 \mathrm{mM} \mathrm{NaOH})$. Mixed PCR products were denatured at $95-$ $100{ }^{\circ} \mathrm{C}$ for 5 minutes and then snap cooled on ice before loading. Vertical acrylamide gel electrophoresis was run in $0.5 \mathrm{x}$ TBE buffer at 12 volts for $5-6$ hours at $4{ }^{\circ} \mathrm{C}$. The gel was stained used silver-staining (Bassam et al. 1991) and banding patterns were analysed by eye. In each gel, one or more samples with different or ambiguous SSCP banding profiles were sequenced. For sequencing, PCR products were purified using ExoSAP-IT (USB, Cleveland, OH, USA), and sequenced commercially (Macrogen Inc., Korea). Cryptic species and haplotype were defined based on previous studies (Chapter 2 and 3).

\section{Data analyses}

The relationship between the distribution pattern of the cryptic species and the three physical factors was tested statistically. All statistical analyses were carried out using IBM SPSS Statistics version 21 for Mac (IBM Corporation, Chicago, IL, USA). Three physical factors were preliminarily defined as two different types of variables: (1) categorical variable for sun and wave exposure and (2) continuous variable for tidal height. For sun and wave exposure, the association between these two parameters and cryptic species distribution was analysed by the Pearson's chi-square test. Tidal height data were initially 
tested for normality and homogeneity. Due to non-normal distribution of the data, the difference between the tidal heights of each cryptic species was tested using the KruskalWallis non-parametric analysis of variance (ANOVA), following Dunn-Bonferroni post hoc tests. Additionally, discriminant function analysis was applied in determining which physical parameters could influence the distribution patterns of the cryptic species (McGarigal et al. 2000).

\section{Results}

A total of 392 samples of B. intricata were collected at Moa Point, and genetically classified, based on SSCP analysis and DNA sequence, into three cryptic species: N2, N4 and N5. Genetic analyses showed that only one COI haplotype was identified from each algal patch, indicating genetic homogeneity within a patch (patch is a genet), and therefore, we used only one genotype representing each patch for statistical analysis $(n=126)$. The occurrences of different cryptic species (distinct algal patch) on the same rock were occasionally observed. Cryptic species N2 was the most abundant species, accounting for approximately $64 \%$ of total samples, followed by cryptic species N4 (26\%) and N5 (10\%). Higher genetic diversity was observed in cryptic species N2, with three haplotype recognized (2A, 2L and $2 \mathrm{M})$, whereas lower variation was found in cryptic species $\mathrm{N} 4$ with two (haplotype 4E1 and 4E12) and N5 with one (haplotype 5A) (Table 5.1). Haplotypes 2L and 2M of cryptic species N2 and haplotype 4E12 of cryptic species N4 were newly reported in this study. Within cryptic species $\mathrm{N} 2$, haplotype $2 \mathrm{~A}$ was relatively common (67\%), comparing to other two haplotype: $2 \mathrm{~L}(25 \%)$ and $2 \mathrm{M}(8 \%)$. The abundance of the two haplotypes of cryptic species N4 were only slightly different in this area (56\% for 4E1 and 54\% for 4E12). Additionally, cryptic species N2 was widely distributed around Moa Point, but the other two cryptic species were restricted to the top and east side of the point (Fig. 5.1).

Pearson's chi-square tests showed a significant association between the distribution of cryptic $B$. intricata species and sun and wave exposure. The occurrence of these cryptic species was significantly associated with wave exposure $\left(\chi^{2}=28.712, \mathrm{df}=5, P<0.0005\right)$. Cryptic species N2 was more frequently observed in wave-exposed areas than the other 
species ( 70\% for all haplotypes), whereas cryptic species N4 was more likely to be found in wave-protected areas ( $70 \%$ for both haplotypes) (Table 5.1$)$. On the other hand, the distribution of cryptic species was non-significantly related to sun exposure $\left(\chi^{2}=3.756\right.$, $\mathrm{df}=5, P=0.585$ ). Cryptic species N2 (haplotype $2 \mathrm{M}$ ), N4 and N5 were likely to be symmetrically dispersed in either sun-exposed or sun-protected areas (Table 5.1). In contrast, two haplotypes of cryptic species N2 (2A and 2L) were unevenly found between sun-exposed and sun-protected areas, being more common in sun-exposed sites (Table 5.1). For tidal position, the Dunn-Bonferroni post hoc tests indicated significant differences in average mean tidal heights among these cryptic species $(P<0.05)$ (Fig. 5.2). Cryptic species N4 was distributed at a higher tidal position, ranging from $1.5-3.4 \mathrm{~m}$., than the other two species: N2 (0.8 - $1.75 \mathrm{~m}$.$) and N5 (1.3 - 1.6 \mathrm{~m}$.) (Table 5.1).

Discriminant analysis (Wilk's lambda test) indicated a significant difference in the distribution of cryptic $B$. intricata species ( $P<0.05$ in all functions, Appendix 5.1). In this analysis, the first two discrimination functions (DF) accounted for $99.5 \%$ of variance between groups (DF1 90.8\% and DF2 8.7\%). Two-dimension plot (DF1 and DF2) of the discriminant analysis of three physical factors clearly showed differentiation between cryptic species (Fig. 5.3). Cryptic species N4 was clearly separated from the other two species, whereas species N2 was intermingled with N5 (Fig. 5.3). Within group correlations between the three physical parameters and discriminant functions, tidal position contributed dominantly to DF1, whereas wave exposure contributed more than other factors to DF2 (Appendix 5.2) implying that tidal position most strongly influenced the distribution pattern of these cryptic species, and followed by wave exposure. 


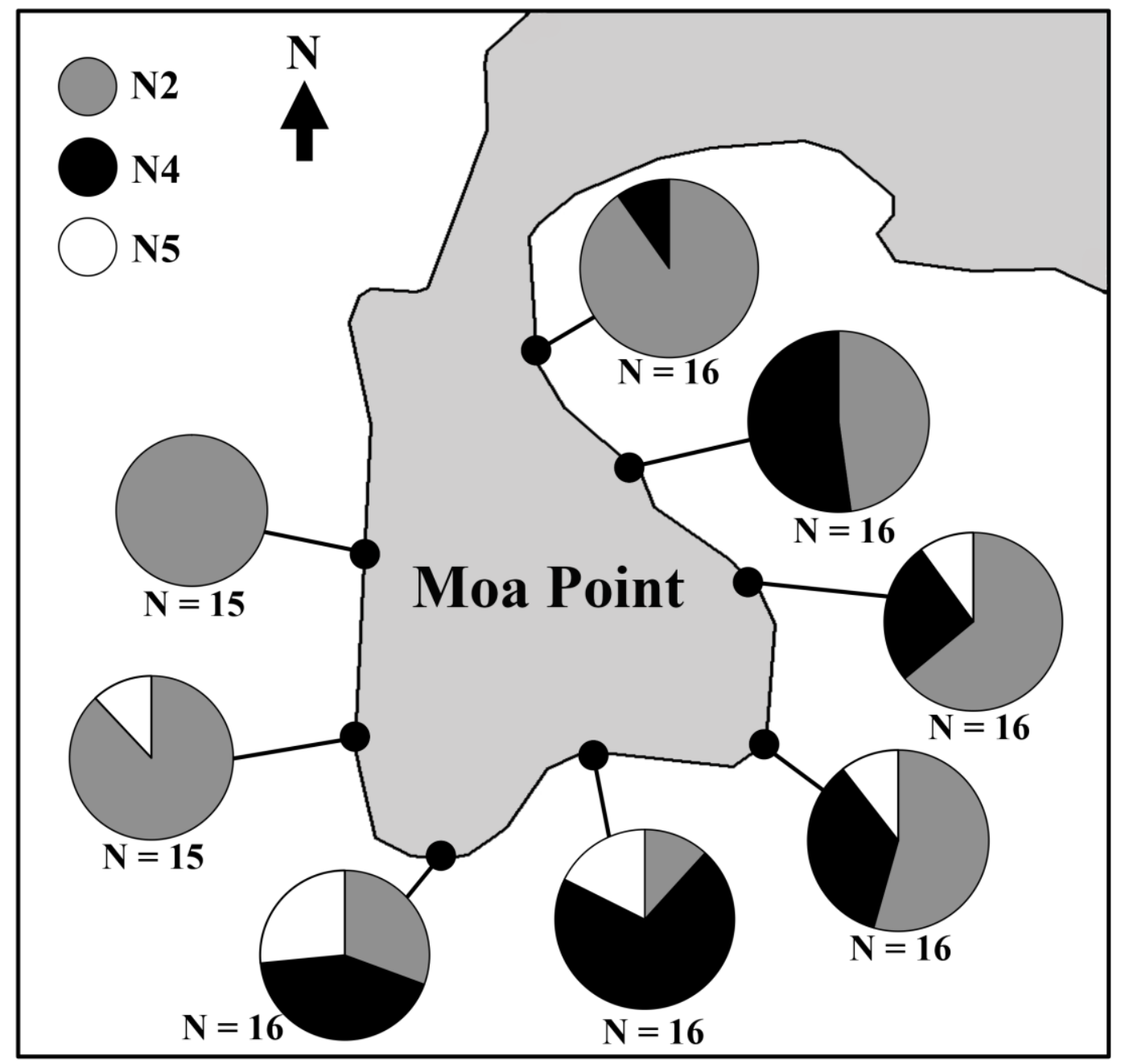

Figure 5.1: Distribution of three cryptic species of $B$. intricata (N2, N4 and N5) around Moa Point, Wellington. Shading represent different cryptic species: Grey: species N2; Black: species N4; and White: species N5. Each pie chart represents the number of patches sampled in several rocks in the area $(\mathrm{N})$. 
Table 5.1. Summary of the B. intricata at Moa Point: cryptic species, COI haplotype, number of patches, percentage in wave and sun exposure area and tidal position range (above $0 \mathrm{~m}$ tidal height).

\begin{tabular}{|c|c|c|c|c|c|c|c|}
\hline \multirow{2}{*}{$\begin{array}{l}\text { Cryptic } \\
\text { species }\end{array}$} & \multirow{2}{*}{$\begin{array}{l}\text { COI } \\
\text { haplotype }\end{array}$} & \multirow{2}{*}{$\begin{array}{l}\text { Number of } \\
\text { patches }\end{array}$} & \multicolumn{2}{|c|}{ Wave exposure } & \multicolumn{2}{|c|}{ Sun exposure } & \multirow{2}{*}{$\begin{array}{l}\text { Tidal position } \\
\text { range (meters) }\end{array}$} \\
\hline & & & wave-exposed & wave-protected & sun-exposed & sun-protected & \\
\hline $\mathrm{N} 2$ & $2 \mathrm{~A}$ & 55 & $76.3 \%$ & $23.7 \%$ & $72.7 \%$ & $27.3 \%$ & $1.15-1.75$ \\
\hline $\mathrm{N} 2$ & $2 \mathrm{M}$ & 5 & $100 \%$ & 0 & $60 \%$ & $40 \%$ & $1.00-1.67$ \\
\hline N5 & $5 \mathrm{~A}$ & 13 & $46.1 \%$ & $53.9 \%$ & $61.5 \%$ & $39.5 \%$ & $1.30-1.60$ \\
\hline $\mathrm{N} 4$ & 4E12 & 14 & $21.4 \%$ & $78.6 \%$ & $57 \%$ & $53 \%$ & $1.65-3.00$ \\
\hline
\end{tabular}




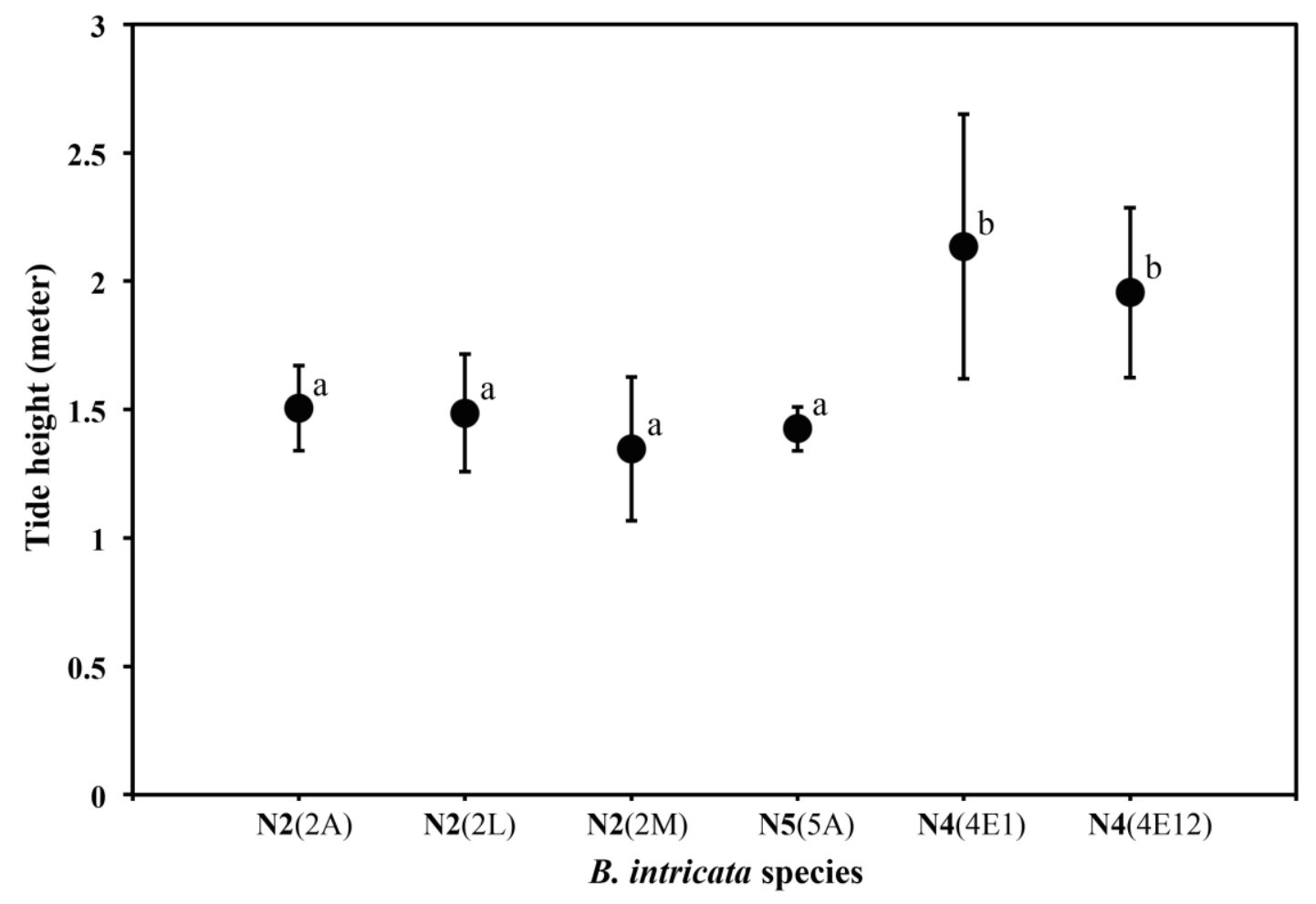

Fig. 5.2: Average mean tidal heights $( \pm \mathrm{SE})$ above $0 \mathrm{~m}$ tidal height of each cryptic $B$. intricata species (all haplotypes) found at Moa Point. The different letters indicate significant difference $(P<0.05)$. 


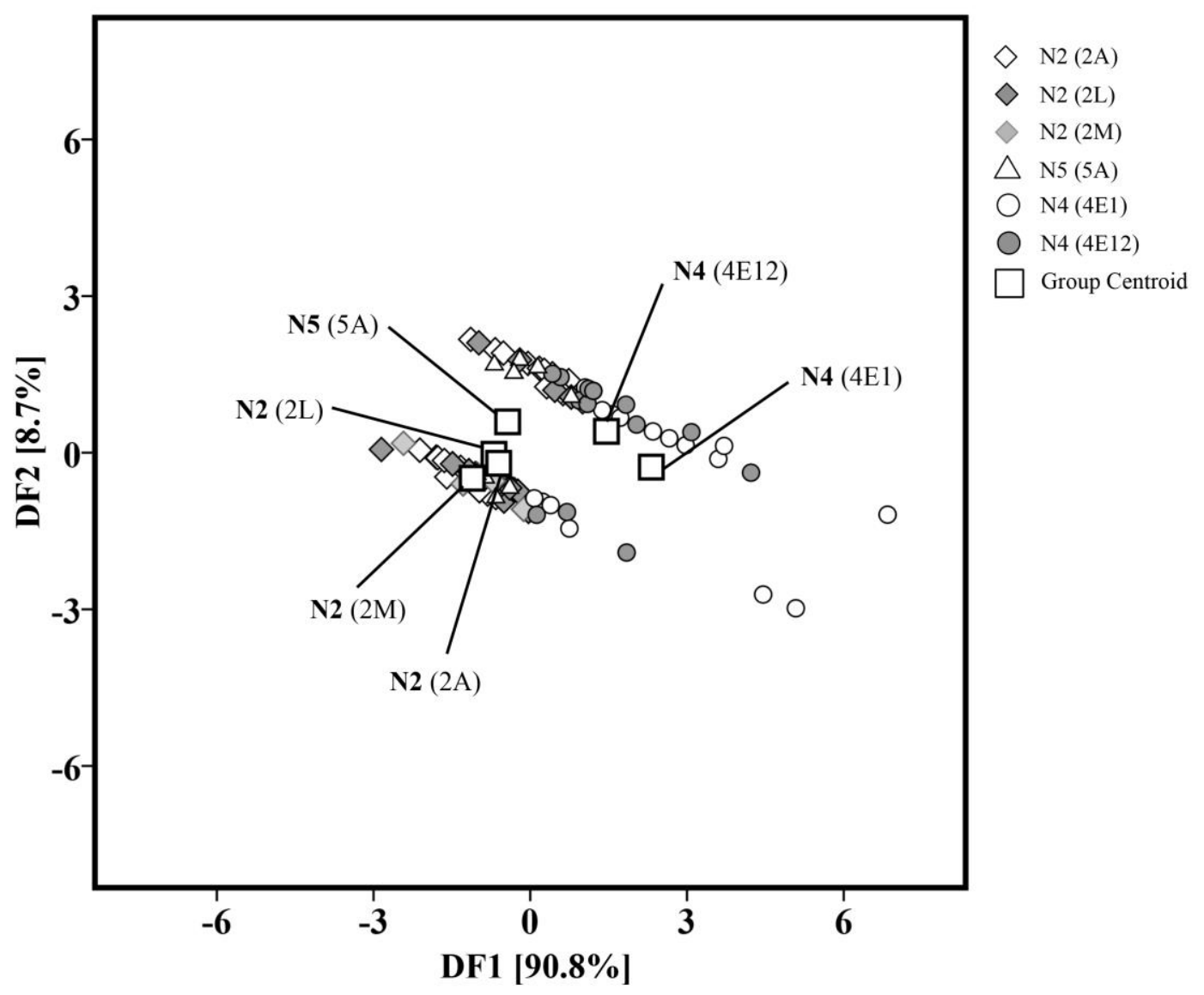

Fig. 5.3: Discriminant analysis plot for three physical parameters (tidal height, wave exposure and sun exposure) of each cryptic $B$. intricata species (all haplotypes) collected from Moa Point. Shape and shading represent each haplotypes of B. intricata: White rhombus: haplotype 2A (N2); Dark grey rhombus: haplotype 2L (N2); Light grey rhombus: haplotype 2M (N2); White triangle: haplotype 5A (N5); White circle: haplotype 4E1 (N4); Grey circle: haplotype 4E12 (N4) and White square: group centroid of each haplotype. 


\section{Discussion}

Our intensive survey, with collection of nearly 400 samples, clearly shows that cryptic $B$. intricata species N2, N4 and N5 grow sympatrically, even on the same rock, along a shoreline of approximately $700 \mathrm{~m}$ at Moa Point, this indicating high levels of cryptic species diversity at a micro-geographic scale. Three additional haplotypes for cryptic species N2 and N4 were also observed in this study. At similar small-area levels within the New Zealand shore, similar patterns of high species-level diversity has been observed in the red alga, Pyropia at Brighton Beach from the South Island (as Porphyra, Schweikert et al. 2012). Many studies on phylogenetic diversity and biogeography have demonstrated the sympatric occurrence of different cryptic algal species within a confined space, especially in red algae, for example Bostrychia radicans (Montagne) Montagne/B. moritziana (Sonder ex Kützing) J. Agardh (Zuccarello and West 2003), Portieria hornemannii (Lyngbye) P. C. Silva (Payo et al. 2013) and Pyropia yezoensis (Ueda) M. S. Hwang \& H. G. Choi (Niwa et al. 2014). As a result, we emphasize the importance of small-scale studies, incorporating intensive sampling, to provide more detail about the diversity pattern and abundance of cryptic algal species at all scales.

Our data also suggested that each patch is made up of only one genet. More variable markers (microsatellites) may indicate that the patches are composed of multiple genets but at present each patch appears to be a clone. Our data indicated a non-random distribution pattern of cryptic B. intricata species at Moa Point. Instead, clear evidence of different distribution pattern was found among cryptic algal species. Cryptic species N4 grew higher on the intertidal shore than other two cryptic species $\mathrm{N} 2$ and N5, and cryptic species N2 were more frequently observed in wave-exposed areas than the other species. These substantial contrasts in small-scale distribution between the cryptic species are very likely strongly influenced and possibly due to the interaction of tide height and wave exposure (wave-exposed vs. wave-protected habitats). This observed pattern indicates spatial niche differentiation between cryptic species of $B$. intricata at Moa Point. Ecological differences between cryptic algal species have previously been observed in the green alga Klebsormidium flaccidum (Kützing) Silva, Mattox \& Blackwell, which indicated that different lineages could be found in different habitats (water, artificial substrate or natural substrate)(Škaloud and Rindi 2013). Here, we were able to 
quantitatively demonstrate niche partitioning among sympatric cryptic algal species in the field.

In intertidal communities, tidal height plays a significant role in shaping the population structure and distribution pattern of sessile marine organisms, including macroalgae (Underwood and Jernakoff 1984, Harley and Helmuth 2003, Hurd et al. 2014). We found that the distributions of three cryptic species of $B$. intricata were mostly segregated between high and middle intertidal shores. Several studies have focused on the vertical distribution along the intertidal of different, or within, algal species. Two closely related brown algae of the genus Fucus, F. vesiculosus L. and F. spiralis L., were shown to inhabit different tidal positions on the coastline of France and Portugal (Zardi et al. 2011). In the red alga Chondrus crispus Stackhouse, genetic differentiations were found between high and low shore populations (Krueger-Hadfield et al. 2013). Few studies have shown a clear correlation between physiological properties of algal species and distribution pattern in facilitating zonation. The upper shore $F$. spiralis had more desiccation tolerance than lower shore F. vesiculosus (Zardi et al. (2011). Additionally, the physiological performance of different genotypes of the red alga Caloglossa vieillardii (Kützing) Setchell (as C. leprieuri (Montagne) J. Agardh) was correlated with their abundance and was suggested to be a reason for these differences in abundance in a population in eastern Australia (Zuccarello et al. 2001). It is possible that the distribution pattern of different cryptic $B$. intricata species across intertidal gradients would reflect their different physiological traits.

Intertidal ecological studies have shown that the high intertidal zone is an extreme environment (e.g. high temperature, decreased salinity, long period of desiccation), and only a few well-adaptive algal taxa maintain their populations in this area (Zardi et al. 2011, Hurd et al. 2014). We found that cryptic species N4 was normally found high on the shore, approximately +1.7 to $+2.5 \mathrm{~m}$ tidal height, but could be up to $+3.5 \mathrm{~m}$, close to the upper limit of any alga in this area (personal observations) while the other two species, N2 and N5, occur lower down, approx. $+1-1.5 \mathrm{~m}$. Laboratory experiments clearly showed that when comparing the specific growth rate of the three cryptic B. intricata species to various salinities and temperatures, cryptic species N4 grew more rapidly than N2 and N5 in all conditions tested (Chapter 4). Comparative physiological study also suggested that cryptic species N4 could grow over a wider range of salinities and temperatures than other 
species N2 and N5 (Chapter 4). The population of cryptic species N4, which could adapt to a broad salinity-temperature range, mostly occupied the upper intertidal shore, whereas the other two cryptic species were likely to be confined to lower shore, possibly due to their limited physiological adaptations. It is likely that differences in physiological response to various culture conditions of the three cryptic species could partially influence their specific distribution along the intertidal gradient at Moa Point. In addition, the less abundant cryptic species N5 (10\% of total samples) correlated well with its lower performance in physiological experiments compared to the other cryptic species (Chapter 4). These results confirms that differences in the pattern of vertical distribution and abundance between cryptic algal species could be due to physiological differences and are adaptations that allow coexistence in the same location.

Different levels of wave exposure also influence the occurrence of intertidal macroalgal species (Scrosati and Mudge 2004, Hurd et al. 2014). For example, in the Canary Island, the brown alga Dictyota cymatophila Tronholm, M. Sansón \& Afonso-Carrillo more frequently occurred in wave-exposed habitats, whereas D. dichotoma (Huds.) J. V. Lamour was found in less exposed areas (Tronholm et al. 2010). Additionally, physical conditions related to wave exposure limit the horizontal distribution of marine macroalgae, as found in the intertidal kelp, Postelsia palmaeformis Ruprecht from the northeast Pacific (Nielsen et al. 2006). Our study clearly indicated the different spatial distribution of three cryptic $B$. intricata species with respect to wave exposure (wave-exposed vs. wave-sheltered habitats). While our measures of wave exposure are very crude, and absolute measures of wave exposure are very difficult to quantify (Airoldi and Virgilio 1998, Knox 2001), we believe we have captured some pattern associated with intensity of wave exposure.

Our findings provide evidence of spatial niche separation between cryptic $B$. intricata species, which can account for their coexistence. We also indicate that the abundance and distribution pattern of cryptic algal species could be driven by both biotic (e.g. genetic composition and physiological performance) and abiotic (e.g. coastal geography and hydrographic pattern) factors. However, these results were obvious only for the differences between cryptic species N4 and other species, but are still equivocal between cryptic species N2 and N5. If distinct niches exist between cryptic species N2 and N5, this could probably be related to other non-measured differences, e.g. mating period or seasonal abundance, as found in sibling species of Dictyota (Tronholm et al. 2010). Further studies 
of cryptic species of $B$. intricata in sympatry should considered other factors, e.g. temporal distribution, reproductive timing and abundance of different life phase that could contribute toward the comprehensive understanding of how cryptic algal species coexist at small scale.

\section{Acknowledgment}

We wish to thank to John van der Sman and Christian Boedeker for valuable suggestions in experimental design and Maren Preuss for sampling help. We also thank Dalice Sim and Cong Zeng for statistical suggestions. Special thanks to Victoria University of Wellington for providing a scholarship to NM. 


\title{
Chapter Six
}

\author{
GENERAL DISCUSSION
}


My $\mathrm{PhD}$ research provides a significant contribution to our knowledge of cryptic species diversity in algae. By using the red alga Bostrychia intricata as a model study, this current project presents five main findings: 1) a monophyletic relationship of four Southern Hemisphere Bostrychia species: B. arbuscula, B. gracilis, B. intricata and B. vaga, which formed in the middle Oligocene epoch ( 30 million years ago), suggesting a postGondwana origin; 2) cryptic diversity within a single morphospecies of $B$. intricata and $B$. vaga, which was consistent with results of multigene phylogeny and DNA-based species delimitation methods; 3 ) contrasting pattern of distribution and demographic history among three cryptic species of B. intricata (N2, N4 and N5) in New Zealand, with respect to historical events (e.g. the Last Glacial Maximum and sea surface warming), showing that these cryptic algal species have diversified and dispersed at different times; 4) differences in physiological performances among three cryptic species of $B$. intricata (N2, N4 and N5) in New Zealand, as revealed by different specific growth rates in culture experiments and 5) different cryptic B. intricata species (N2, N4 and N5) seemed to be distributed unevenly in particular intertidal habitats (ecological niches), which could facilitate their sympatric coexistence at small-scales.

The current research clearly demonstrates that cryptic algal species could be distinct in many biological aspects, such as evolutionary history, phylogeographic pattern and ecophysiological performance, while maintaining identical morphological features, suggesting that morphologically indistinguishable cryptic algal species should be recognized as independent entities. Although, this study does not attempt to provide comprehensive morphological data, I have found some morphological features, which overlap among cryptic species of $B$. intricata. I suggest that a proper morphological study (e.g. discriminant analysis of morphometric characters) of these cryptic algal species should be undertaken, but interpretations should be done cautiously as morphological variation has often been reported within cryptic algal species (Zuccarello and West 2006, Verbruggen 2014).

This study also adds to the knowledge of delineation of cryptic species. Due to morphologically similar, delimitating cryptic species must be mainly achieved by molecular data. Differences in molecular markers and species-delimitation methods have been applied for estimating the true number of cryptic species, which are subject to congruency of results across the markers and methods. However, incongruences among 
the results from different markers and methods have also been reported in several studies, including this current $\mathrm{PhD}$ project (Chapter 2), and this uncertainity of delineation of cryptic species strongly affects our understanding of their diversity and evolutionary histories. A possible solution is to delimit species using whole genomic data, but this could impact of delaying the analyses or of consuming resources and budget. Another possibility is to incorporate genetic characteristics with other criteria, for example, phylogenetic data as I have used in chapter 2. In addition to phylogenetic analyses, a biological species concept is one of the most powerful criteria to delineate species, and has been extensively used in several researches on cryptic species (Lee 2000, Zuccarello and West 2003, Xu et al. 2010). In this study, I have done some crossing experiments between different cryptic species and it showed reproductive incompatibility among them (see details below, Appendix 6.1). Furthermore, different eco-physiological performances were observed between cryptic species in this study as indicated in Chapter 4 and 5, suggesting that cryptic species are potentially seperable with eco-physiological data. I recommend that the use of combining genetic data with other traits (e.g. phylogenetic, reproductive isolation and eco-physiology) is beneficial to delimit cryptic species and could helps us to understand more about the nature of cryptic species.

\section{Diversity and evolution of cryptic algal species}

The increasing use of molecular techniques has revealed the existence of cryptic species in many groups of organisms (Bickford et al. 2007, Liu et al. 2011, Westram et al. 2013). Even though multiple cryptic species complexes have been abundantly detected in marine macroalgae, (Zuccarello et al. 2003, Payo et al. 2013, Vieira et al 2014), this current project clearly shows different evolutionary histories of cryptic algal species, by using combined results from different genetic markers and analysis approaches, such as multigene phylogenies, sequences-based species delimitation methods and divergence time estimation based on a molecular clock of combined molecular markers (chloroplast $r b c \mathrm{~L}$ gene and mitochondrial COI gene).

Multigene phylogenies indicated monophyly of the four Bostrychia species endemic to the Southern Hemisphere, and their formation 30 Mya (Chapter 2). These four Bostrychia species apparently have a more ancient divergence than other similarly distributed algae in 
this hemisphere (Fraser et al. 2010, Martin and Zuccarello 2012). It is obvious that speciation of these Bostrychia's occurred in the Southern Hemisphere, and possibly centered in New Zealand, as some species (B. arbuscula, B. gracilis and some cryptic species of $B$. vaga) seem to be restricted to New Zealand. However, more sampling covering all species ranges of these algae are needed to clarify the origin of these four Bostrychia species, and this would lead to a significant advance in the understanding of speciation and evolution of Bostrychia species as well as other marine algal taxa in the Southern Hemisphere.

Congruent results form multigene phylogenies and species delimitation methods based on mitochondrial COI indicated higher levels of genetic diversity of $B$. intricata (8 cryptic species) and B. vaga (4 cryptic species) than previous discoveries (Zuccarello and West 2008, Fraser at al. 2013). The occurrence of some cryptic species are likely to be confined to particular geographical region, for example, cryptic B. intricata species N6 was only observed from South Africa, while cryptic species N3 was restricted to the subantarctic islands.

Species delimitations using morphological data combined with DNA have recently been applied in algal taxonomy and systematics (Leliaert $t$ al. 2014, Vieira et al. 2014, Zuccarello et al. 2015). In this study, I examined some morphological characters between cryptic species of $B$. intricata and $B$. vaga and found that their morphology varied considerably. For example, number of tier cell ranged from $4-6$ cells between and within cryptic $B$. intricata species, suggesting that species delimitation based morphological features is unlikely for these cryptic species. Therefore species boundaries of these two cryptic species were mainly based on genetic composition. Numbers of recognized species in both $B$. intricata and $B$. vaga were slightly different when using either different genetic markers ( $r b c \mathrm{~L}$ and $\mathrm{COI}$ ) or species delimitation methods (GMYC model, ABGD and statistical parsimony). These contrasts are probably due to either the different mutation rates of the two markers, as found in chapter 2, showing that COI evolved faster than $r b c \mathrm{~L}$, or different algorithm in species delimitation methods (branching pattern of gene tree for GMYC model vs. intra- versus inter-specific genetic distances for AGBD method). This suggests that species boundaries, especially cryptic algal species, should be estimated carefully when using only one marker or species delimitation method. Consequently, I recommend that multiple species delimitation methods with various genetic markers, 
incorporated with phylogenetic analyses should be applied for studying algal diversity, especially cryptic algal species.

Dating analyses clearly showed that cryptic species of $B$. intricata and B. vaga have diverged at different times. In particular, diversification of cryptic species $B$. intricata appeared to be relatively recent, for example, $81,000-19,000$ years ago for species $\mathrm{N} 2$, or $50,000-1,300$ years ago for species N5 (Chapter 3). The origin of these cryptic algal species has occurred after the split of Gondwana ( 180 mya) as well as after the breaking up of New Zealand-Australia continent ( $80-60$ mya) (Short and Woodroffe 2009). This finding, combined with distinct geographic distributions, except for cryptic species N1 and N4 of B. intricata (Fraser et al. 2013), suggests that speciation of these cryptic species likely occurred in allopatry, probably due to oceanographic barriers. I assume that the allopatric origin of these cryptic algal species could be related with transoceanic dispersal facilitating by the start of the Antarctic Circumpolar Current (ACC) ( 32 - 28 mya; McLoughlin 2001) and then isolated geographically.

This current study estimates the diversification timing of macroalgae by using combined substitution rates of different gene: chloroplast $r b c \mathrm{~L}$ and mitochondrial COI. Apparent mutation rates vary between species and different regions throughout the genome (Lynch 2010). Therefore, the combined mutation rate from different genetic region could generate more accurate estimation of divergence time than using only one genetic marker (Parfrey et al. 2011, Smith et al. 2013).

Additional sampling of these cryptic algal species from different locations (e.g. Australia and South Africa for B. intricata, and Australia and subantarctic islands for B. vaga) are needed to clarify the biodiversity and geographic distribution pattern of these algae in the Southern Hemisphere. Another possibility is to seek other criteria to delineate these cryptic algal species, such as reproduction isolation. Reproductive isolation has been used as one of the characters to delimit species (the biological species concept), and there are a few studies that accessed whether different cryptic algal lineages are reproductively incompatible, mostly in the red algae (e.g. Zuccarello and West 2003, Kamiya 2004, Zuccarello et al. 2011). Reproductive incompatibility was found between, but also within algal lineages, such as Bostrychia moritziana/B. radicans complex (Zuccarello and West 2003), Are different cryptic species of B. intricata and B. vaga reproductively isolated? I 
have done the preliminary study of hybridization between three cryptic species of $B$. intricata (N2, N4 and N5). Results indicated the reproductive incompatibility between the isolates of three cryptic species, except for the cross of isolates C2 (N2) and M5 (N5), which was compatible, but female isolated $(\mathrm{C} 2)$ produced pseudocystocarps (pericarp forming without mature carposporophyte) (Appendix 6.1). These results suggest the possibility of being independent evolutionary units for these cryptic species of $B$. intricata. Further hybridization studies between other different cryptic species of $B$. intricata and $B$. vaga could help to expand our understanding of species concept in cryptic algal species.

\section{Phylogeographic contrasts of cryptic algal species in New Zealand}

Few studies have determined the population connectivity and demographic history of different cryptic red algal species in the Southern Hemisphere, despite many well-defined cryptic algal species in this region (Fraser et al. 2013, Boo et al. 2014, Vieira et al. 2014). This current research, using partial COI sequences, distinctly indicated the three cryptic species of B. intricata (N2, N4 and N5) occurred in New Zealand, and they exhibited different patterns of distribution and historical demography. Concordant with previous evidences of different level of genetic diversity along geographic gradients in New Zealand (Fraser et al. 2009c, Macaya and Zuccarello 2010a, Buchanan and Zuccarello 2012), the current study demonstrated that genetic diversity was higher in the northern than southern regions. In particular, all three cryptic B. intricata species was found in northern New Zealand (North Island and top of the South Island), whereas cryptic species N4 was only encountered in southern areas. This distribution contrast among three cryptic

algal species revealed a biogeographic break between northern and southern regions of New Zealand, which separated in top of the South Island (Cape Campbell of east coast and Golden Bay of west coast), and this break was found in some population studies of marine taxa in New Zealand (Apte and Gardner 2002, Goldstein et al. 2006).

The Last Glacial Maximum (LGM) has been found to have a significant impact on the distribution pattern of marine taxa, including macroalgae, in the Southern Hemisphere, as revealed by the reduction of genetic diversity or near homogeneity of genetic composition (Fraser et al. 2009,c 2012, Macaya and Zuccarello 2010b, Buchanan and Zuccarello 2012). 
Differences in distribution pattern and population structure of cryptic $B$. intricata species (N4 vs. N2 and N5) has likely been shaped by the effect of LGM, as evidenced by low genetic diversity in southern New Zealand and different divergence time observed between these cryptic species. Concordant with dating analyses, the high genetic diversity and population differentiation (west and east coast) observed in South Island for cryptic species N4 suggest that this cryptic species may have persisted in this region throughout the LGM.

Disparity among population structure and demographic history of cryptic $B$. intricata species N2 and N4 have been confirmed by different analyses, for example, haplotype network (star-like shaped network of N2 vs. complicated network of N4), SAMOVA algorithm (2 groups of N2 vs. 6 groups of N4), mismatch distribution (unimodal of N2 vs. multimodal of N4) and dating analyses (more recent diversification of $\mathrm{N} 2$ than N4). This finding clearly showed that cryptic species N4 has arrived and dispersed in New Zealand before species N2, suggesting different life histories between cryptic B. intricata species $\mathrm{N} 2$ and N4.

Further research could study the phylogeographic pattern of cryptic $B$. intricata species from other geographic region in the Southern Hemisphere. For example, two cryptic species of B. intricata (N7 and N8) were discovered in southern Australia (Chapter 2). It is interesting to test whether cryptic species N7 and N8 exhibited phylogeographic differentiation as found in New Zealand species, and this would enable us to have a better understanding of distribution and demographic partitioning of cryptic B. intricata species in different areas.

Recently, microsatellite have been developed and extensively used for studying population genetic and phylogeographic structure of marine algae (Wang et al. 2008, Guillemin et al. 2014) as these markers have potential to provide more detail about recent historical events related to distribution pattern of species (Madesis et al. 2013). Due to the likely speciation process of cryptic $B$. intricata being recent, another possibility is to develop microsatellite markers for B. intricata to precisely assess the level of genetic structure and estimate the migration rate within cryptic species. This could help to explain more clearly the population history and the pathways of spread of cryptic algal species in the Southern Hemisphere. 


\section{Eco-physiological performance correlate with distribution pattern of cryptic algal species}

Eco-physiological performances have been extensively studied in intertidal macroalgae, and most results revealed distinct eco-physiological responses between or within algal species, and these differences may correlate to their distribution and proportional occurrences in the field (Orfanidis et al. 1999, Zuccarello et al. 2001, Zardi et al 2011, Hayakawa et al. 2012, Watanabe et al. 2014). For example, Caloglossa leprieurii haplotype B and $\mathrm{C}$, which had a higher growth rate than haplotype $\mathrm{A}$ in all culture conditions tested, were also more abundant than haplotype $\mathrm{A}(\sim 10 \%$ of total samples) in the field (Zuccarello et al. 2001). The current research aimed to assess whether different cryptic species of $B$. intricata distributed in New Zealand are physiologically different (Chapter 4). Culture experiment of three main cryptic species (N2, N4 and N5) in various salinities and temperatures clearly indicated a significant difference of specific growth rate among cryptic species. Cryptic species N4 had the highest growth rate in all conditions tested, followed by $\mathrm{N} 2$ and then N5. This finding implies that different allelic combinations produce a different range of physiological responses, but probably not for morphological features, in cryptic algal species.

New Zealand has a north-south gradient in environmental conditions, including a warmer sea surface temperature in northern than southern regions. The contrasting physiological performance between cryptic species observed in growth experiments (Chapter 4) possibly explains the different distributional pattern of cryptic $B$. intricata species along the New Zealand coastline found in Chapter 3. Wide distribution throughout New Zealand of cryptic species N4 could possibly be due to its ability to tolerate a broader range of temperatures and salinities than the other two cryptic species N2 and N5, which were confined to northern regions of New Zealand.

The sympatric occurrences of different cryptic species of $B$. intricata have been found in some populations around Cook Strait, the central seaway between North and South Islands (Chapter 3). The observed pattern of cryptic algal species led to the interesting question of how these cryptic algal species, which are supposed to need identical ecological resources, manage to sympatrically coexist. To address this question, I intensively sampled cryptic 
species of $B$. intricata in different habitats with respect to tidal height, wave-exposure and sun-exposure around Moa Point, Wellington. I showed that the three cryptic species of $B$. intricata, N2, N4 and N5, coexist at the small scale, and they exhibited different distribution patterns in the area. Cryptic species N4 was mostly found in the higher intertidal shore than species N2 and N5, whereas cryptic species N2 was more often found at wave-exposed area than the other two species. This is evidence for ecological differences between these cryptic $B$. intricata species suggest that cryptic algal species could sympatrically coexist by occupying distinct spatial niches.

Many studies have previously demonstrated that differences in physiological performance could promote algal zonation and abundance in the intertidal (Zuccarello et al. 2001, Tronholm et al. 2010, Zardi et al 2011, Krueger-Hadfield et al. 2013). Distribution pattern and relative abundance of the three cryptic species $B$. intricata observed at Moa Point could be explained by this physiological differentiation (Chapter 4). For example, cryptic species N4, which could tolerate a broad salinity-temperature range, mostly occupied the upper intertidal shore, where more extreme environmental fluctuations occur. In contrast, the other two cryptic species N2 and N5 was often observed to middle to lower shore, possibly due to their limited physiological adaptations (Chapter 5). Additionally, cryptic species N5 grew more slowly and had lower growth rate than other cryptic species, as seen in the culture experiment (Chapter 4), reflecting its small proportion of total number of samples $(\sim 10 \%)$ in the area (Chapter 5). This current research was not only to clearly show eco-physiological differences between cryptic algal species, but also revealed the possibility of distinct physiology and ecological niches in promoting small- (sympatric coexistence) and large-scale distribution (Chapter 2) of cryptic algal species.

Further research should be focused on the physiological performance of other cryptic $B$. intricata species from other geographic range, for example, cryptic species N3 from subantarctic island, and species N7 and N8 from Australia, and to assess whether the physiological performance correlates with their geographic distribution. Additional projects could measure other physiological characters (e.g. photosynthetic capacity in different levels of desiccation and light intensity) among cryptic B. intricata, and this could help to improve the knowledge of physiological properties in cryptic algal species. Another possibility is to conduct a study of gene expression on genes that are supposed to be involved in physiological performance in different cryptic species of $B$. intricata. For 
example, two small heat shock protein-encoding genes (sHSPs) are involving in mechanism of heat resistance in unicellular red alga Cyanidioschyzon merolae Luca, Taddei \& Varano (Kobayashi et al. 2014). This study could help to better understand how genetic and physiological regulatory mechanisms contribute to the distribution and adaptation of cryptic algal species.

Sympatric occurrence of cryptic species of $B$. intricata was found in several populations in central New Zealand, and therefore another possibility could be to test whether the distribution of cryptic $B$. intricata species at different nearby locations exhibited the same pattern observed at Moa Point. Results of the study could advance our understanding of ecological phenomenon of sympatric coexistence of cryptic algal species at the small scale. 


\section{REFERENCES}


Adams, N. M. 1994. Seaweed of New Zealand. University press, Christchurch, Canterbury, $360 \mathrm{pp}$.

Airoldi, L. \& Virgilio, M., 1998. Responses of turf-forming algae to spatial variations in the deposition of sediments. Mar. Ecol. Prog. Ser. 165: 271-282.

Allcock, A. L. \& Strugnell J. M. 2012. Southern Ocean diversity: new paradigms from molecular ecology. Trends Ecol. Evol. 27: 520-528.

Amato, A., Kooistra, W. H. C. F., Levialdi Ghiron, J. H., Mann, D. G., Proschold, T. \& Montresor, M. 2007. Reproductive isolation among sympatric cryptic species in marine diatoms. Protist. 158: 193-207.

Apte, S. \& Gardner, J. P. A. 2002. Population subdivision in the New Zealand greenshell mussel (Perna canaliculus) inferred from single-strand conformation polymorphism analysis of mitochondrial DNA. Mol. Ecol. 11: 1617-1635.

Ayers, K. L. \& Waters, J. M. 2005. Marine biogeographic disjunction in central New Zealand. Mar. Biol. 147: 1045-1052.

Avise, J. C. 2000. Phylogeography: the history and formation of species. Harvard University Press, Cambridge, 447 pp.

Barraclough, T. G. \& Nee, S. 2001. Phylogenetics and speciation. Trends Ecol. Evol. 16: 391-99.

Bartoli, G., Sarnthein, M., Weinelt, M., Erlenkeuser, H., Garbe-Schonberg, D. \& Lew, D. W. 2005. Final closure of Panama and the onset of northern hemisphere glaciation. Earth Planet. Sc. Lett. 237: 33-44.

Bassam, B. J., Caetano-Anollés, G. \& Gresshoff, P.M. 1991. Fast and sensitive silver staining of DNA in polyacrylamide gels. Anal. Biochem. 196: 80-83. 
Beheregaray, L. B. and Caccone, A. 2007. Cryptic biodiversity in a changing world. J. Biol. 6: 1-5.

Benzie, J. A. H., Ballment, E. \& Edyvane, K. 2000. Allozymes as genetic identification markers of Sargassum spp. (Phaeophyta) from the Great Barrier Reef, Australia. Bot. Mar. 43: $169-179$.

Bhattacharya, D., Elwood, H. J., Goff, L. J. \& Sogin, M. L. 1990. Phylogeny of Gracilaria lemaneiformis (Rhodophyta) based on sequence analysis of its small subunit ribosomal rna coding region. J. Phycol. 26: 181-186.

Bickford, D., Lohman, D. J., Sodhi, N. S., Ng, P. K. L., Meier, R., Winker, K., Ingram, K. K. \& Das, I. 2007. Cryptic species as a window on diversity and conservation. Trends Ecol. Evol. 22: 148-155.

Boo, G. H., Mansilla' A., Nelson, W., Bellgrove, A. \& Boo, S. M. 2014. Genetic connectivity between trans-oceanic populations of Capreolia implexa (Gelidiales, Rhodophyta) in cool temperate waters of Australasia and Chile. Aqua. Bot. 119: 73-79.

Brante, A., Fernández, M. \& Viard, F. 2012. Phylogeography and biogeography concordance in the marine gastropod Crepipatella dilatata (Calyptraeidae) along the southeastern Pacific coast. J. Hered. 103: 630-7.

Breeman, A. M. 1988. Relative importance of temperature and other factors in determining geographic boundaries of seaweeds: experimental and phenological evidence. Helgol. Meeresunters. 42: 199-241.

Broderick, M. E. and Dawes, C. J. 1998. Seasonal photosynthetic and respiratory responses of the red alga Bostrychia tenella (Ceramiales, Rhodophyta) from a salt marsh and mangal. Phycologia. 37: 92-99. 
Brodie, J. \& Zuccarello, G. C. 2007. Systematics of the species-rich algae: red algal classification, phylogeny and speciation. In Hodkinson, T. R. \& Parnell, J. A. N. [Eds.] Reconstructing the Tree of Life: Taxonomy and Systematics of Species Rich Taxa. Systematics Association Special Volume Series 72, CRC Press, Florida, USA, pp. 323336.

Brookfield, J. 2002. Quick guide: fitness. Curr. Biol. 12: R717.

Brokaw, N. \& Busing R. T. 2000. Niche versus chance and tree diversity in forest gaps. Trends Ecol. Evol. 15: 183-188.

Buchanan, J. \& Zuccarello, G. C. 2012. Decoupling of short- and long-distance dispersalpathways in the endemic New Zealand seaweed Carpophyllum maschalocarpum (Phaeophyceae, Fucales). J. Phycol. 48: 518-529.

Bush, G. L. 1975. Modes of animal speciation. Annu. Rev. Ecol. Syst. 6: 339-64.

Carstens, B. C., Pelletier, T. A., Reid, N. M. \& Satler, J. D. 2013. How to fail at species delimitation. Mol. Ecol. 22: 4369-4383.

Chen, G. \& Hare, M. P. 2008. Cryptic ecological diversification of a planktonic estuarine copepod, Acartia tonsa. Mol. Ecol. 17: 1451-1468.

Cho, G. Y., Kogame, K. Kawaii, H. \& Boo, S. M. 2007. Genetic diversity of Scytosiphon lomentaria (Scytosiphonaceae, Phaeophyceae) from the pacific and Europe based on RuBisCo large subunit and spacer, and ITS nrDNA sequences. Phycologia 46: 657-665.

Clement, M., Posada, D. \& Crandall, K. A. 2000. TCS: a computer program to estimate gene genealogies. Mol. Ecol. 9: 657-1659.

Coyne, J. A. \& Orr, H. A. 2004. Speciation. Sinauer Associations, Massachusetts, 545 pp. 
Collins, C. J., Fraser, C. I., Ashcroft, A. \& Waters, J. M. 2010. Asymmetric dispersal of southern bull-kelp (Durvillaea antarctica) adults in coastal New Zealand: testing an oceanographic hypothesis. Mol. Ecol. 19: 4572-4580.

Cracraft, Joel. 1983. Species concepts and speciation analysis. In Johnston, R. F. [Ed.] Current Ornithology. Plenum Press, New York, pp. 159-187.

Cumming, R. A., Nikula, R., Spencer, H. G. \& Waters, J. M. 2014. Transoceanic genetic similarities of kelp-associated sea slug populations: long-distance dispersal via rafting. $J$. Biogeogr. 41: 2357-2370.

Degerlund, M., Huseby, S., Zingone, A., Sarno, D. and Landfald, B. 2012. Functional diversity in cryptic species of Chaetoceros socialis Lauder (Bacillariophyceae). J. Plankton Res. 34: 416-431.

Dellicour, S. \& Mardulyn, P. 2014. SPADS 1.0: a toolbox to perform spatial analyses on DNA sequence data sets. Mol. Ecol. Resour. 14: 647-651.

Dennis, A. B. \& Hellberg, M. E. 2010. Ecological partitioning among parapatric cryptic species. Mol. Ecol. 19: 3206-3225.

De Queiroz, K. 2007. Species concepts and species delimitation. Syst. Biol. 56: 879886.

De Troch, M., Fiers, F. \& Vincx, M. 2003. Niche segregation and habitat specialisation of harpacticoid copepods in a tropical seagrass bed. Mar. Biol. 142: 345-355

Drummond, A. J., Suchard, M. A., Xie, D. \& Rambaut, A. 2012. Bayesian phylogenetics with BEAUti and the BEAST 1.7. Molecular Biology and Evolution 29: 1969-1973.

Dupanloup, I., Schneider, S. \& Excoffier, L. 2002. A simulated annealing approach to define the genetic structure of populations. Mol. Ecol. 11: 2571-2581. 
Excoffier, L. \& Lischer, H. E. L. 2010. Arlequin suite ver 3.5: A new series of programs to perform population genetics analyses under Linux and Windows. Mol. Ecol. Resour. 10: 564-567.

Felsenstein, J. 2006. Accuracy of coalescent likelihood estimates: Do we need more sites, more sequences, or more loci? Mol. Biol. Evol. 23: 691-700.

Fraser, C. I., Hay, C. H., Spencer, H. G. \& Waters, J. M. 2009b. Genetic and morphology analyses of the southern bull kelp Durvillaea antarctica (Phaeophyceae: Durvillaeles) in New Zealand reveal cryptic species. J. Phycol. 45: 436-443.

Fraser, C. I., Nikula, R., Ruzzante, D. E. \& Waters, J. M. 2012. Poleward bound: biological impacts of Southern Hemisphere glaciation. Trends Ecol. Evol. 27: 462-471.

Fraser C. I., Nikula R., Spencer H. G. \& Waters J. M. 2009c. Kelp genes reveal effect of subantarctic sea ice during the Last Glacial Maximum. Proc. Natl. Acad. Sci. USA 106: 3249-3253.

Fraser, C. I., Nikula, R. \& Waters, J. M. 2011. Oceanic rafting by a coastal community. Proc. Biol. Sci. 278: 649-655.

Fraser, C. I., Spencer H. G. \& Waters, J. M. 2009a. Glacial oceanographic contrasts explain phylogeography of Australian bull kelp. Mol. Ecol. 18: 2287-2296.

Fraser C. I., Winter D. J., Spencer H. G. \& Waters J. M. 2010. Multigene phylogeny of the southern bull-kelp Durvillaea (Phaeophyceae: Fucales). Mol. Phylo. Evol. 57: 1301-1311.

Fraser C. I., Zuccarello G. C., Spencer H. G., Salvatore L.C., Carcia G. R. \& Waters J. M. 2013 Genetic affinities between trans-oceanic populations of non-buoyant macroalgae in the high latitudes of the Southern Hemispheres. PLOS One 8: e69138

Freeland, J. R. 2005. Molecular Ecology. John Wiley \& Sons, Chichester, 400 pp. 
Freshwater, D. W., Fredericq, S., Butler, B. S., Hommersand, M. H. \& Chase, M. W. 1994. A gene phylogeny of the red algae (Rhodophyta) based on plastid rbcL. Proc. Natl. Acad. Sci. USA 91: 7281-7285.

Freshwater, D. W. \& Rueness, J. 1994. Phylogenetic relationships of some European Gelidium (Gelidiales, Rhodophyta) species based on $r b c \mathrm{~L}$ nucleotide sequence analysis. Phycologia 33: 187-194.

Fujita, M. K., Leaché, A. D., Burbrink, F. T. Mcguire, J. A. \& Moritz, C. 2012. Coalescent-based species delimitation in an integrative taxonomy. Trends Ecol. Evol. 27: $480-488$.

Garham, J. A., Wilcox, L. W. \& Garham L. E. 2009. Algae. 2nd ed. Benjamin Cummings, San Francisco, California, 616 pp.

Gause, G. F. 1932. Experimental studies on the struggle for existence. J. Exp. Biol. 9: $389-402$.

Gause, G. F. 1934. The struggle for existence. Williams and Wilkins, Baltimore, Maryland, $192 \mathrm{pp}$.

Gillespie, R. G. \& Roderick, G. K. 2002. Arthropods on islands: colonization, speciation and conservation. Ann. Rev. Entomol. 47: 595-632.

Goff, L. J. \& Coleman, A. W. 1988. The use of plastid DNA restriction endonuclease patterns in delineating red algal species and populations. J. Phycol. 24: 357-368.

Goldstien, S. J., Schiel, D. R. \& Gemmell N. J. 2006. Comparative phylogeography of coastal limpets across a marine disjunction in New Zealand. Mol. Ecol. 15: 3259-3268.

Grant, W. S. \& Bowen, B. W. 1998. Shallow population histories in deep evolutionary lineages of marine fishes: insights from sardines and anchovies and lessons for conservation. Heredity 89: 415-426. 
Guillemin, M. L., Valero, M., Faugeron, S., Nelson, W. \& Destombe, C. 2014. Tracing the Trans-Pacific Evolutionary History of a domesticated seaweed (Gracilaria chilensis) with Archaeological and Genetic Data. PLOS One. 9: e114039.

Hardin, G. 1960. The competitive exclusion principle. Science. 131: 1292-1297.

Harley, C. D. G. \& Helmuth, B. S. T. 2003. Local and regional-scale effects of wave exposure, thermal stress, and absolute versus effective shore level on patterns of intertidal zonation. Limnol. Oceanogr. 48: 1498-1508.

Harper, J. T. \& Saunders, G. W. 2001. The application of sequences of the ribosomal cistron to the systematics and classification of the florideophyte red algae (Florideophyceae, Rhodophyta). Cah. Biol. Mar. 42: 25-38.

Harpending, H.C. 1994. Signature of ancient population growth in a low-resolution mitochondrial DNA mismatch distribution. Hum. Biol. 66: 591-600.

Hart, M. W. \& Sunday, J. 2007. Thing fall apart: biological species from unconnected parsimony networks. Biol. Lett. 3: 509-512.

Hassold, N. J. C., Rea, D. K., Pluijm, B. A. \& Pares, J. M. 2009. A physical record of the Antarctic Circumpolar Current: Late Miocene to recent slowing of abyssal circulation. Palaeogeogr. Palaeocl. 275: 28-36.

Hayakawa, Y., Ogawa, T., Yoshikawa, S., Ohki, K. \& Kamiya, M. 2012. Genetic and ecophysiological diversity of Cladophora (Cladophorales, Ulvophyceae) in various salinity regimes. Phycol. Res. 60: 86-97.

Hemmer-Hansen, J., Nielsen, E. E., Gronkjaer, P. \& Loeschcke, V. 2007.

Evolutionary mechanisms shaping the genetic population structure of marine fishes; lessons from the European flounder (Platichthys flesus L.). Mol. Ecol. 16: 3104-3118

Hewitt, G. M. 2004. Genetic consequences of climatic oscillations in the Quaternary. Philos. Trans. R. Soc. Lond. B 359: 183-195. 
Hey, J., Waples, R. S., Arnold, M. L., Butlin, R. K. \& Harrison, R. G. 2003.

Understanding and confronting species uncertainty in biology and conservation. Trends Ecol. Evol. 18: 597-603.

Howard, D. A. \& Berlocher, S. H. 1998. Endless Forms: Species and Speciation. Oxford University Press, Oxford, 496 pp.

Hurd, C. L., Harrison, P. J., Bischof, K. and Lobban, C. S. 2014. Seaweed Ecology and Physiology. 2nd ed. Cambridge University Press, Cambridge, 562 pp.

Inomata, N., Wang, X. R., Changtragoon, S. \& Szmidt A. F. 2009. Level and patterns of DNA variation in two sympatric mangrove species, Rhizophora apiculata and $R$. mucronata from Thailand. Genes Genet. Syst. 84: 277-286.

Jobb, G., Von Haeseler, A. \& Strimmer, K. 2004. TREEFINDER: a powerful graphical analysis environment for molecular phylogenetics. BMC Evol. Biol. 4: 18.

Jone, T. C., Gemmill C. E. C. \& Pilditch, C. A. 2008. Genetic variability of New Zealand seagrass (Zostera muelleri) assessed at multiple spatial scale. Aqua. Bot. 88: 3946.

Kamiya, M. \& West, J. A. 2014. Cryptic diversity in the euryhaline red alga Caloglossa ogasawaraensis (Delesseriaceae, Ceramiales). Phycologia. 53: 374-82.

Kamiya, M., West, J. A., King, R. J., Zuccarello, G. C., Tanaka, J. \& Hara, Y. 1998. Evolutionary divergence in the red algae Caloglossa leprieurii and C. apomeiotica. J. Phycol. 34: 361-370.

Kamiya, M. 2004. Speciation and biogeography of the Caloglossa leprieurii complex (Delesseriaceae, Rhodophyta). J. Plant Res. 5: 421-428.

Kamiya, M., Zuccarello, G. C. \& West, J. A. 2004. Phylogeography of Caloglossa leprieurii and related species (Delesseriaceae, Rhodophyta) based on the $r b c \mathrm{~L}$ gene sequences. Jap. J. Phycol. (Supplementary) 52: 147-151. 
Karsten, U., Koch, S., West, J. A. and Kirst, G. O. 1994a. The intertidal red alga Bostrychia simpliciuscula Harvey ex J. Agardh from a mangrove swamp in Singapore: acclimation to light and salinity. Aquat. Bot. 48: 313-323.

Karsten, U., Koch S., West, J. A. \& Kirst, G. O. 1996. Physiological responses of the eolittoral macroalga Stictosiphonia hookeri (Rhodomelaceae, Rhodophyta) from Argentina and Chile: salinity, light and temperature acclimation. Eur. J. Phycol. 31: $361-368$.

Karsten, U., West, J. A. \& Ganesan, E. K. 1993. Comparative physiological ecology of Bostrychia moritziana (Ceramiales, Rhodophyta) from freshwater and marine habitats. Phycologia. 32: 401-409.

Karsten, U., West J. A. \& Zuccarello, G. C.1992. Polyol content of Bostrychia and Stictosiphonia (Rhodomelaceae, Rhodophyta) from field and culture. Bot. Mar. 35: 11-20.

Karsten, U., West, J. A., Zuccarello, G. \& Kirst, G. O. 1994b. Physiological ecotypes in the marine red alga Bostrychia radicans (Ceramiales, Rhodophyta) from the east coast of the USA. J. Phycol. 30: 174-182.

King, R. \& Puttock, C. 1989. Morphology and taxonomy of Bostrychia and Stictosiphonia (Rhodomelaceae/ Rhodophyta. Austral. Syst. Bot. 2: 1-73.

Knowlton, N. 2000. Molecular genetic analyses of species boundaries in the sea. Hydrobiologia. 420: 73-90.

Knox, G. A. 2001. The ecology of seashores. CRC Press, Boca Raton, Florida, 557 pp.

Kobayashi, Y., Harada, N., Nishimura, Y., Saito, T., Nakamura, M., Fujiwara, T., Kuroiwa, T. \& Misumi, O. 2014. Algae Sense Exact Temperatures: Small Heat Shock Proteins Are Expressed at the Survival Threshold Temperature in Cyanidioschyzon merolae and Chlamydomonas reinhardtii. Genome Biol. Evol. 6: 2731-2740. 
Krueger-Hadfield, S. A., Roze, D., Mauger, S. \& Valero, M. 2013. Inter-gametophytic selfing and microgeographic genetic structure shape populations of the intertidal red seaweed Chondrus crispus. Mol. Ecol. 22: 3242-3260.

Lai, C. H., Morley, S. A., Tan, K. S. \& Peck, L. S. 2011. Thermal niche separation in two sympatric tropical intertidal Laternula (Bivalvia: Anomalodesmata). J. Exp. Mar. Biol. Ecol. 405: 68-72.

Lane, C. E., Mayes, C., Druehl, L. D. \& Saunders, G. W. 2006. A multi-gene molecular investigation of the kelp (Laminariales, Phyophyceae) supports substantial taxonomic reorganization. J. Phycol. 42: 493-512.

Leasi, F., Tang, C. Q., De Smet, W. H. \& Fontaneto, D. 2013. Cryptic diversity with wide salinity tolerance in the putative euryhaline Testudinella clypeata (Rotifera, Monogononta). Zool. J. Linn. Soc. 168: 17-28.

Lee, C. E. 2000. Global phylogeography of a cryptic copepod species complex and reproductive isolation between genetically proximate "populations". Evolution. 54: 20142027.

Le Gall, L. \& Saunders, G. W. 2010. DNA barcoding is a powerful tool to uncover algal diversity: a case study of the Phyllophoraceae (Gigartinales, Rhodophyta) in the Canadian flora. J. Phycol. 46: 374-389.

Leliaert. F., Verbruggen, H., Vanormelingen, P., Steen, F., Lopez-Bautista, J. M., Zuccarello, G. C. \& De Clerck, O. 2014. DNA-based species delimitation in algae. Eur. J. Phycol. 49: 179-196.

Le Port, A. \& Lavery, S. 2012. Population structure and phylogeography of the short-tailed stingray, Dasyatis brevicaudata (Hutton 1875), in the Southern Hemisphere. J. Hered. 103: 174-185.

Levinton, J. S. 2013. Marine biology: function, biodiversity, ecology. 4th ed. Oxford University press, New York, 576 pp. 
Lewis, J. R. 1964. The ecology of rocky shores. English Universities Press, London, 323 pp.

Librado, P. \& Rozas, J. 2009. DnaSP v5: A software for comprehensive analysis of DNA polymorphism data. Bioinformatics 25: 1451-1452.

Lim, G. S., Balke, M. \& Meier, R. 2011. Determining species boundaries in a world full of rarity: singletons, species delimitation methods. Syst. Biol. 61: 165-169.

Lindstrom, S. C. 2008. Cryptic diversity and phylogenetic relationships within the Mastocarpus papillatus species complex (Rhodophyta, Phyllophoraceae). J. Phycol. 44: $1300-1308$.

Liu, J., Möller, M., Gao, L. M., Zhang, D. Q. \& Li, D. Z. 2011. DNA barcoding for the discrimination of Eurasian yews (Taxus L., Taxaceae) and the discovery of cryptic species. Mol. Ecol. Resour. 11: 89-100.

Lomolino, M. V., Riddle B. R. \& Brown, J. H. 2006. Biogeography. 3rd ed. Sinauer Association, Sunderland, Massachusetts, 845 pp.

Lynch, M. 2010. Evolution of the mutation rate. Trends Genet. 26: 345-352.

Macaya, E. C. \& Zucarello, G. C. 2010a. DNA barcoding and genetic divergence in the giant kelp Macrocystis (Laminariales). J Phycol. 46:736-742.

Macaya, E. C. \& Zuccarello, G. C. 2010b. Genetic structure of the giant kelp Macrocystis pyrifera along the southern Pacific. Mar. Ecol. Prog. Ser. 420: 103-112.

Madesis, P., Ganopoulos, I. \& Tsaftaris A. 2013. Microsatellites: evolution and contribution. Methods Mol. Biol. 1006: 1-13. 
Martin P. \& Zuccarello G. C. 2012. Molecular phylogeny and timing of radiation in Lessonia (Phaeophyceae, Laminariales). Phycol. Res. 60: 276-287.

Mayr, E. 1942. Systematics and the Origin of Species. Columbia University Press, New York, $372 \mathrm{pp}$.

Mayr, E. 1963. Animal Species and Evolution.Belknap Press of Harvard University Press, Cambridge, Massachusetts, 797 pp.

McCourt, R. M. 1984. Niche differences between sympatric Sargassum species in the northern Gulf of California. Mar. Ecol. Prog. Ser. 18: 139-148.

McGarigal, K., Cushman, S. A. \& Stafford, S. G. 2000. Multivariate Statistics for Wildlife and Ecology Research. Springer-Verlag, New York, 283 pp.

Mcloughlin, S. 2001. The breakup history of Gondwana and its impact on pre - Cenozoic floristic provincialism. Austral. J. Bot. 49: 271-300.

Mikheyev, S. A., Vo, T. \& Mueller, U. G. 2008. Phylogeography of post-Pleistocene population expansion in a fungus-gardening ant and its microbial mutualisms. Mol. Ecol. 17: 4480-4488.

Mishler, B. D. \& Brandon, R. N. 1987. Individuality, pluralism, and the phylogenetic species concept. Biol. Philos. 2: 397-414.

Montecinos, A., Broitman, B. R., Faugeron, S., Haye, P. A., Tellier, F. \& Guillemin, M. 2012. Species replacement along a linear coastal habitat: phylogeography and speciation in the red alga Mazzaella laminarioides along the south east pacific. BMC Evol. Biol. 12:97.

Mostaert, A. S., Karsten, U. and King, R. J. 1995. Physiological responses of Caloglossa leprieurii (Ceramiales, Rhodophyta) to salinity stress. Phycol. Res. 43: 215222. 
Nam, K. W., Maggs, C. A., Mclvor, L. \& Stanhope, M. J. 2000. Taxonomy and phylogeny of Osmundea (Rhodomelaceae, Rhodophyta) in Atlantic Europe. J. Phycol. 36: 759-772.

Nielsen, K. J., Blanchette, C. A. Menge, B. A. \& Lubchenco, J. 2006. Physiological snapshots reflect ecological performance of the sea palm, Postelsia palmaeformis (Phaeophyceae) across intertidal elevation and exposure gradients. J. Phycol. 42: 548-559.

Nikula, R., Fraser, C. I., Spencer, H. G. \& Waters, J. M. 2010. Circumpolar dispersal by rafting in two subantarctic kelp-dwelling crustaceans. Mar. Ecol. Prog. Ser. 405: 221-230.

Niwa, K., Kikuchi, N., Hwang, M. S., Choi, H. G. \& Aruga, Y. 2014. Cryptic species in the Pyropia yezoensis complex (Bangiales, Rhodophyta): sympatric occurrence of two cryptic species even on same rocks. Phycol. Res. 62: 36-43.

Odum, E. P. 1959. Fundamentals of ecology. 2nd ed. W. B. Saunders Co. Philadelphia, Pennsylvania, 546 pp.

Orfanidis, S., Venekamp, L. A. H. \& Breeman, A. 1999. Ecophysiological adaptations of two Mediterranean red algae in relation to distribution. Eur. J. Phycol. 34: $469-476$.

Papadopoulou, A., Monaghan, M. T., Barraclough, T. G. \& Vogler, A. P. 2009. Sampling error does not invalidate the Yule-coalescent model for species delimitation. A response to Lohse (2009). Syst. Biol. 58: 442-444.

Parfrey, L. W., Lahr, D. J. G., Knoll, A. H. \& Katz, L. A. 2011. Estimating the timing of early eukaryotic diversification with multigene molecular clocks. Proc. Natl Acad. Sci. USA 108: 13624-13629.

Payo, D. A., Leliaert, F., Verbruggen, H., D’hondt, S., Calumpong, H. P. \& De Clerck, O. 2013. Extensive cryptic species diversity and fine scale-scale endemism in the marine red alga Portieria in the Philippines. P. Roy. Soc. B. - Biol. Sci. 280: 20122660. 
Phillips, N., Burrows, R., Rousseau, F., De Reviers, B. \& Saunders, G. W. 2008 Resolving evolutionary relationships among the brown algae using chloroplast and nuclear genes. $J$. Phycol. 44: 394-405.

Phooprong, S., Ogawa, H. and Hayashizaki, K. 2007. Photosynthetic and respiratory responses of Gracilaria salicornia (C Ag) Dawson (Gracilariales, Rhodophyta) from Thailand and Japan. J. Appl. Phycol. 19: 795-80.

Pons, J., Barraclough, T. G., Gomez-Zurita, J., Cardoso, A., Duran, D. P., Hazell, S., Kamoun, S., Sumlin, W. D. \& Vogler, A. P. 2006. Sequence - based species delimitation for the DNA taxonomy of undescribed insects. Syst. Biol. 55: 595-609.

Post, E. 1936. Sytematische und pflanzengeographische Notizen zur BostrychiaCaloglossa Assoziation. Revue Algologie 9: 1-84.

Puillandre, N., Lambert, A., Brouillet, S. \& Achaz, Z. 2012. ABGD, automatic barcode gap discovery for primary species delimitation. Mol. Ecol. 21: 1864-1877.

Racey, P. A., Barratt, E. M., Burland, T. M., Deaville, R., Gotelli, D., Jones, G. \& Piertney, S. B. 2007. Microsatellite DNA polymorphism confirms reproductive isolation and reveals differences in population genetic structure of cryptic pipistrelle bat species. Biol. J. Linn. Soc. 90: 539-50.

Rambaut, A. 2009. FigTree. v1.3.1. Available at: http://tree.bio.ed.ac.uk/software (last accessed 27 March 2014).

Rambaut, A. \& Drummond, A. J. 2009. Tracer v1.5. http://beast.bio.ed.ac.uk/tracer (last accessed 1 March 2014).

Ronquist, F. \& Huelsenbeck, J. P. 2003. MrBayes 3: bayesian phylogenetic inference under mixed model. Bioinformatics 19: 1572-1574. 
Ronquist, F., Teslenko, M., van der Mark, P., Ayres, D. L., Darling, A., Höhna, S., Larget, B., Liu, L., Suchard, M. A. \& Huelsenbeck, J. P. 2012. MRBAYES 3.2: Efficient Bayesian phylogenetic inference and model selection across a large model space. Syst. Biol. 61: 539-542.

Ross, P. M., Hogg, I. D., Pilditch, C. A. \& Lundquist, C. J. 2009. Phylogeography of New Zealand's coastal benthos. N. Z. J. Mar. Freshwater Res. 43: 1009-1027.

Ross, P. M., Hogg, I. D., Pilditch, C. A., Lundquist, C. J. \& Wilkins, R. J. 2012. Population genetic structure of the New Zealand estuarine clam Austrovenus stutchburyi (Bivalvia: Veneridae) reveals population subdivision and partial congruence with biogeographic boundaries. Estuar. Coast. 35: 143-154.

Ryder, K., West, J. A. and Nicholls, D. 1999 Effects of initial enrichment of nitrogen and phosphorus on Bostrychia and Caloglossa (Ceramiales, Rhodophyta) growth using digital imaging. Phycol. Res. 47: 39-51.

Sale P. F. 1982. Stock-recruit relationships and regional coexistence in a lottery competitive system: a simulation study. Amer. Nat. 120: 139-159.

Sampoya, E. M., Franceschinis, L., Hoegh-Guldberg, O. \& Dove, S. 2007. Niche partitioning of closely related symbiotic dinoflagellates. Mol. Ecol. 16: 3721-3733

Saunders, G.W. 2005. Applying DNA barcoding to red macroalgae: a preliminary appraisal holds promise for future applications. Philos. Trans. R. Soc. Lond. B. Biol. Sci. 360: 1879-1888.

Saunders, G. W. 2009. Routine DNA barcoding of Canadian Gracilariales (Rhodophyta) reveals the invasive species Gracilaria vermiculophylla in British Columbia. Mol. Ecol. Resour. 9: 140-150.

Schneider, S., Roessli, D. \& Excoffier, L 2000. Arlequin: a software for population genetic data. Genetics and Biometry Laboratory, University of Geneva, Switzerland. 
Schneider, K. R. \& Helmuth, B. 2007. Spatial variability in habitat temperature may drive patterns of selection between an invasive and native mussel species. Mar. Ecol. Prog. Ser. 339: 157-167.

Schweikert, K., Sutherland, J. E., Burritt, D. J. \& Hurd, C. L. 2012. Analysis of spatial and temporal diversity and distribution of Porphyra (Rhodophyta) in southeastern New Zealand supported by the use of molecular tools. J. Phycol. 48: 530-538.

Scrosati, R. \& Mudge, B. 2004. Effects of elevation, wave exposure, and year on the proportion of gametophytes and tetrasporophytes in Mazzaella parksii (Rhodophyta, Gigartinaceae) populations. Hydrobiologia. 520: 199-205.

Sharyn, J. G., Schiel, D. R. \& Gemmell, N. J. 2006. Comparative phylogeography of coastal limpets across a marine disjunction in New Zealand. Mol. Ecol. 15: 3259-3268.

Shaw, J. 2001. Biogeographic patterns and cryptic speciation in bryophytes. $J$. Biogeogr. 28: 253-261.

Shears, N. T., Smith, F., Babcock, R. C., Duffy, C. A. \& Villouta, E. 2008. Evaluation of biogeographic classification schemes for conservation planning: application to New Zealand's coastal marine environment. Conserv. Biol. 22: 467-481.

Sherwood, A. R., Kurihara, A., Conklin, K. Y., Sauvage, T. \& Presting, G. G. 2010. The Hawaiian Rhodophyta biodiversity survey (2006-2010): a summary of principal findings. BMC Plant Biol. 10: 1-29.

Short, A. D. \& Woodroffe, C. D. 2009. The coast of Australia. Cambridge University Press, New York, 302 pp.

Silberfeld T., Bittner L., Fernández - Garćia C., Cruaud C., Rousseau F., Reviers B., Leliaert F., Payri C.E. \& De Clerck O. 2013. Species diversity, phylogeny and large scale biogeographic patterns of the genus Padina (Phaeophyceae, Dictyotales). J. Phycol. 49: $130-142$. 
Silva, P. C., Basson, P. W. \& Moe, R. L. 1996. Catalogue of the benthic marine algae of the Indian Ocean. Univ. Calif. Publ. Bot. 79: 1-1259.

Silvertown, J. 2004. Plant coexistence and the niche. Trends Ecol. Evol. 19: 605-611. Silvertown, J. \& Law, R. 1987. Do plants need niches? Some recent development in plant community ecology. Trends Ecol. Evol. 2: 24-26.

Silvestro, D. \& Michalak I. 2012. raxmlGUI: a graphical front-end for RAxML. Org. Divers. Evol. 12: 335-337.

Škaloud, P. \& Rindi, F. 2013. Ecological differentiation of cryptic species within an asexual protist morphospecies: a case study of filamentous green alga Klebsormidium (Streptophyta). J. Eukaryot. Microbiolo. 60: 350-362.

Smith, B. T., Bryson Jr, R. W., Chua, V., Africa, L. \& Klicka, J. 2013. Speciational history of North American Haemorhous finches (Aves: Fringillidae) inferred from multilocus data. Mol. Phylo. Evol. 66: 1055-1059.

Smith, P. J., McMillan, P. J., Bull, B., McVeagh, S. M., Gaffney, P. M., \& Chow, S. 2002. Genetic and meristic variation in black and smooth oreos in the New Zealand Exclusive Economic Zone. N. Z. J. Mar. Freshwater. Res. 36: 737-50.

Spocer, R. \& Roy, M. S. 2002. Phylogeographic analysis of the brooding brittle star Amphipholis squamata (echinodermata) along the coast of New Zealand reveals high cryptic genetic variation and cryptic dispersal potential. Evolution 56: 1954-1967.

Suggate, R. P. \& Almond P. C. 2005. The Last Glacial Maximum (LGM) in western South Island, New Zealand: implications for the global LGM and MIS 2. Quat. Sci. Rev. 24: 16-17.

Tajima, F. 1989. Statistical method for testing the neutral mutation hypothesis by DNA polymorphism. Genetics 123: 585-595. 
Tanane, A. S. 2008. Phylogears. v2.0. http://www.fifthdimension.jp/ (last accessed 1 October 2013).

Tanabe, A. S. 2011. Kakusan4 and Aminosan: two programs for comparing nonpartitioned, proportional and separate model for combined molecular phylogenetic analyses of multilocus sequence data. Mol. Ecol. Resour. 11: 914-921.

Tronholm, A., Sanson, M., Afonso-Carrillo, J., Verbruggen, H. \& De Clerck, O. 2010. Niche partitioning and the coexistence of two cryptic Dictyota (Dictyotales, Phaeophyceae) species from the Canary Island. J. Phycol. 46: 1075-1087.

Tokeshi, M. 1999. Species coexistence: ecological and evolutionary perspectives. Blackwell Science, Oxford, 454 pp.

Uddstrom, M. J. \& Oien, N. A. 1999. On the use of high-resolution satellite data to describe the spatial and temporal variability of sea surface temperatures in the New Zealand region. J. Geophys. Res. 104: 20729-20751.

Underwood, A. J. \& Jernakoff, P. 1984. The effects of tidal height, wave-exposure, seasonality and rock-pools on grazing and the distribution of intertidal macroalgae in New South Wales. J. Exp. Mar. Biol. Ecol. 75: 71-96.

Veale, A. J. \& Lavery S. D. 2012. The population genetic structure of the intertidal waratah anemone (Actinia tenebrosa) around New Zealand. N. Z. J. Mar. Freshwater Res. 46: 523-536.

Verbruggen, H. 2014. Morphological complexity, plasticity, and species diagnosability in the application of old species names in DNA-based taxonomies. J. Phycol. 50: 26-31.

Vieira, C., D’hondt, S., De Clerck, O. \& Payri, C. E. 2014. Toward an inordinate fondness for stars, beetles and lobophora? Species diversity of the genus Lobophora (Dictyotales, Phaeophyceae) In New Caledonia. J. Phycol. 50: 1101-1119. 
Yang, M. Y., Geraldino, P. J. L. \& Kim, M. S. 2013. DNA barcode assessment of Gracilaria salicornia (Gracilariaceae, Rhodophyta) from Southeast Asia. Bot. Stud. 54: 27.

Yoshida, T., Nakajima, Y. \& Nakata, Y. 1990. Check - list of marine algae of Japan. Jap. J. Phycol. 38: 269-320.

Wallis, G. P. \& Trewick, S. A. 2009. New Zealand phylogeography: evolution on a small continent. Mol. Ecol. 18: 3548-3580.

Wang, X. L., Zhao, F. J., Hu, Z. M., Critchley, A. T., Morrell, S. L. \& Duan D. L. 2008. Inter-simple sequence repeat (ISSR) analysis of genetic variation of Chondrus crispus populations from North Atlantic. Aqua. Bot. 88: 154-159.

Watanabe, Y., Nishihara, G.N., Tokunaga, S. and Terada, R. 2014. The effect of irradiance and temperature on the photosynthesis of a cultivated red alga, Pyropia tenera (=Porphyra tenera), at the southern limit of distribution in Japan. Phycol Res. 62: 187196.

Waters, J. M. \& Roy, M. S. 2003. Marine biogeography of southern Australia: phylogeographical structure in a temperate sea-star. J. Biogeor. 30: 1787-1796.

Waters, J. M., Fraser, C. I. \& Hewitt G. M. 2013. Founder takes all: densitydependent processes structure biodiversity. Trends Ecol. Evol. 28: 78-85.

West, J. A., Loiseaux de Goër, S. \& Zuccarello, G. C. 2013. Monosiphonous growth and cell-death in an unusual Bostrychia (Rhodomelaceae, Rhodophyta): B. anomala sp. nov. Algae. 28: 161-171.

West, J. A. \& McBride, D. L. 1999. Long-term and diurnal carpospore discharge patterns in the Ceramiaceae, Rhodomelaceae and Delesseriaceae (Rhodophyta). Hydrobiologia. 298/299: 101-113. 
West, J. A., Zuccarello, G. C. \& Karsten, U. 1996. Reproductive biology of Stictosiphonia hookeri (Rhodomelaceae, Rhodophyta) from Argentina, Chile, South Africa and Australia in laboratory culture. Hydrobiologia. 326/327: 277-282.

Westram, A. M., Jokela, J. \& Keller, I. 2013. Hidden biodiversity in an ecologically important freshwater amphipod: differences in genetic structure between two cryptic species. PLOS One. 8:e69576.

White, T. L., Adams, W. T. \& Neale, D. B. 2007. Forest genetics. CABI Publication, Cambridge, 692 pp.

Wiens, J. J. 2007. Species delimitation: new approaches for discovering diversity. Syst. Biol. 56: 875-878.

Wiens, J. J. \& Graham, C. H. 2005. Niche conservation: Integrating evolution, ecology, and conservation biology. Annu. Rev. Ecol. Evol. Syst. 36: 519-539.

Xu, J., De Barro, P. J. and Liu S. S. 2010. Reproductive incompatibility among genetic groups of Bemisia tabaci supports the proposition that the whitefly is a cryptic species complex. B. Entomol Res. 100: 359-366.

Zardi, G. I., Nicastro, K. R., Canovas, F., Costa, J. F. Serrão, E. A. \& Pearson, G. A. 2011. Adaptive traits are maintained on steep selective gradients despite flow and hybridization in the intertidal zone. PLOS One 6: e19402.

Zhang, D. Y., Lin, K. \& Hanski, I. 2004. Coexistence of cryptic species. Ecol. Lett. 7: $165-16$.

Zuccarello, G. C., Buchanan, J. \& West, J. A. 2006. Increased sampling for inferring phylogeographic patterns in Bostrychia radicans/Bostrychia moritziana in the eastern USA. J. Phycol. 42: 1349-1352. 
Zuccarello, G. C., Muangmai, N., Preuss, M., Sanchez, L. B., Loiseaux de Goër, S. \& West, J. A. 2015. The Bostrychia tenella species complex: morphospecies and genetic cryptic species with resurrection of B. binderi. Phycologia (in press).

Zuccarello, G. C., Sandercock, B. \& West, J. A. 2002. Diversity within red algal species: variation in world-wide samples of Spyridia filamentosa (Ceramiaceae) and Murrayella periclados (Rhodomelaceae) using DNA markers and breeding studies. Eur. J. Phycol. 37: 403-18.

Zuccarello, G. C., Buchanan, J., West, J. A. \& Pedroche, F. F. 2011. Genetic diversity of the mangrove-associated alga Bostrychia radicans / B. moritziana (Ceramiales, Rhodophyta) from southern Central America. Phycol. Res. 59: 98-104.

Zuccarello, G. C., Moon, D. \& Goff, L. J. 2004. A phylogenetic study of parasitic genera placed in the family Choreocolacaceae (Rhodophyta). J. Phycol. 40: 937-945.

Zuccarello, G. C., Schidlo, N., Mclvor, L. \& Guiry, M. D. 2005. A molecular reexamination of speciation in the intertidal red alga Mastocarpus stellatus (Gigartinales, Rhodophyta) in Europe. Eur. J. Phycol. 40: 337-344.

Zuccarello, G. C. \& West, J. A. 2002. Phylogeography of the Bostrychia calliptera/B. pinnata complex (Rhodomelaceae, Rhodophyta) and divergence rates based on nuclear, mitochondrial and plastid DNA markers. Phycologia 41: 49-60.

Zuccarello G. C. \& West J. A. 2003. Multiple cryptic species: molecular diversity and reproductive isolation in the Bostrychia radicans/B. moritzia complex (Rhodomelaceae, Rhodophyta) with focus on North American Isolates. J. Phycol. 39: 948-959.

Zuccarello G.C. \& West J.A. 2006. Molecular phylogeny of the subfamily Bostrychioideae (Ceramiales, Rhodophyta): subsuming Stictosiphonia and highlighting polyphyly in species of Bostrychia. Phycologia 45: 24-36. 
Zuccarello G. C. \& West J. A. 2008. Bostrychia (Rhodomelaceae, Rhodophyta) species of New Zealand, and relationships in the Southern Hemisphere. N. Z. J. Mar. Freshwater Res. 42: $315-324$.

Zuccarello G. C. \& West J. A. 2011. Insights into evolution and speciation in the red alga Bostrychia. 15 years of research. Algae 26: 3-14.

Zuccarello, G. C., West, J. A., Kamiya M. \& King R.J. 1999b. A rapid method to score plastid haplotypes in red seaweeds and its use in determining parental inheritance of plastid in the red alga Bostrychia (Ceramiales). Hydrobiologia 401: 207-214.

Zuccarello, G. C., West, J. A. \& King, R. J. 1999a. Evolutionary divergence in the Bostrychia moritziana/B. radicans complex (Rhodomelaceae, Rhodophyta): molecular and hybridization data. Phycologia 38: 234-244.

Zuccarello, G. C., Yeates, P. H., Wright, J. T. and Bartlett, J. 2001. Population structure and physiological differentiation of haplotypes of Caloglossa leprieurii (Rhodophyta) in a mangrove intertidal zone. J. Phycol. 37: 235-244.

Zuccarello, G. C., Yoon, H. S., Kim, H., Sun, L., Loiseaux De Goër, S. \& West, J. A. 2011. Molecular phylogeny of the upright Erythropeltidales (Compsopogonophyceae, Rhodophyta): Multiple cryptic lineages of Erythrotrichia carnea. J. Phycol. 47: 627-637. 
Appendices 
Appendix 2.1. Samples used in this study, including location, collection number, Genbank accession numbers

\begin{tabular}{|c|c|c|c|c|c|}
\hline \multirow[b]{2}{*}{ Species } & \multirow[b]{2}{*}{ Location } & \multirow[b]{2}{*}{ Collection No. } & \multicolumn{3}{|c|}{ GenBank accession numbers } \\
\hline & & & $r b c \mathrm{~L}$ & COI & LSU \\
\hline Bostrychia arbuscula Harvey & Brighton Beach, South Island, New Zealand & D335 & AY920845 & KM502795 & AY920894 \\
\hline B. arbuscula & Pohara Beach, South Island, New Zealand & $\mathrm{P} 01$ & KM502822 & KM502797 & KM502847 \\
\hline B. arbuscula & Moa Point, North Island, New Zealand & M084 & KM502821 & KM502796 & KM502846 \\
\hline B. calliptera (Montagne) Montage & Sontecomapan, Vera Cruz, Mexico & C4300.MX & KM502840 & KM502815 & - \\
\hline B. calliptera & Cali, Columbia & C3191.CO & KM502841 & KM592816 & - \\
\hline $\begin{array}{l}\text { B. gracilis (King \& Puttock) } \\
\text { Zuccarello \& West }\end{array}$ & Taranaki, North Island, New Zealand & T01 & KM502824 & KM502798 & KM502849 \\
\hline B. gracilis & Maraehako Bay, North Island, New Zealand & Mtk055 & KM502823 & KM502797 & KM502848 \\
\hline $\begin{array}{l}\text { B. intricata (Bory de Saint - } \\
\text { Vincent) Montagne }\end{array}$ & Kommetjie, Cap Province, South Africa & 2875 & KM502825 & KM502799 & KM502850 \\
\hline B. intricata & Kommetjie, Cap Province, South Africa & 2876 & KM502826 & KM502800 & KM502851 \\
\hline B. intricata & Umhlanga Rocks KwaZulu Natal, South Africa & 4557 & KM502827 & KM502801 & KM502852 \\
\hline B. intricata & Concepción, Bío Bío, Chile & Chl008 & KM502834 & KM502808 & KM502859 \\
\hline B. intricata & Concepción, Bío Bío, Chile & Chl009 & KM502835 & KM502809 & KM502860 \\
\hline B. intricata & Auckland Island & W01 & KM502836 & KM502810 & KM502861 \\
\hline B. intricata & Campbell Island & Cab011 & KM502837 & KM502811 & KM502862 \\
\hline B. intricata & Whiskey Bay, Victoria, Australia & 3472 & KM502831 & KM502805 & KM502856 \\
\hline B. intricata & Narooma, New South Wales, Australia & Anr589 & KM502832 & KM502806 & KM502857 \\
\hline
\end{tabular}




\begin{tabular}{|c|c|c|c|c|c|}
\hline B. intricata & Batemans, New South Wales, Australia & Abt598 & KM502833 & KM502807 & KM502858 \\
\hline B. intricata & Manukua Harbor, North Island, New Zealand & Mnu 165 & KM502838 & KM502812 & KM502863 \\
\hline B. intricata & Pohara Beach, South Island, New Zealand & Phr411 & KM502839 & KM502813 & KM502864 \\
\hline B. intricata & Castle Point, North Island, New Zealand & Cas026 & KM502828 & KM502802 & KM502853 \\
\hline B. intricata & Kapiti Coast, North Island, New Zealand & Kap144 & KM502829 & KM502803 & KM502854 \\
\hline B. intricata & Moa Point, North Island, New Zealand & Moa011 & KM502830 & KM502804 & KM502855 \\
\hline $\begin{array}{l}\text { B. moritziana (Sonder ex Kützing) } \\
\text { J. Agardh }\end{array}$ & Farasan Island, Saudi Arabia & Sab4069 & AY920816 & KM502788 & AY920867 \\
\hline $\begin{array}{l}\text { B. simpliciuscula Harvey ex J. } \\
\text { Agardh }\end{array}$ & Forster, New South Wales, Australia & 3562 & AY920827 & KM502789 & AY920877 \\
\hline B. tenella (Lamouroux) J.Agardh & Mangrove Trail, Broome, Western Australia & 3743 & AY920838 & KM502790 & AY920888 \\
\hline B. vaga Hooker \& Harvey & Millers Landing, Victoria, Australia & 3781 & KM502819 & KM502793 & KM502844 \\
\hline B. vaga & Campbell Island & Cab010 & KM502817 & KM502791 & KM502842 \\
\hline B. vaga & Auckland, North Island, New Zealand & Auc01 & KM502820 & KM502794 & KM502845 \\
\hline B. vaga & Gentle Annie Beach, South Island, New Zealand & Gta527 & KM502818 & KM502792 & KM502843 \\
\hline
\end{tabular}


Appendix 2.2. Substitution rate calculated between an Atlantic (C3400.MX) and a Pacific (C3191.CO) isolate of B. calliptera using the calibration time of the estimated final closure of the Isthmus of Panama (2.5 - 3.0 Mya).

\begin{tabular}{ccccccc}
\hline & $\begin{array}{c}\text { Number of } \\
\text { base pairs }\end{array}$ & $\begin{array}{c}\text { Number of difference } \\
\text { between sequences }\end{array}$ & $p$ Distance & \% Divergence & $\begin{array}{c}\text { Substitutions } \\
\left(\text { site }^{-1} \text { year }^{-1}\right)\end{array}$ & $\begin{array}{c}\% \text { Divergence } \\
\left(\mathrm{Mya}^{-1}\right)\end{array}$ \\
\hline$r b c \mathrm{~L}$ & 1,163 & 3 & 0.00228 & 0.228 & $3.8-4.5 \times 10^{-10}$ & $0.038-0.045$ \\
$\mathrm{COI}$ & 638 & 5 & 0.0078 & 0.78 & $13-15 \times 10^{-10}$ & $0.13-0.15$ \\
\hline
\end{tabular}


Appendix 2.3. Genetic distance (\%) within and between lineages recognized by phylogenetic analyses and species delimitation approach of Bostrychia arbuscula, B. gracilis, B.intricata and B. vaga

\begin{tabular}{|c|c|c|c|c|c|c|c|c|c|c|c|c|c|c|}
\hline$r b c \mathrm{~L}$ & BA & BG & N1 & N2 & N3 & N4 & N5 & N6 & N7 & N8 & V1 & V2 & V3 & V4 \\
\hline B. arbuscula (BA) & $0-0.08$ & & & & & & & & & & & & & \\
\hline B. gracilis (BG) & $4.0-4.1$ & $0-0.1$ & & & & & & & & & & & & \\
\hline B.intricata N1 & $6.7-6.9$ & $5.8-6.9$ & 0.3 & & & & & & & & & & & \\
\hline B.intricata $\mathrm{N} 2$ & $6.9-8$ & $6.3-8$ & $3.9-4.5$ & 0 & & & & & & & & & & \\
\hline B.intricata $\mathrm{N} 3$ & $7.2-7.4$ & $6.6-7.4$ & $2.6-3$ & $3.8-4$ & 0.3 & & & & & & & & & \\
\hline B.intricata $\mathrm{N} 4$ & $7.3-7.4$ & $6.8-7.5$ & $2.9-3.2$ & 4.2 & $0.1-0.5$ & 0 & & & & & & & & \\
\hline B.intricata N5 & $7.8-7.9$ & $6.1-7.8$ & $4.1-4.2$ & 1 & $4.2-4.4$ & 4.7 & 0 & & & & & & & \\
\hline B.intricata N6 & $6.7-7.8$ & $6.6-7.7$ & $3.3-3.6$ & $4-4.5$ & $3.6-3.8$ & $3.7-4$ & $4.2-4.7$ & $0.5-0.7$ & & & & & & \\
\hline B.intricata N7 & 6.2 & $5.8-6.2$ & $3.6-3.7$ & 2.4 & $3.8-4$ & 4.2 & 1.8 & $4.5-4.9$ & 0 & & & & & \\
\hline B.intricata $\mathrm{N8}$ & $7.7-7.8$ & $6.4-7.7$ & $4.3-4.4$ & 1.2 & 4.5 & 4.7 & 2.2 & $4.5-4.9$ & 2.4 & 0 & & & & \\
\hline B. vaga $\mathrm{V} 1$ & $9.2-9.3$ & $7.7-8.6$ & $8.2-8.3$ & $7.8-8.7$ & 8.9 & 9 & 8.5 & $8.3-8.6$ & 7.3 & 8.9 & 0 & & & \\
\hline B. vaga $\mathrm{V} 2$ & $5.6-5.7$ & $5.6-5.7$ & $5.8-5.9$ & $4.4-5.5$ & 5.8 & 6.3 & 5.5 & $5.9-5.2$ & 4.3 & 5.8 & 0.4 & 0 & & \\
\hline B. vaga $\mathrm{V3}$ & $9.7-9.9$ & $8.3-9.2$ & $9.2-9.3$ & $8.7-9.8$ & 10 & 10 & 9.5 & $8.9-9.6$ & 8.4 & 10 & 4 & 2 & 0 & \\
\hline B. vaga $\mathrm{V} 4$ & $8.2-8.3$ & $6.9-7.9$ & $7.6-7.7$ & $7.4-8.3$ & 8.4 & 8.2 & 8.1 & $7.5-8.2$ & 7.3 & 8.4 & 6.3 & 3.6 & 7.1 & 0 \\
\hline
\end{tabular}

B. arbuscula (BA) $\quad 0-0$

B. gracilis (BG) $\quad 8.7-9.3 \quad 0.2$

B.intricata N1 $12.4-13 \quad 13-13.6 \quad 0.2$

B.intricata N2 $\quad 14-14.6 \quad 15.1-15.6 \quad 9.6-10.1 \quad 0.2$

B.intricata N3 $\quad 13-13.3-13.6-13.8-6.3-6.6 \quad 9.6-9.8=0$

$\begin{array}{lllllll}\text { B.intricata N4 } & 14-14.6 & 13.8-14.3 & 7.2-8.2 & 9-9.8 & 3.7-4.2 & 1\end{array}$

$\begin{array}{llllllll}\text { B.intricata N5 } & 14.6-14.9 & 15.6-15.9 & 8.7-9 & 12.5-12.7 & 12.5-12.7 & 10.1-10.6 & 0\end{array}$

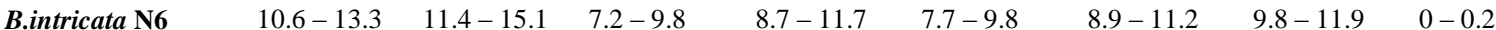

$\begin{array}{lllllllllll}\text { B.intricata N7 } & 14-14.3 & 15.1-15.4 & 8.5 & 11.7-11.9 & 11.7-11.9 & 10.6-11.1 & 4.2 & 8.9-11.2 & 0\end{array}$

$\begin{array}{llllllllllll}\text { B.intricata N8 } & 12.7-13 & 13.3-13.6 & 7.2-7.4 & 9.3-9.6 & 9-9.1 & 10.1-10.6 & 11.1 & 7.4-10.1 & 9.3 & 0\end{array}$ 


\begin{tabular}{|c|c|c|c|c|c|c|c|c|c|c|c|c|c|c|}
\hline B. vaga V1 & $18-18.3$ & $19.2-20.2$ & $14.8-15.5$ & $17.8-18.1$ & 15.6 & $16.1-15.9$ & 16.4 & $15.5-17.5$ & 15.4 & 16.4 & 0 & & & \\
\hline B. vaga $\mathrm{V} 2$ & $18.3-18.6$ & $20.2-20.5$ & $15.4-15.9$ & $18.3-18.6$ & 16.7 & $17.2-17.5$ & 18 & $15.1-18.3$ & 15.6 & 16.4 & 4.2 & 0 & & \\
\hline B. vaga $\mathrm{V3}$ & $16.1-16.4$ & $17-17.2$ & $12.5-12.7$ & $16.1-16.4$ & 14 & $14-14.3$ & 13.8 & $12.2-15.5$ & 14 & 14.3 & 10.9 & 11.7 & 0 & \\
\hline B. vaga $\mathrm{V} 4$ & $15.1-14.8$ & $14-14.3$ & $14.8-15.5$ & $15.1-15.4$ & 15.1 & $15.1-15.6$ & 14.3 & $13-16.4$ & 14 & 13.6 & 16.2 & 15.6 & 13.3 & 0 \\
\hline \multicolumn{15}{|l|}{ LSU } \\
\hline B. arbuscula (BA) & $0.1-0.8$ & & & & & & & & & & & & & \\
\hline B. gracilis (BG) & $2.3-2.7$ & 0.2 & & & & & & & & & & & & \\
\hline B.intricata N1 & $2.8-3.2$ & 2.1 & 0 & & & & & & & & & & & \\
\hline B.intricata $\mathrm{N} 2$ & $3-3.4$ & $1.8-1.9$ & 1.1 & 0 & & & & & & & & & & \\
\hline B.intricata $\mathrm{N} 3$ & $2.8-3.2$ & $2.1-2.2$ & $0-0.5$ & 1.1 & 0.5 & & & & & & & & & \\
\hline B.intricata $\mathrm{N} 4$ & $2.8-3.3$ & 2.1 & 0 & $1.2-1.3$ & $0-0.5$ & 0.1 & & & & & & & & \\
\hline B.intricata N5 & $3-3.4$ & 1.7 & 1.2 & 0.8 & $1.3-1.4$ & $1.3-1.4$ & 0 & & & & & & & \\
\hline B.intricata N6 & $1.7-4.5$ & $1.2-3.5$ & $1.1-2.6$ & $1.1-2.7$ & $1.1-2.7$ & $1.1-2.5$ & $1.1-2.8$ & $0.2-0.3$ & & & & & & \\
\hline B.intricata N7 & $2.9-3.3$ & 1.7 & 1.2 & 0.9 & $1.2-1.4$ & $1.2-1.3$ & 0.1 & $1-2.8$ & 0 & & & & & \\
\hline B.intricata $\mathrm{N8}$ & $3-3.5$ & $1.9-2.2$ & $1.3-1.5$ & $0.6-0.8$ & $1.3-1.7$ & $1.3-1.6$ & $0.8-1$ & $1-3$ & $0.7-0.9$ & 0.2 & & & & \\
\hline B. vaga V1 & $3.8-4.1$ & 3.1 & 3 & 2.6 & $3-3.2$ & 3 & 3.1 & $1.3-3.7$ & 3 & $2.9-3.1$ & 0 & & & \\
\hline B. vaga $\mathrm{V} 2$ & $3.6-4$ & 2.9 & 2.8 & 2.7 & $2.8-3$ & 2.8 & 3.2 & $1.3-3.6$ & 3.2 & $2.8-3$ & 0.2 & 0 & & \\
\hline B. vaga $\mathrm{V3}$ & $4.3-4.6$ & 3.6 & 3.2 & 3.2 & $3.3-3.4$ & $3.3-3.4$ & 3.4 & $1.5-3.8$ & 3.6 & $3.3-3.5$ & 1.1 & 1.4 & 0 & \\
\hline B. vaga V4 & $3.6-4$ & 3.1 & 2.8 & 3 & $2.8-3$ & 2.8 & 3 & $1.5-3.9$ & 2.9 & $2.7-2.8$ & 1.6 & 1.6 & 1.6 & 0 \\
\hline
\end{tabular}


Appendix 2.4. The appropriate DNA substitution models calculated through Kakusan 4 for $r b c \mathrm{~L}, \mathrm{COI}$ and LSU (without codon partition).

\begin{tabular}{lccc}
\hline & $1^{\text {st }}$ position & $2^{\text {nd }}$ position & $3^{\text {rd }}$ position \\
\hline AIC model selection & & & \\
\hline$r b c \mathrm{~L}$ & $\mathrm{GTR}+\mathrm{G}$ & $\mathrm{HKY} 85+\mathrm{G}$ & $\mathrm{GTR}+\mathrm{G}$ \\
COI & $\mathrm{HKY} 85+\mathrm{G}$ & $\mathrm{K} 80+\mathrm{G}$ & $\mathrm{HKY} 85+\mathrm{G}$ \\
LSU & & $\mathrm{GTR}+\mathrm{G}$ & \\
\hline BIC model selection & & & \\
\hline$r b c \mathrm{~L}$ & $\mathrm{GTR}+\mathrm{G}$ & $\mathrm{HKY} 85+\mathrm{G}$ & $\mathrm{K} 80+\mathrm{G}$ \\
$\mathrm{COI}$ & $\mathrm{K} 80+\mathrm{G}$ & $\mathrm{HKY} 85+\mathrm{G}$ & $\mathrm{HKY} 85+\mathrm{G}$ \\
LSU & & $\mathrm{GTR}+\mathrm{G}$ & \\
\hline
\end{tabular}


Appendix 2.5. Phylogenetic tree inferred from Bayesian Inference analyses of $r b c \mathrm{~L}$ data set for our Bostrychia species. Support values at each node are bootstrap values from ML (left) and Bayesian posterior probability (right). Asterisk $(*)$ indicates full support $(100 \%$, 1.0) in both analyses and hyphen (-) indicates no support.

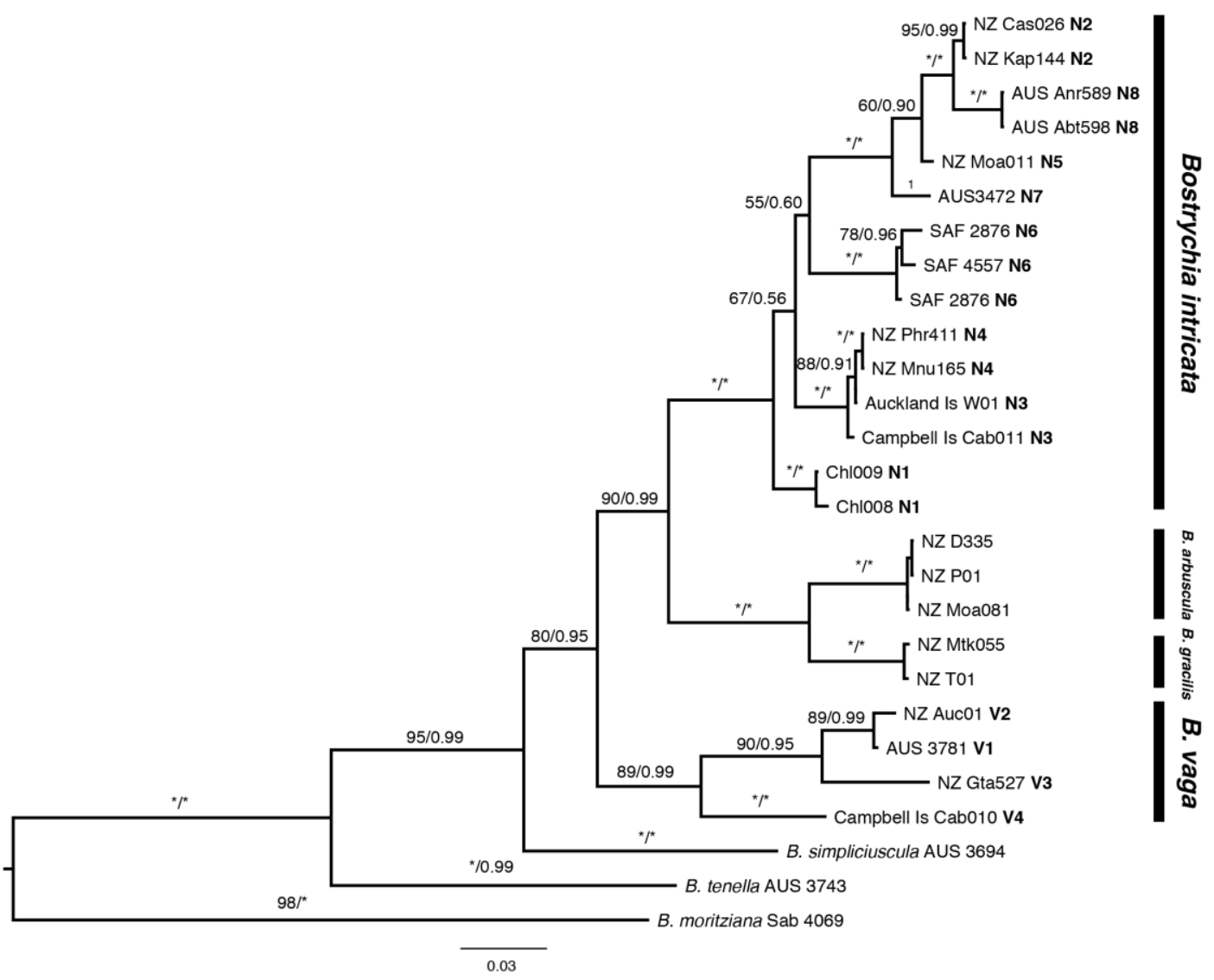


Appendix 2.6. Phylogenetic tree inferred from Bayesian Inference analyses of COI data set for our Bostrychia species. Support values at each node are bootstrap values from ML (left) and Bayesian posterior probability (right). Asterisk (*) indicates full support (100\%, 1.0) in both analyses and hyphen (-) indicates no support.

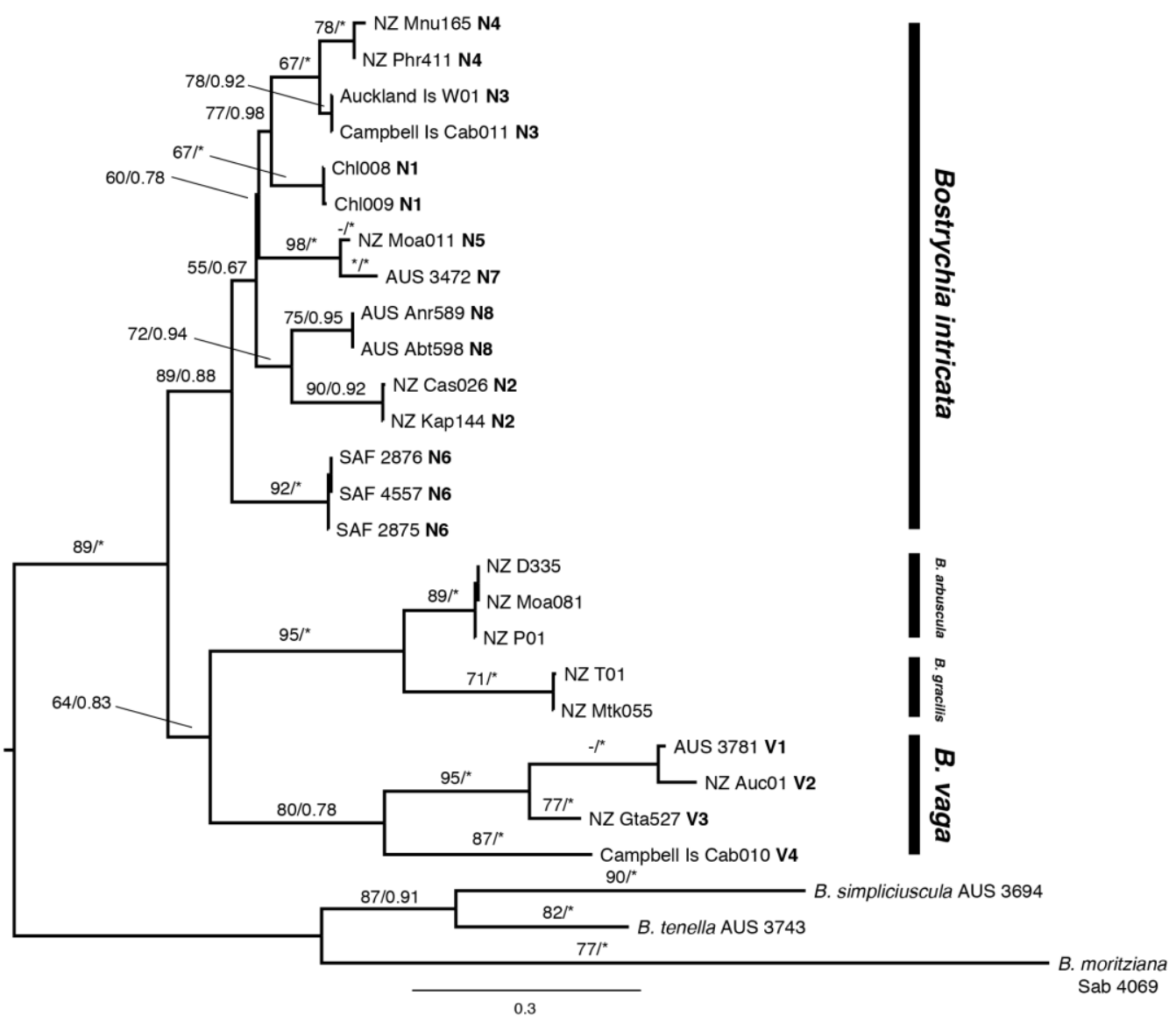


Appendix 2.7. Phylogenetic tree inferred from Bayesian Inference analyses of LSU data set for our Bostrychia species. Support values at each node are bootstrap values from ML (left) and Bayesian posterior probability (right). Asterisk $(*)$ indicates full support $(100 \%$, 1.0) in both analyses and hyphen (-) indicates no support.

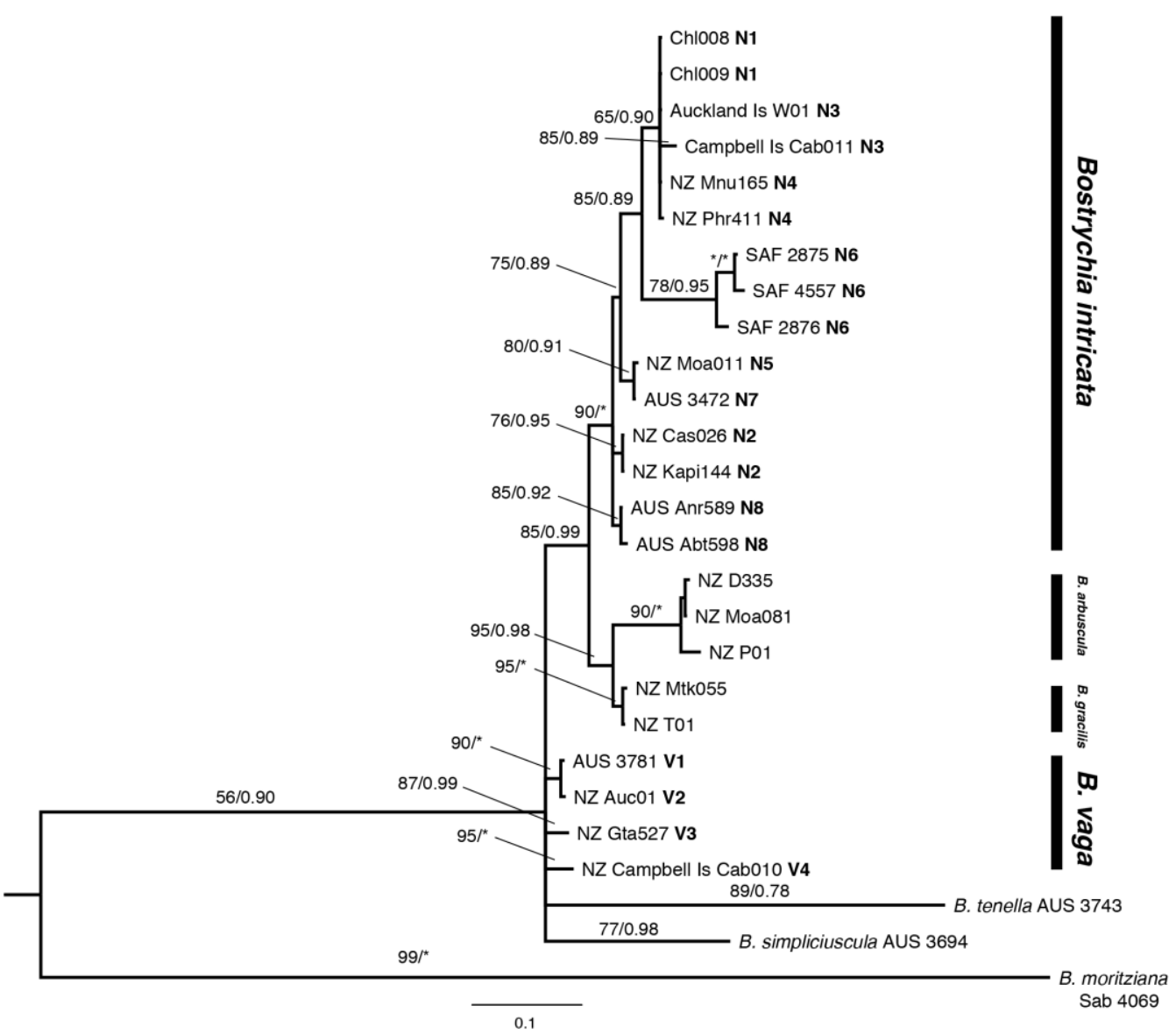


Appendix 2.8. GMYC-based species delimitation based on all COI haplotypes from this study and Fracer et al. (2013). The black bars and letters indicate the cryptic species obtained from this species delimitations method.

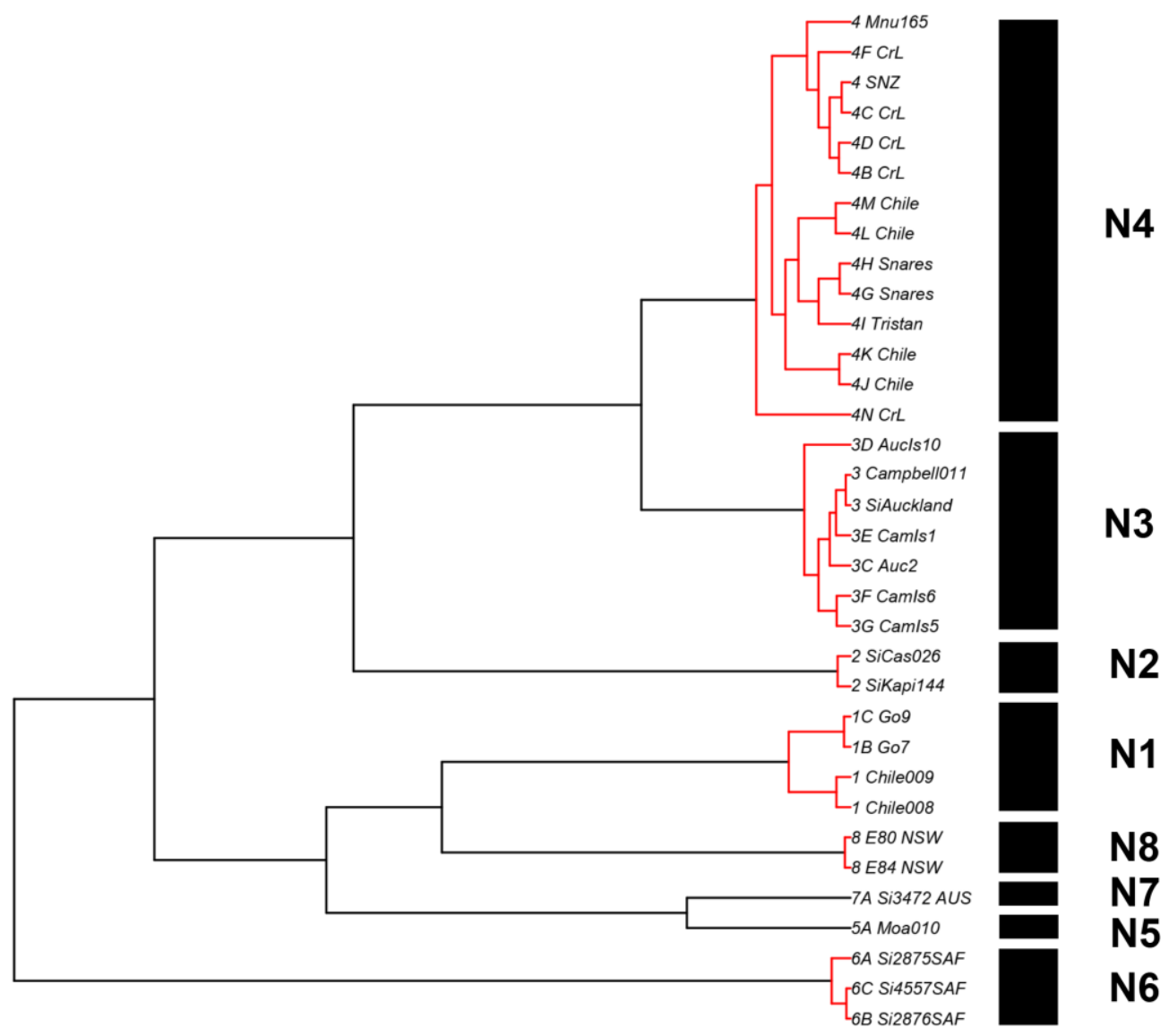


Appendix 3.1. Map of New Zealand showing regional hydrographic conditions. The north/south and west/east splits described by Apte \& Gardner (2002) and Shears et al. (2008) are separated by dashed line; western NI, western SI, eastern NI and eastern SI. CC: Cape Campbell; GOL: Golden Bay; NI: North Island and SI: South Island.

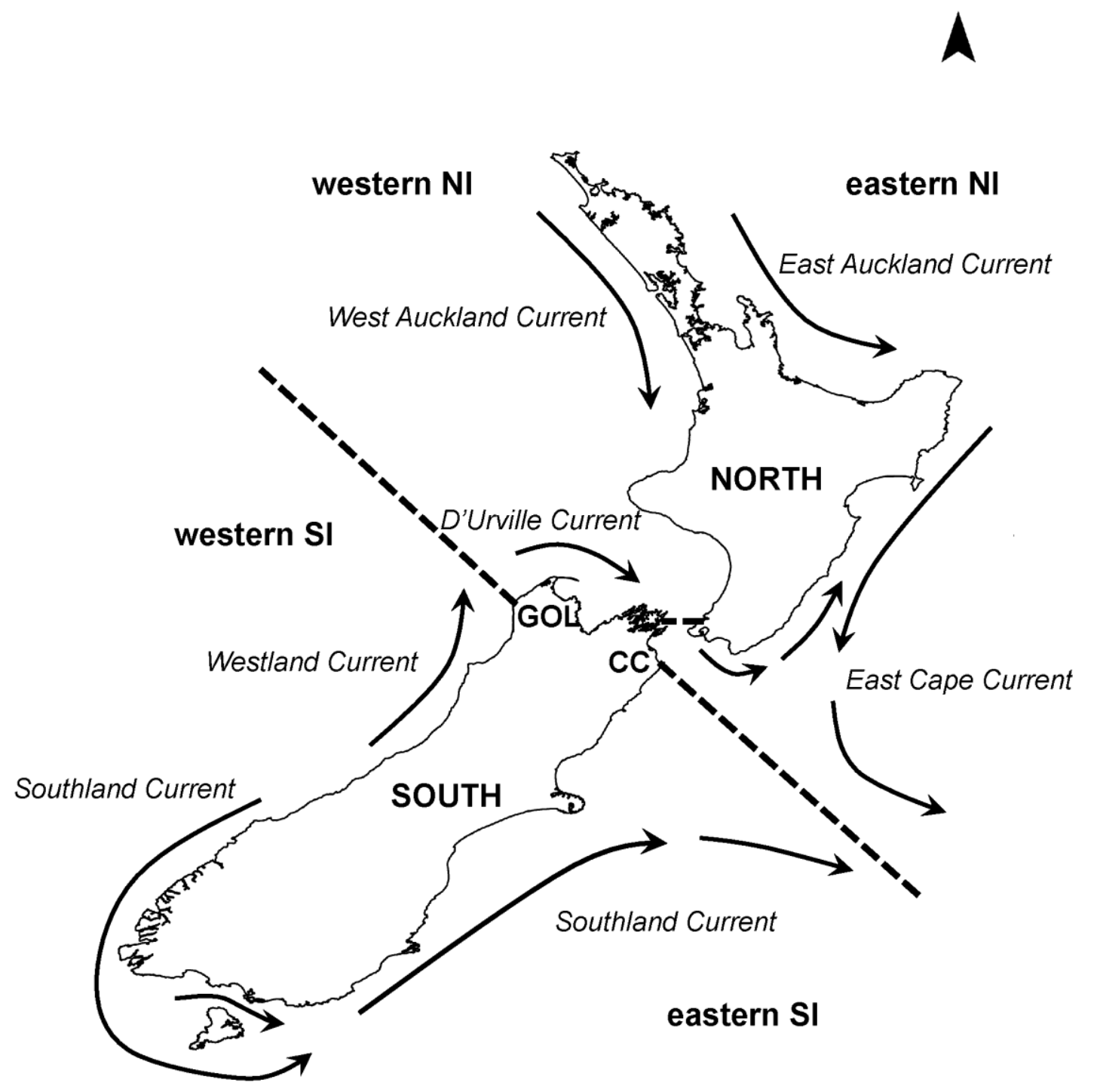


Appendix 3.2. Samples used for the phylogenetic analysis, and haplotype network, including location of sample, COI haplotype designation and Genbank Accession Number. Bold letters indicate new sequence generated in this study.

\begin{tabular}{|c|c|c|c|}
\hline Taxon & Location & Haplotype & $\begin{array}{l}\text { Accession } \\
\text { Number }\end{array}$ \\
\hline \multirow[t]{20}{*}{ Bostrychia intricata } & Falkland Island & $1 \mathrm{~A}$ & JN881519 \\
\hline & Gough Island & 1B & JN881518 \\
\hline & Gough Island & $1 \mathrm{C}$ & JN881517 \\
\hline & Tristan da Cunha & $1 \mathrm{D}$ & JN881516 \\
\hline & $\begin{array}{l}\text { Casnell Island, Leigh, North Island, New } \\
\text { Zealand }\end{array}$ & $2 \mathrm{~A}$ & KP791809 \\
\hline & $\begin{array}{l}\text { Moa Point, Wellington, North Island, } \\
\text { New Zealand }\end{array}$ & $2 \mathrm{~B}$ & JN881543 \\
\hline & $\begin{array}{l}\text { Titirangi Bay, Havelock, South Island, } \\
\text { New Zealand }\end{array}$ & $2 \mathrm{C}$ & KP791810 \\
\hline & $\begin{array}{l}\text { Waihau Bay, East Cape, North Island, } \\
\text { New Zealand }\end{array}$ & $2 \mathrm{D}$ & KP791811 \\
\hline & $\begin{array}{l}\text { Porangahua Beach, Hawke Bay, North } \\
\text { Island, New Zealand }\end{array}$ & $2 \mathrm{E}$ & KP791812 \\
\hline & Castle Point, North Island, New Zealand & $2 \mathrm{~F}$ & KP791813 \\
\hline & Castle Point, North Island, New Zealand & $2 \mathrm{G}$ & KP791814 \\
\hline & $\begin{array}{l}\text { Cabel Bay, Nelson, South Island, New } \\
\text { Zealand }\end{array}$ & $2 \mathrm{H}$ & KP791815 \\
\hline & $\begin{array}{l}\text { Cabel Bay, Nelson, South Island, New } \\
\text { Zealand }\end{array}$ & $2 \mathrm{I}$ & KP791816 \\
\hline & $\begin{array}{l}\text { Red Rock, Wellington, North Island, New } \\
\text { Zealand }\end{array}$ & $2 \mathrm{~J}$ & KP791817 \\
\hline & $\begin{array}{l}\text { Waihau Bay, East Cape, North Island, } \\
\text { New Zealand }\end{array}$ & $2 \mathrm{~K}$ & KP791818 \\
\hline & Campbell Island & $3 \mathrm{~A}$ & JN881535 \\
\hline & Auckland Island & $3 \mathrm{~B}$ & JN881533 \\
\hline & Auckland Island & $3 \mathrm{C}$ & JN881534 \\
\hline & Auckland Island & $3 \mathrm{D}$ & JN881532 \\
\hline & Canpbell Island & $3 \mathrm{E}$ & JN881539 \\
\hline
\end{tabular}




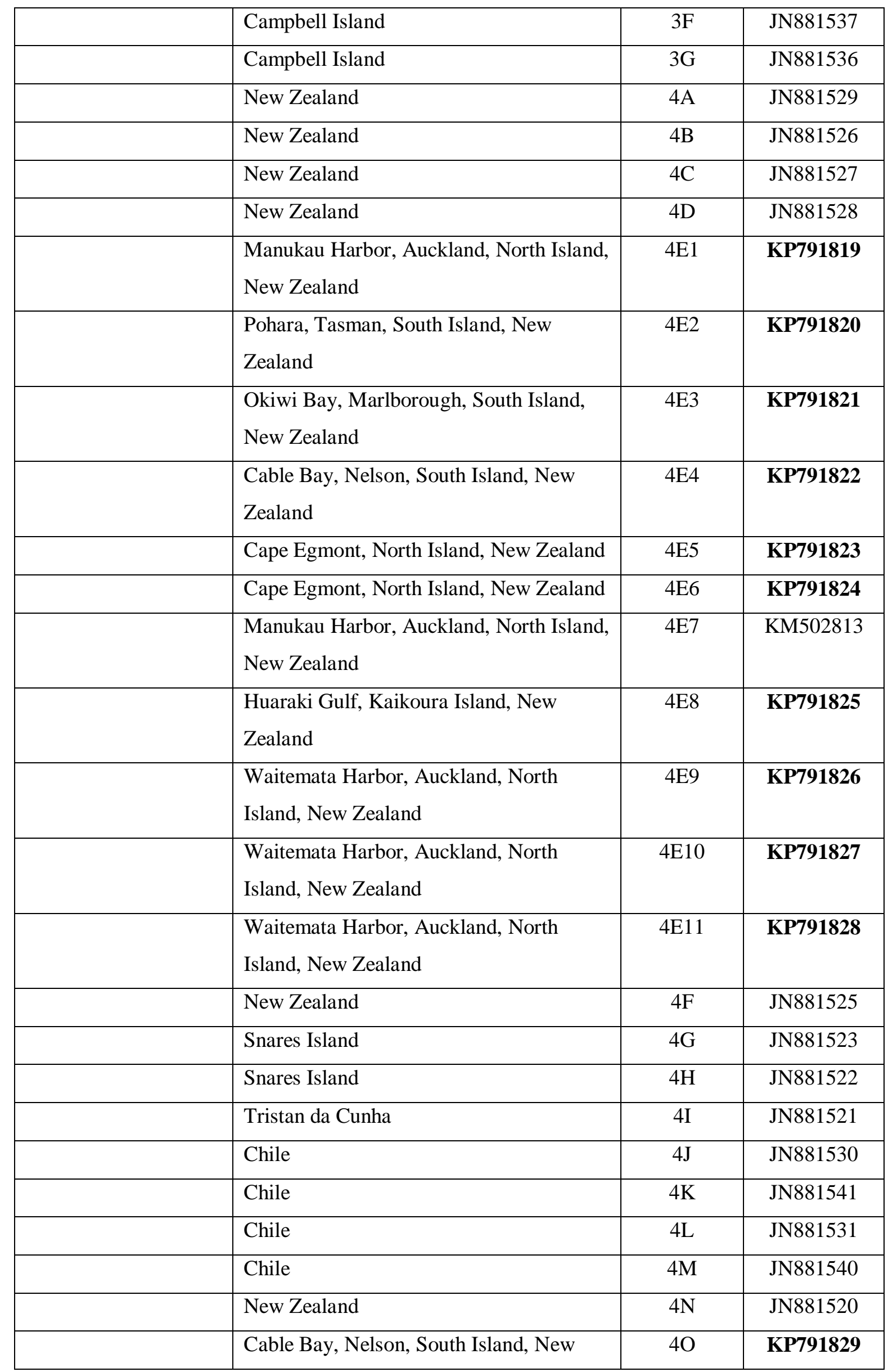




\begin{tabular}{|c|c|c|c|}
\hline & Zealand & & \\
\hline & $\begin{array}{l}\text { French Farm Bay, Akaroa, Bank } \\
\text { Peninsula, South Island, New Zealand }\end{array}$ & $4 \mathrm{P}$ & KP791830 \\
\hline & $\begin{array}{l}\text { Paparoa Point, Kaikoura, South Island, } \\
\text { New Zealand }\end{array}$ & $4 Q$ & KP791831 \\
\hline & $\begin{array}{l}\text { Waipatiki Beach, Hawke Bay, North } \\
\text { Island, New Zealand }\end{array}$ & $4 \mathrm{R}$ & KP791832 \\
\hline & $\begin{array}{l}\text { Waipatiki Beach, Hawke Bay, North } \\
\text { Island, New Zealand }\end{array}$ & $4 \mathrm{~S}$ & KP791833 \\
\hline & $\begin{array}{l}\text { Charleston, Westport, South Island, New } \\
\text { Zealand }\end{array}$ & $4 \mathrm{~T}$ & KP791834 \\
\hline & $\begin{array}{l}\text { Charleston, Westport, South Island, New } \\
\text { Zealand }\end{array}$ & $4 \mathrm{U}$ & KP791835 \\
\hline & $\begin{array}{l}\text { Charleston, Westport, South Island, New } \\
\text { Zealand }\end{array}$ & $4 \mathrm{~V}$ & KP791836 \\
\hline & $\begin{array}{l}\text { Gentle Antie seaside, Westport, South } \\
\text { Island, New Zealand }\end{array}$ & $4 \mathrm{~W}$ & KP791837 \\
\hline & $\begin{array}{l}\text { Gibson Beach, Cape Foulwind, Westport, } \\
\text { South Island, New Zealand }\end{array}$ & $4 \mathrm{X}$ & KP791838 \\
\hline & $\begin{array}{l}\text { Wharariki Beach, Puponga, South Island, } \\
\text { New Zealand }\end{array}$ & $4 \mathrm{Y}$ & KP791834 \\
\hline & $\begin{array}{l}\text { Moa Point, Wellington, North Island, } \\
\text { New Zealand }\end{array}$ & $5 \mathrm{~A}$ & KM502804 \\
\hline & $\begin{array}{l}\text { Kenupuru Bay, Haverock, South Island, } \\
\text { New Zealand }\end{array}$ & 5B & KP791808 \\
\hline & Kommetjie, Cap Province, South Africa & $6 \mathrm{~A}$ & KM502799 \\
\hline & Kommetjie, Cap Province, South Africa & $6 \mathrm{~B}$ & KM502800 \\
\hline & $\begin{array}{l}\text { Umhlanga Rocks KwaZulu Natal, South } \\
\text { Africa }\end{array}$ & $6 \mathrm{C}$ & KM502801 \\
\hline & Whiskey Bay, Victoria, Australia & $7 \mathrm{~A}$ & KM502805 \\
\hline & Narooma, New South Wales, Australia & $8 \mathrm{~A}$ & KM502806 \\
\hline Bostrychia gracilis & Taranaki, North Island, New Zealand & & KM502798 \\
\hline Bostrychia arbuscula & $\begin{array}{l}\text { Brighton Beach, South Island, New } \\
\text { Zealand }\end{array}$ & & KM502795 \\
\hline Bostrychia vaga & Auckland, North Island, New Zealand & & KM502794 \\
\hline
\end{tabular}


Appendix 3.3. Phylogenetic tree inferred from Bayesian Inference analyses of COI data set for Bostrychia intricata. Support values at each node are bootstrap values from ML bootstrap (left) and Bayesian Posterior Probability (right). Asterisk (*) indicates full support $(100 \%, 1.0)$ in both analyses and a hyphen (-) indicates no support. Bold letters at each branch tip refer to haplotypes found in this study. H: Haplotype; NZ: New Zealand.

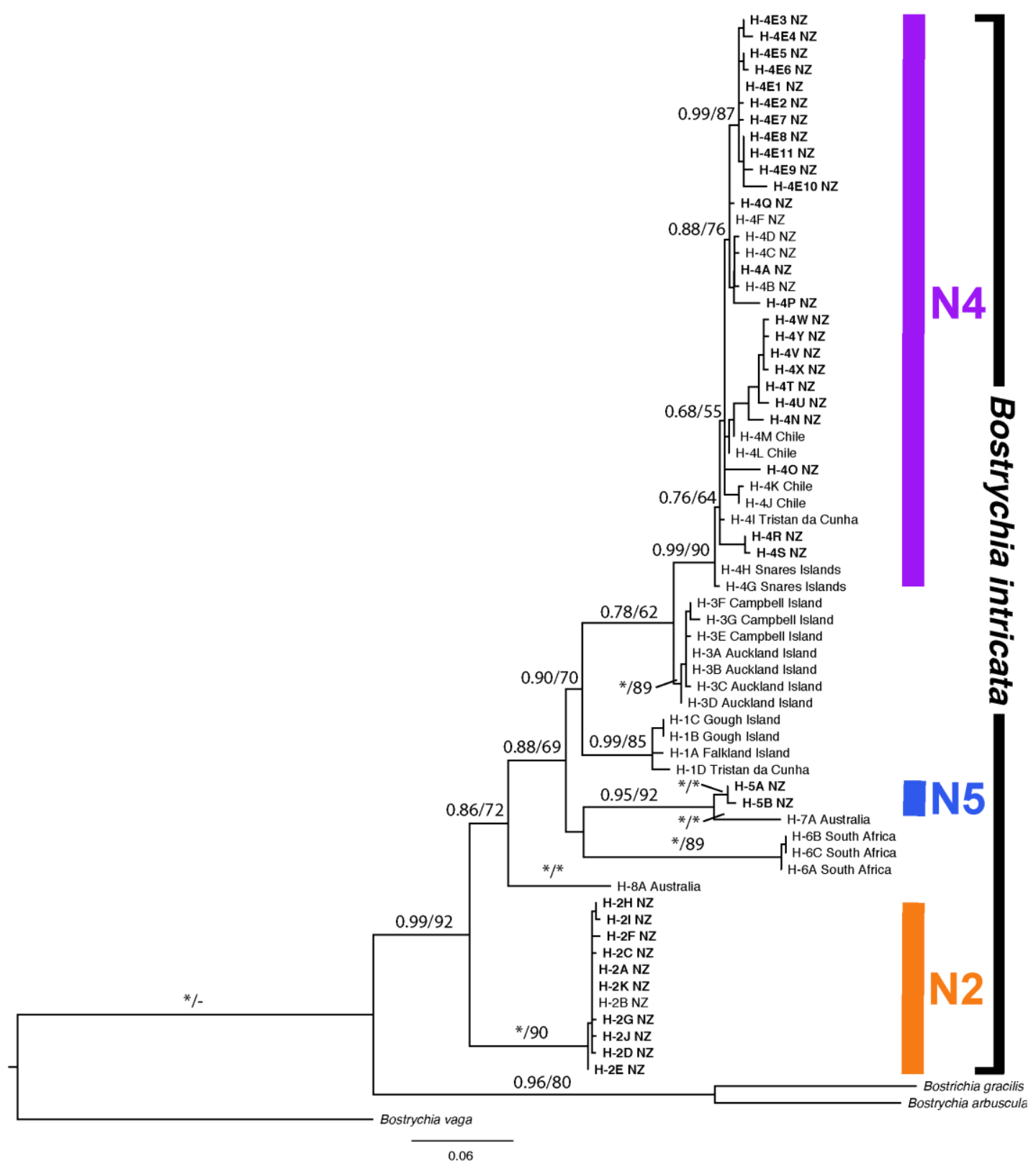


Appendix 3.4. Population pairwise $F_{\mathrm{st}}$ values estimated from COI sequences of $B$. intricata species N2. Statistical significance $(P<0.05)$ indicated by bold type. For population codes refer to Table 3.1- Figure 3.1.

\begin{tabular}{|c|c|c|c|c|c|c|c|c|c|}
\hline & \multicolumn{8}{|c|}{ North Island } & \multirow{2}{*}{$\begin{array}{l}\text { South Island } \\
\text { NZ26 }\end{array}$} \\
\hline & NZ5 & NZ6 & NZ7 & NZ9 & NZ10 & NZ11 & NZ12 & NZ18 & \\
\hline NZ5 & & & & & & & & & \\
\hline NZ6 & 0.178 & & & & & & & & \\
\hline NZ7 & 0.370 & 0.013 & & & & & & & \\
\hline NZ9 & 0.111 & 0.159 & 0.306 & & & & & & \\
\hline NZ10 & 0.429 & 0.362 & 0.374 & 0.389 & & & & & \\
\hline NZ11 & 0 & 0.179 & 0.370 & 0.111 & 0.429 & & & & \\
\hline $\mathrm{NZ12}$ & 0 & 0.231 & 0.430 & 0.159 & 0.488 & 0 & & & \\
\hline NZ18 & 0.243 & 0.253 & 0.367 & 0.228 & 0.453 & 0.243 & 0.285 & & \\
\hline NZ26 & 0.111 & 0.159 & 0.305 & 0.111 & 0.389 & 0.111 & 0.159 & 0.228 & \\
\hline
\end{tabular}


Appendix 3.5. Population pairwise $F_{\mathrm{st}}$ values estimated from COI sequences of $B$. intricata species N 4. Statistical significance $(P<0.05)$ indicated by bold type. Population codes refer to Table S1- Figure 1. NI= North Island; SI: South Island.

\begin{tabular}{|c|c|c|c|c|c|c|c|c|c|c|c|c|c|c|c|c|c|c|c|c|c|}
\hline & \multicolumn{2}{|c|}{ Eastern NI } & \multicolumn{8}{|c|}{ Western NI } & \multicolumn{5}{|c|}{ Eastern SI } & \multicolumn{6}{|c|}{ Western SI } \\
\hline & NZ3 & NZ8 & NZ13 & NZ17 & NZ30 & NZ32 & NZ33 & NZ34 & NZ36 & NZ37 & NZ21 & NZ23 & NZ24 & NZ44 & NZ46 & NZ38 & NZ39 & NZ40 & NZ41 & NZ42 & NZ43 \\
\hline NZ3 & & & & & & & & & & & & & & & & & & & & & \\
\hline NZ8 & 0.850 & & & & & & & & & & & & & & & & & & & & \\
\hline NZ13 & 0.370 & 0.948 & & & & & & & & & & & & & & & & & & & \\
\hline NZ17 & 0.437 & 0.981 & 0.136 & & & & & & & & & & & & & & & & & & \\
\hline NZ30 & 0.396 & 0.949 & 0.082 & 0 & & & & & & & & & & & & & & & & & \\
\hline NZ32 & 0.468 & 0.983 & 0.162 & 0 & 0.019 & & & & & & & & & & & & & & & & \\
\hline NZ33 & 0.436 & 0.981 & 0.137 & 0 & 0 & 0 & & & & & & & & & & & & & & & \\
\hline NZ34 & 0.436 & 0.981 & 0.137 & 0 & 0 & 0 & 0 & & & & & & & & & & & & & & \\
\hline NZ36 & 0.453 & 0.982 & 0.150 & 0 & 0.100 & 0 & 0 & 0 & & & & & & & & & & & & & \\
\hline NZ37 & 0.433 & 0.954 & 0.225 & 0.285 & 0.166 & 0.314 & 0.284 & 0.285 & 0.300 & & & & & & & & & & & & \\
\hline NZ21 & 0.723 & 0.978 & 0.904 & 1 & 0.909 & 1 & 1 & 1 & 1 & 0.920 & & & & & & & & & & & \\
\hline NZ23 & 0.591 & 0.915 & 0.698 & 0.778 & 0.909 & 0.796 & 0.777 & 0.777 & 0.787 & 0.719 & 0.257 & & & & & & & & & & \\
\hline NZ24 & 0.417 & 0.828 & 0.386 & 0.417 & 0.370 & 0.448 & 0.416 & 0.433 & 0.433 & 0.412 & 0.433 & 0.006 & & & & & & & & & \\
\hline NZ44 & 0.611 & 0.879 & 0.715 & 0.769 & 0.706 & 0.789 & 0.769 & 0.769 & 0.779 & 0.729 & 0.566 & 0.018 & 0.116 & & & & & & & & \\
\hline NZ46 & 0.618 & 0.912 & 0.753 & 0.828 & 0.748 & 0.845 & 0.828 & 0.828 & 0.837 & 0.771 & 0.418 & 0.051 & 0.111 & 0.021 & & & & & & & \\
\hline NZ38 & 0.826 & 0.956 & 0.926 & 0.960 & 0.927 & 0.960 & 0.960 & 0.960 & 0.962 & 0.933 & 0.955 & 0.878 & 0.784 & 0.817 & 0.825 & & & & & & \\
\hline NZ39 & 0.436 & 0.736 & 0.412 & 0.417 & 0.395 & 0.417 & 0.417 & 0.417 & 0.432 & 0.424 & 0.521 & 0.326 & 0.240 & 0.356 & 0.654 & 0.369 & & & & & \\
\hline $\mathrm{NZ40}$ & 0.873 & 0.984 & 0.968 & 1 & 0.971 & 1 & 1 & 1 & 1 & 0.974 & 1 & 0.929 & 0.840 & 0.875 & 0.924 & 0.814 & 0.535 & & & & \\
\hline NZ41 & 0.846 & 0.967 & 0.943 & 0.975 & 0.944 & 0.975 & 0.975 & 0.974 & 0.976 & 0.949 & 0.972 & 0.889 & 0.798 & 0.881 & 0.821 & 0.484 & 0.427 & 0.821 & & & \\
\hline $\mathrm{NZ42}$ & 0.834 & 0.962 & 0.935 & 0.969 & 0.936 & 0.969 & 0.969 & 0.968 & 0.971 & 0.941 & 0.965 & 0.883 & 0.788 & 0.822 & 0.871 & 0.062 & 0.375 & 0.810 & 0.286 & & \\
\hline NZ43 & 0.818 & 0.947 & 0.916 & 0.949 & 0.917 & 0.945 & 0.949 & 0.949 & 0.952 & 0.923 & 0/942 & 0.866 & 0.775 & 0.802 & 0.855 & 0.064 & 0.362 & 0.771 & 0.444 & 0.054 & \\
\hline
\end{tabular}


Appendix 3.6. Analysis of molecular variance (AMOVA) of cryptic species N4 of $B$. intircata from COI sequences. Groups were defined according to four biogeographic regions in NZ, as eastern North Island, western North Island, eastern South Island and western South Island (Appendix 3.5). d.f.: degree of freedom. SS: sum of squares.

Asterisk: significant value $P<0.01$.

\begin{tabular}{llllll}
\hline Source of Variation & d.f. & SS & $\begin{array}{c}\text { Variance } \\
\text { components }\end{array}$ & $\begin{array}{l}\text { \% } \\
\text { Variation }\end{array}$ & Fixation indices \\
\hline Among groups & 3 & 343.729 & 2.16704 & 67.57 & $F_{\mathrm{CT}}=0.67579^{*}$ \\
Among populations & 17 & 91.839 & 0.47585 & 14.83 & $F_{\mathrm{SC}}=0.54230^{*}$ \\
Within Populations & 193 & 105.839 & 0.56380 & 17.58 & $F_{\mathrm{ST}}=0.85161^{*}$ \\
\hline Total & 213 & 541.463 & 3.20669 & & \\
\hline
\end{tabular}


Appendix 3.7. Mismatch distribution of cryptic Bostrychia intricata species N2 (A) and N4 (B) based on COI sequences. Dashed lines indicate the expected distributions under a recent expansion model, and solid lines indicates the observed distributions. Bold letters at each branch tip refer to haplotypes found in this study. H: Haplotype.
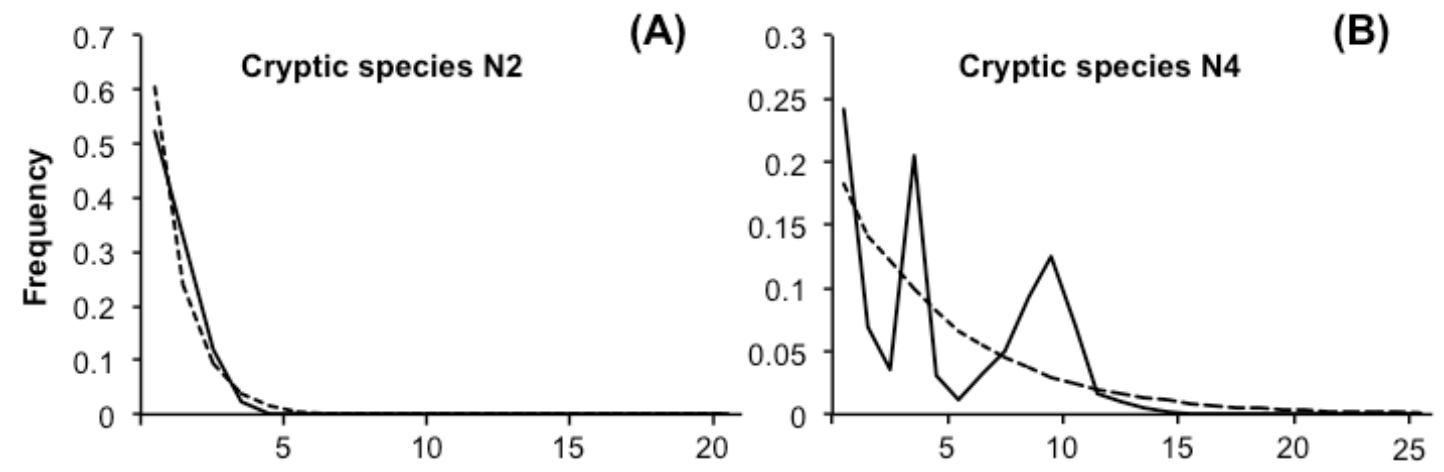

Number of pairwise differences 
Appendix 3.8. Bayesian tree for Bostrychia intricata reconstructed using BEAST under a relaxed clock model of the COI sequences. Bars show 95\% highest posterior densities of divergences dates and scale bar are in million years. Black dots at node indicate the support of $>95 \%$ Bayesian posterior probabilities.

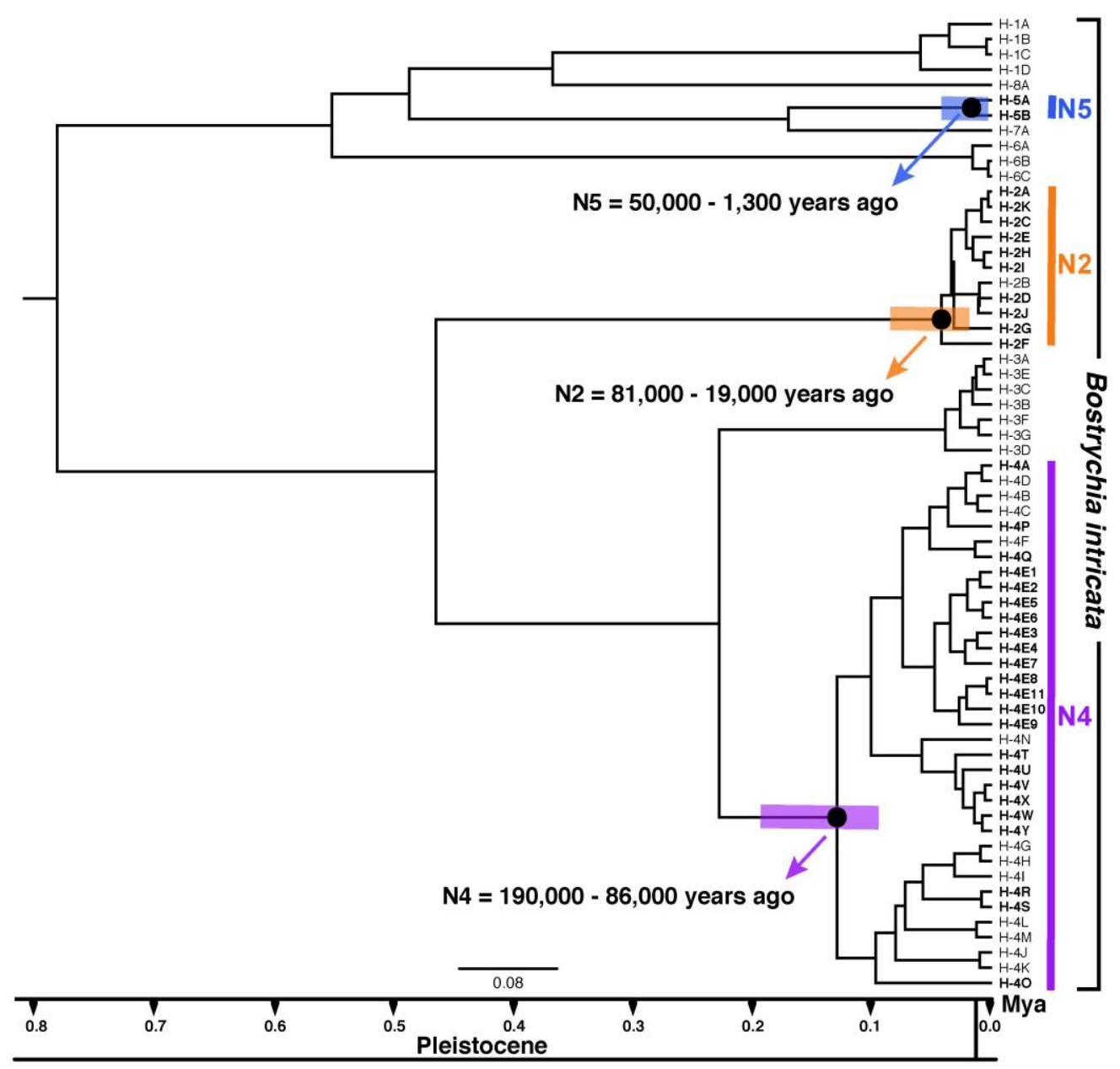


Appendix 4.1.Average specific growth rate $\left(\%\right.$ day $\left.^{-1}\right)$ of all $B$. intricata isolates in various conditions of temperature and salinity. Number and letter in brackets after each isolates indicates the COI haplotypes (Muangmai et al. 2014, 2015). Bold indicates the greatest growth rate of each isolate.

\begin{tabular}{|c|c|c|c|c|c|c|c|c|c|}
\hline Temperature & & $10^{\circ} \mathrm{C}$ & & & $15^{\circ} \mathrm{C}$ & & & $20^{\circ} \mathrm{C}$ & \\
\hline Salinity & $25 \mathrm{psu}$ & $32 \mathrm{psu}$ & $40 \mathrm{psu}$ & $25 \mathrm{psu}$ & $32 \mathrm{psu}$ & $40 \mathrm{psu}$ & $10 \mathrm{psu}$ & $32 \mathrm{psu}$ & $40 \mathrm{psu}$ \\
\hline $\mathrm{M} 2(2 \mathrm{~A})$ & $0.10 \pm 0.01$ & $0.69 \pm 0.15$ & $0.21 \pm 0.03$ & $0.68 \pm 0.06$ & $1.28 \pm 0.21$ & $1.01 \pm 0.10$ & $0.13 \pm 0.03$ & $0.21 \pm 0.01$ & $0.12 \pm 0.02$ \\
\hline $\mathrm{T} 2(2 \mathrm{C})$ & $0.13 \pm 0.04$ & $0.59 \pm 0.04$ & $0.32 \pm 0.04$ & $0.77 \pm 0.04$ & $1.83 \pm 0.09$ & $1.03 \pm 0.11$ & $0.11 \pm 0.01$ & $0.19 \pm 0.01$ & $0.09 \pm 0.01$ \\
\hline $\mathrm{N} 2$ & $0.11 \pm 0.02$ & $0.62 \pm 0.09$ & $0.24 \pm 0.07$ & $0.76 \pm 0.07$ & $1.59 \pm 0.28$ & $1.03 \pm 0.13$ & $0.13 \pm 0.02$ & $0.17 \pm 0.03$ & $0.11 \pm 0.03$ \\
\hline P4 (4E2) & $1.23 \pm 0.11$ & $1.57 \pm 0.05$ & $0.92 \pm 0.02$ & $1.42 \pm 0.04$ & $2.87 \pm 0.16$ & $2.11 \pm 0.07$ & $0.36 \pm 0.01$ & $0.52 \pm 0.05$ & $0.49 \pm 0.04$ \\
\hline $\mathrm{C} 4(4 \mathrm{~T})$ & $1.26 \pm 0.04$ & $1.59 \pm 0.04$ & $1.09 \pm 0.08$ & $1.73 \pm 0.13$ & $3.07 \pm 0.06$ & $2.11 \pm 0.05$ & $0.38 \pm 0.04$ & $0.68 \pm 0.05$ & $0.51 \pm 0.01$ \\
\hline N4 & $1.23 \pm 0.06$ & $1.57 \pm 0.07$ & $0.97 \pm 0.09$ & $1.52 \pm 0.19$ & $2.96 \pm 0.12$ & $2.08 \pm 0.06$ & $0.37 \pm 0.05$ & $0.58 \pm 0.08$ & $0.47 \pm 0.03$ \\
\hline M5 (5A) & $0.05 \pm 0.01$ & $0.26 \pm 0.06$ & $0.08 \pm 0.01$ & $0.76 \pm 0.11$ & $1.48 \pm 0.12$ & $0.84 \pm 0.03$ & $0.11 \pm 0.01$ & $0.18 \pm 0.01$ & $0.12 \pm 0.01$ \\
\hline
\end{tabular}


Appendix 5.1. The Wilks' lambda tests of the discriminant function analysis (function 1 through 3) of three cryptic species of $B$. intricata collected from Moa Point, Wellington (df = degree of freedom; Sig. = significance probability).

\begin{tabular}{lcccc}
\hline Test of Functions (s) & Wilks' lambda test & Chi-square & $\mathrm{df}$ & Sig. \\
\hline 1 through 2 & .379 & 116.864 & 15 & .000 \\
2 through 3 & .914 & 10.841 & 8 & .014 \\
3 & .993 & 0.860 & 3 & .021 \\
\hline
\end{tabular}


Appendix 5.2. Contribution to discriminant functions (DFs) of three physical parameters in three cryptic species of $B$. intricata collected from Moa Point, Wellington. Asterisk (*) indicates largest absolute correlation between each variable and any discriminant function.

\begin{tabular}{llll}
\hline Physical & \multicolumn{3}{c}{ Functions } \\
\cline { 2 - 4 } parameters & DF1 [90.8\%] & DF2 [8.7\%] & DF [0.5\%] \\
\hline Tidal height & $.992 *$ & -.353 & -.155 \\
Wave exposure & .398 & $.908 *$ & .128 \\
Sun exposure & .130 & .010 & $.992 *$ \\
\hline
\end{tabular}


Appendix 6.1. Preliminary results of crossing experiment between three cryptic species of B. intricata (N2, N4 and N5) isolated from New Zealand. Female isolates on horizontal and male isolates on vertical axis. Detail of each isolate referred to Table 4.1 of Chapter 4. $+=$ positive cross, producing carpospores; $-=$ negative cross; ${ }^{\mathrm{a}}=$ pseudocystocarps formed (pericarp forming without mature carposporophyte); ${ }^{b}=$ germinating carpospores of hybrid.

For crossing experiments the following procedures were used: one male plant and one female plant, each about $1 \mathrm{~cm}$ long, were combined in $75 \mathrm{ml} \mathrm{PES} / 2$ medium in $50 \mathrm{x}$ $70 \mathrm{~mm}$ Pyrex ${ }^{\mathrm{TM}}$ No. 3140 crystallizing dishes with polycarbonate covers. Culture dishes were placed $15^{\circ} \mathrm{C}, 12: 12 \mathrm{~h} \mathrm{LD}$ cycle, at $30-40 \mu \mathrm{mol}$ photons $\mathrm{m}-2 \mathrm{~s}-1$ produced by cool white fluorescent lighting. Control female plants were also maintained separately to check for development of male structures and carposporophytes. Self-crossing (crosses of males and females from same tetrasporophyte) of individual isolates were also performed at the same time as outcrosses as a control for carposporophyte formation. Crosses were checked every 7 days for growth and reproduction to determine whether females were developing normal procarps with trichogynes and males were developing normal spermatangial stichidia that released spermatia. Crosses were considered positive only if carpospores were discharged from two or more carposporophytes and these carpospores germinated in a normal bipolar manner.

\begin{tabular}{|l|l|l|l|l|l|}
\hline & M2 (N2) & C2 (N2) & M4 (N4) & P4 (N4) & M5 (N5) \\
\hline M2 (N2) & $+{ }^{\mathrm{b}}$ & + & - & - & - \\
\hline C2 (N2) & + & + & - & - & - \\
\hline M4 (N4) & - & - & $+{ }^{b}$ & - & \\
\hline P4 (N4) & - & - & + & $+{ }^{b}$ & - \\
\hline M5 (N5) & - & $+^{a}$ & - & - & + \\
\hline
\end{tabular}

